\title{
Aging modifies joint power and work when gait speeds are matched.
}

\author{
Luis Eduardo Cofré Lizama \\ Submitted in total fulfillment of the requirements of the degree of \\ Master of Physiotherapy by Research
}

March 2011

School of Physiotherapy

Faculty of Medicine, Dentistry and Health Sciences

The University of Melbourne 


\section{Abstract}

It is well known that ankle joint power generation is reduced in healthy older adults during gait. No general consensus exists, however, as to what fundamental or core compensatory actions are made at the knee and hip joints by the older adults to compensate for this loss in ankle joint power. The failure to control, and the relatively high variability, in gait speed may account for this lack of agreement. This study investigated the effect of aging on lower limb joint power and mechanical work during gait. The gait patterns of twelve old $(66.8 \pm 4.5 \mathrm{yr})$ and 12 young adults $(26.6$ $\pm 2.9 \mathrm{yr})$ were recorded for a range of matched $\left(1.0 \mathrm{~m} \cdot \mathrm{s}^{-1}, 1.3 \mathrm{~m} \cdot \mathrm{s}^{-1}, 1.6 \mathrm{~m} \cdot \mathrm{s}^{-1}\right)$ and self-selected speeds. Matched speeds did not differ between the groups. Combining matched speeds, the older adults generated $14 \%$ less A2 power and mechanical work $(p<0.05)$. Compared to the young adults, the older adults produced $45 \%$ more $\mathrm{H} 2$ peak power, $7 \%$ more $\mathrm{H} 3$ peak power, $35 \%$ more $\mathrm{K} 3$ peak power and $11 \%$ more $\mathrm{K} 4$ peak power $(p<0.05)$. No significant $\mathrm{H} 1$ power and mechanical work differences were found. The older adults also exhibited less ankle plantar flexion, more hip flexion and anterior pelvic tilt $(p<0.05)$. At the $1.6 \mathrm{~m} \cdot \mathrm{s}^{-1}$ speed the older adults adopted a different gait pattern compared to young adults, generating more H3 than A2 mechanical work. This shows that the older adults rely more on hip flexors to propel the leg into swing when ankle plantar flexor function is reduced. This may partly explain how gait dysfunctions emerge with aging. 


\section{Declaration}

\section{This is to certify that:}

i. The thesis comprises only my original work, and has not been published elsewhere or contributed to the award of a previous degree.

ii. Due acknowledgement has been made in the text to all other material used.

iii. The thesis is less than 50,000 words in length, exclusive of tables, maps, bibliographies and appendices.

iv. The content of this thesis reflects the work done during the period of candidature. Assistance of others in the design and execution of this project has been duly acknowledged.

Luis Eduardo Cofré Lizama

March 2011 


\section{Acknowledgment}

I wish to thank Associate Professor Noel Lythgo, a "true blue mate”, for his support, encouragement, optimism and friendship during my candidature. Thank you for showing me that everything can be achieved even become a “leyenda”. I also wish to thank Professor Mary Galea for her motivation, guidance and support and Professor David Morgan for all the time he gave me and for showing me that there is always a solution. Overall I would like to thank them for letting me be part of a team, and for letting me appreciate their inspirational work at the Rehabilitation Sciences Research Centre.

This work is dedicated to my family, especially to Teresa, Luis, Jorge and Lastenia and friends from Chile who gave me all their positive thoughts and energy from the other side of the world to complete this degree. Specially, I want to dedicate this work to Ana Maria (very soon my wife) who gave me the strength to stay focused even when life seemed to be adverse. Thanks for bringing me patience, happiness and most importantly love during this amazing stay in Australia.

Finally I would like to thank life for placing such wonderful people from all around the globe in my journey; each of them has brought new perspectives and new possibilities to my view of the world. Thank you for opening my mind, eyes and heart.

"Life is like gait: they are made of single actions, but only when they are beautifully and harmoniously synchronized they can move you forward" 


\section{Table of Contents}

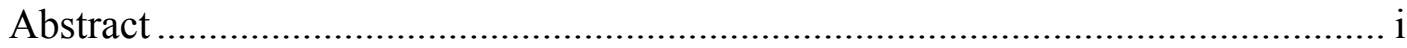

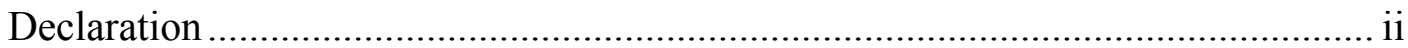

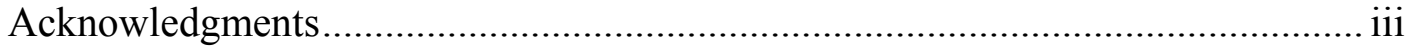

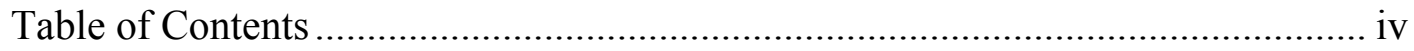

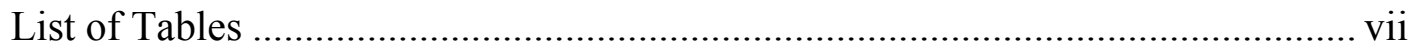

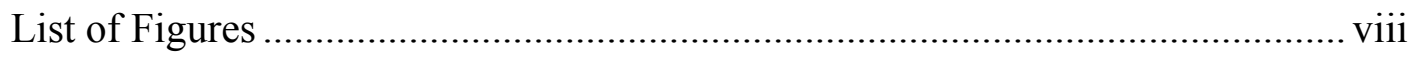

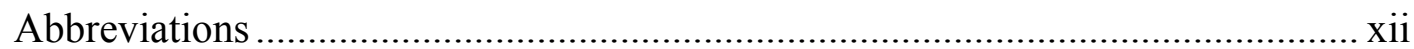

Chapter 1: Introduction 1

Chapter 2: Literature Review 5

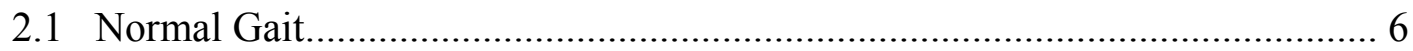

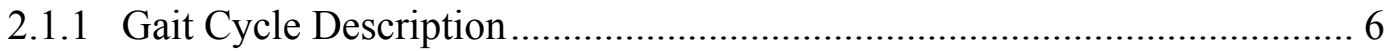

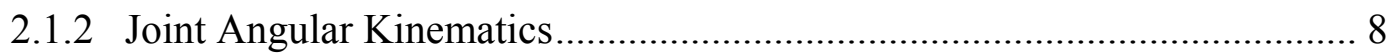

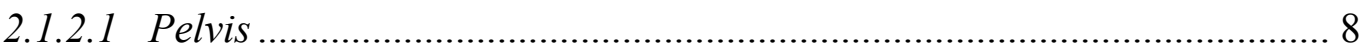

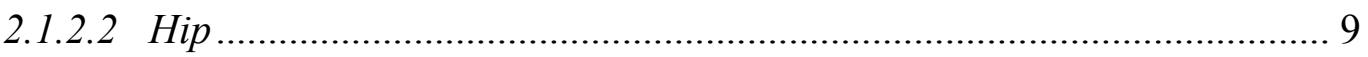

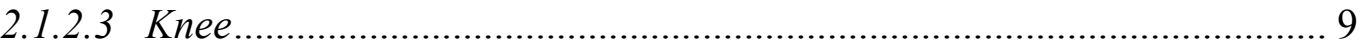

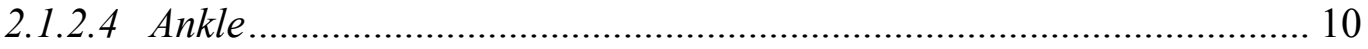

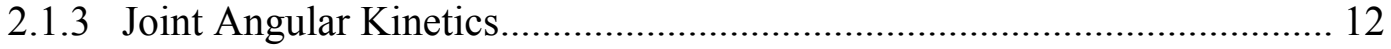

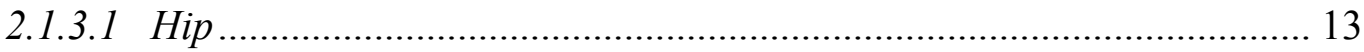

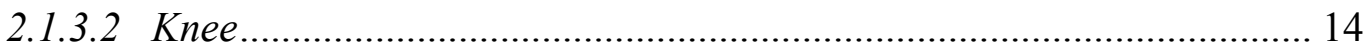

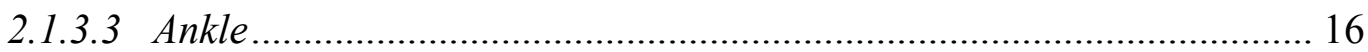

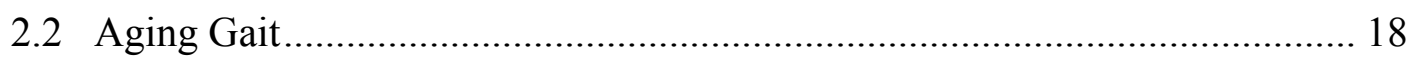

2.2.1 Basic Spatiotemporal Gait Parameters .................................................. 18

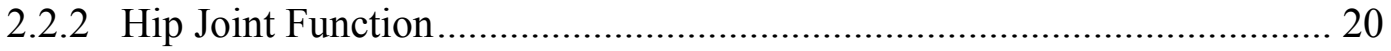

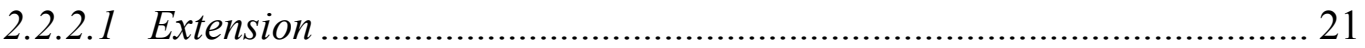

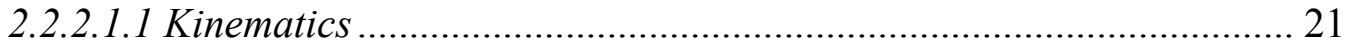

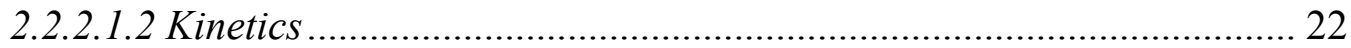

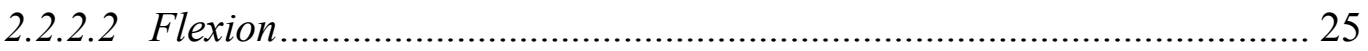

2.2.2.2.1 Hip Flexor Contracture .................................................................. 26 
2.2.3 Knee Joint Function 28

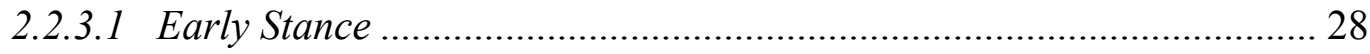

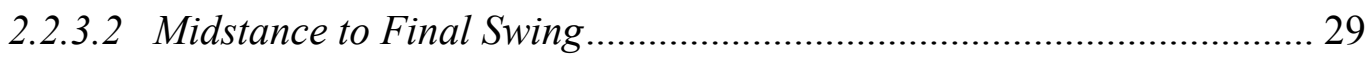

2.2.4 Ankle Joint Function ........................................................................ 31

2.2.5 Mechanisms Underlying Age-related Gait Changes................................ 33

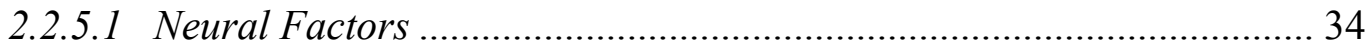

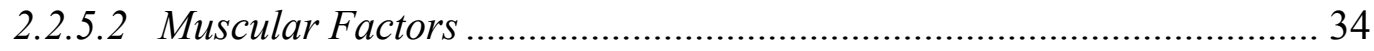

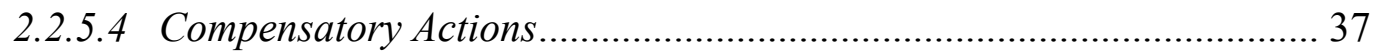

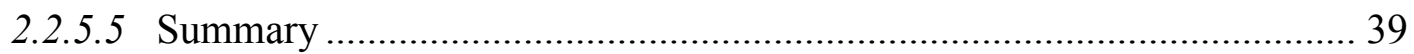

Chapter 3: Methods $\quad 42$

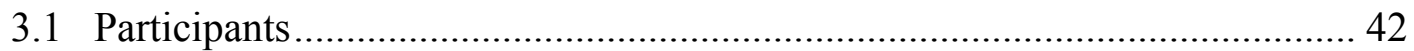

3.1.1 Recruitment Process .......................................................................... 42

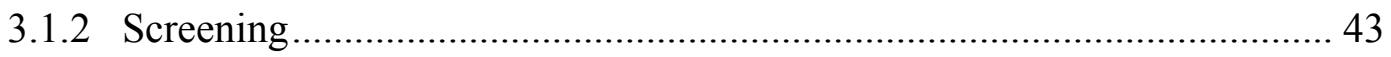

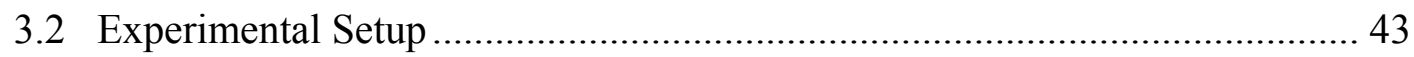

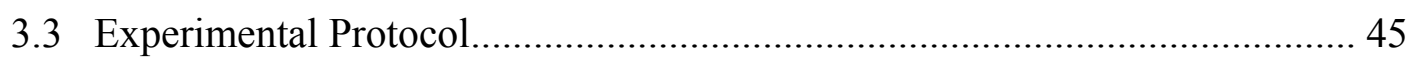

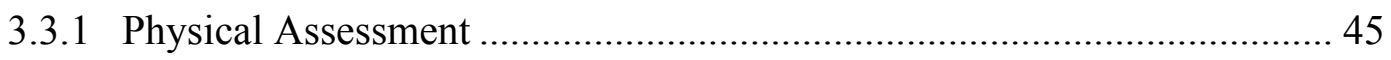

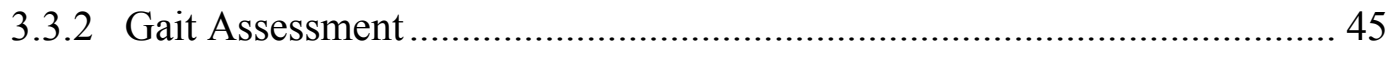

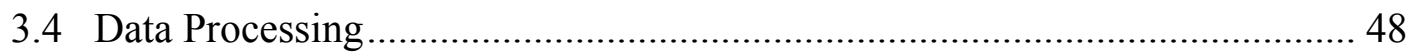

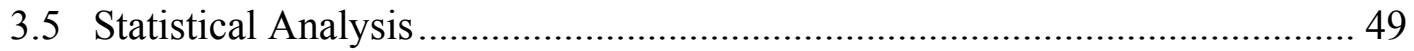

Chapter 4: Objectives of Investigation 52

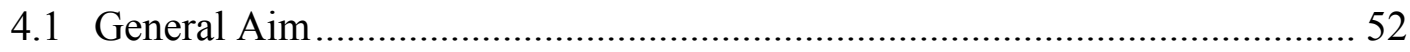

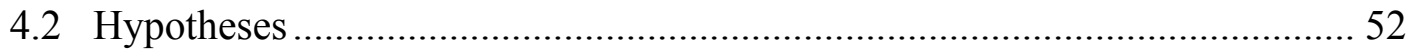

Chapter 5: Results 53

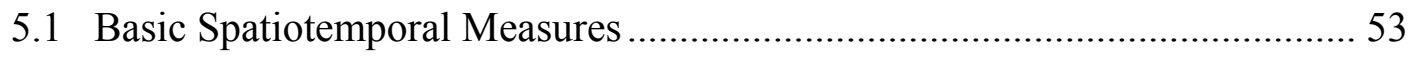

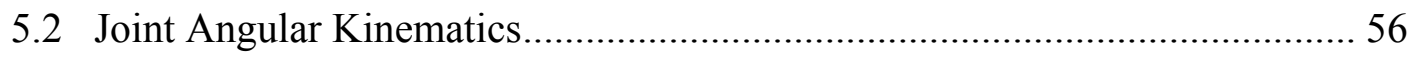

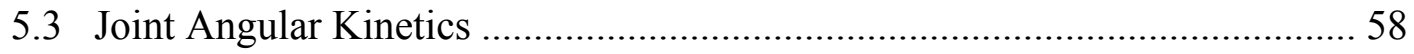

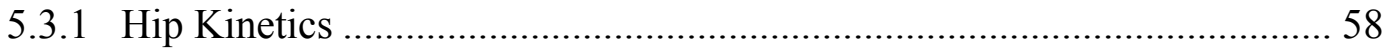

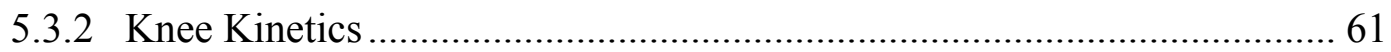


5.3.3 Ankle Kinetics. 62

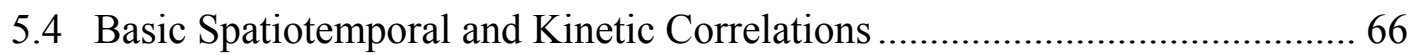

\section{Chapter 6: Discussion and Conclusion}

6.1 Importance of controlling gait speed when investigating aging gait 70

6.2 Neuromuscular adaptations in elderly gait. 71

6.2.1 Importance of ankle function in elderly gait ........................................... 73

6.2.2 Reliance by the elderly on hip muscle activity during gait ....................... 76

6.2.3 The role of knee flexion in aging gait..................................................... 81

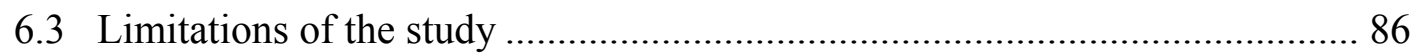

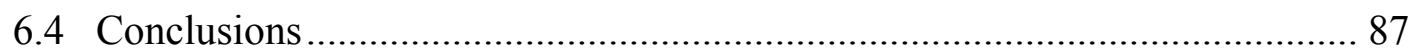

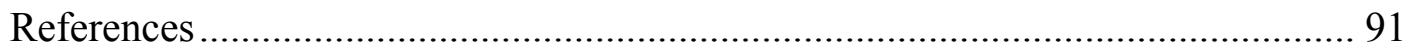

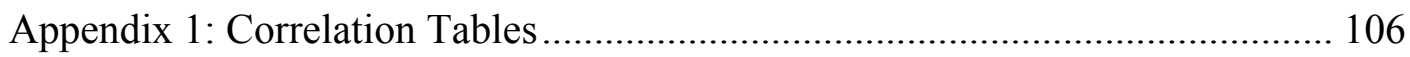

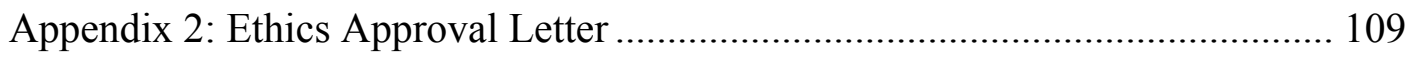

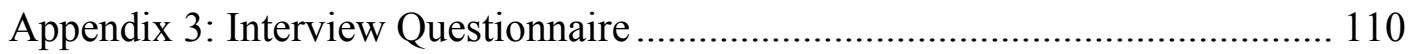

Appendix 4: Short Physical Performance Battery …......................................... 111 


\section{List of Tables}

Table 2.1 Summary of findings in studies that compared older and young adult joint powers and mechanical work. Kinematic and spatiotemporal differences associated are also presented.

Table 3.1 Participant demographics

Table 3.2 Time thresholds to score maximum points in the SPPB

Table 5.1 Spatiotemporal and kinematic measures: mean $\pm(\mathrm{SD})$. Significant pvalues are shown in bold $(\alpha=0.05)$. IDS: initial double support, FDS: final double support.

Table 5.2 Peak joint powers: mean $\pm(\mathrm{SD})$. Significant $p$-values are shown in bold $(\alpha=0.05)$

Table 5.3 Joint work: mean \pm (SD). Significant $p$-values are shown in bold $(\alpha=0.05)$. 


\section{List of Figures}

Figure 2.1 Phases, sub-phases, events and corresponding percentages of gait cycle.... 7

Figure 2.2 Basic spatiotemporal measures of gait (Adapeted from Whittle, 1993, p.53)

Figure 2.3 Example of sagittal kinematics of the pelvis in a young adult.

Figure 2.4 Example of sagittal kinematics of the hip in a young adult. 9

Figure 2.5 Example of sagittal kinematics of the knee in a young adult. 10

Figure 2.6 Example of sagittal kinematics of the ankle in a young adult. 11

Figure 2.7 Hip joint power pattern in the sagittal plane.

Figure 2.8 Knee joint power pattern in the sagittal plane.

Figure 2.9 Ankle joint power pattern in the sagittal plane.

Figure 2.10 Changes in cadence, stride length and step length with aging (figure was produced using OpenSim 1.9.1).

Figure 2.11 Schematic representation of the effect of aging on temporal gait measures

Figure 2.12 Mean hip joint torque curve for young and older adults (taken from DeVita and Hortobágyi, 2000, p.1808).

Figure $2.13 \mathrm{H} 1$ joint power and maximum hip extension during gait. (A) H1 starts at $10 \%$ of GC. (B) $\mathrm{H} 1$ ends at $35 \%$ of GC (figure was produced using OpenSim 1.9.1).

Figure 2.14 (A) A representation of hip flexor contracture and increased anterior pelvic tilt coupled with reduced hip extension and increased anterior trunk inclination. (B) Similar pattern to that shown in "A" but without 
increased anterior trunk inclination. (C) Young subject during the same period of the GC. Pelvic tilt shown by a line (white) drawn from the ASIS to PSIS (figure was produced using OpenSim 1.9.1).

Figure 2.15 (A) Example of push-off for an older adult with reduced ankle plantar flexion and A2 joint power generation. (B) Example of ankle plantar flexion and A2 power generation for a young adult (figure was produced using OpenSim 1.9.1)............................................................. 32

Figure 2.16 Flow chart illustrating the neuromuscular factors that may affect gait functionality. MN: motor neurons; MU: motor units.

Figure 2.17 Left panel shows phase of stance where elastic energy is absorbed and recovered. Right panel shows a plot of the elastic energy absorbed (“Push I”) and recovered (“Push II”) by the muscle-tendon unit (MTU) and tendinuous tissues (TT) (Adapted from Ishikawa 2005, p.607).

Figure 2.18 Muscle co-activation EMG patterns. The two panels on the left show (from top to bottom) muscle activity for vastus lateralis (VL), biceps femoris (BF), TA (tibialis anterior), gastrocnemius lateralis (GL) and vertical ground reaction force (Fz) in a young (left column) and older adult (right column) walking at $1.5 \mathrm{~m} \cdot \mathrm{s}^{-1}$. The two panels on the right show the EMG plots for the same muscles when walking at $1.8 \mathrm{~m} \cdot \mathrm{s}^{-1}$ (adapted from Hortobágyi et al., 2009, p.559).

Figure 2.19 Schematic representation of the neuromuscular adaptations in gait with aging. The diagram links the gait impairments to the functional limitation, and the neuromuscular adaptation, and its compensatory action. The dashed line with “?” indicate possible situations not completely supported by current literature (adapted from McGibbon 2003, p. 103)

Figure 2.20 Proposed relationship between power absorption and generation in order to produce propulsion when ankle function is compromised by aging. 
Figure 3.1 Experimental setup showing walkway dimensions (top panel), force plate dimensions and positioning (bottom panel).

Figure 3.2 Thomas test for the assessment of hip flexors contracture. (a) No elevation of the right thigh when the left leg is maximally flexed at the hip; no hip flexors contracture (pass). (b) Right thigh raised when the left leg is maximally flexed at the hip; hip flexors contracture present (fail). (Adapted from Peeler, 2007, p.16).

Figure 3.3 Marker placement.

Figure 3.4 Grid system used to adjust start position. (A) Unsuccessful trial in which foot does not successfully land on the force plate. (B) Adjusted start point to obtain a successful foot landing.

Figure 3.5 Flow chart shows inferential statistics $(\alpha$ level $=0.05)$ used to investigate the effect of aging on the spatiotemporal and kinematic measures. The Bonferroni adjustment to the $\alpha$ level is shown.

Figure 3.6 Flow chart shows inferential statistics $(\alpha$ level $=0.05)$ used to investigate the effect of aging on the kinetic measures. The Bonferroni adjustment to the $\alpha$ level is shown. Peak powers and mechanical work are identified with letters and numbers. The letter represents the joint $(\mathrm{A}=$ ankle, $\mathrm{H}=$ hip, $\mathrm{K}=\mathrm{knee}$ ) and the numeral represents the peak of interest $(1,2,3$, etc. $)$

Figure 5.1 Plots of cadence, step and stride length for both age groups across the three matched speeds. The shaded region indicates \pm SD from mean. * Indicates significant differences $(p<0.05)$.

Figure 5.2 Plot shows mean peak ankle plantar flexion and mean peak anterior pelvic tilt for both groups at matched speed conditions. The shaded region indicates $\pm \mathrm{SD}$ from mean. * Indicates significant differences $(p<0.05)$. 
Figure 5.3 Plot shows hip flexion and extension means and standard deviation for both groups at matched speed conditions. The shaded region indicates \pm SD from mean. . $*$ Indicates significant differences $(p<0.05)$.

Figure 5.4 Typical plots of joint power and mechanical work for an older adult (EM68) and young adult (YF23). EM68: 68 year old male. YF23; 23 year old female.

Figure 5.6 Plot shows correlations between A2 peak power and speed for older adults (red), young adults (blue) and both groups together (black line)... 67

Figure 5.7 Plot shows correlations between H3 peak power and speed for older adults (red), young adults (blue) and both groups together (black line).... 68

Figure 5.8 Plot shows correlations between H1 peak power and speed for older adults (red), young adults (blue) and both groups together (black line).... 68

Figure 6.1 Plots of mean H1, H3 and A2 peak joint powers for the three matched speeds for the older (OLD) and young adult (YG) groups.

Figure 6.2 Schematic representation of the aging affect on A2, K4 and H3 peak power observed in older adult gait in this study.

Figure 6.3 Schematic representation of the aging affect on $\mathrm{H} 1$ peak power observed in older adult gait in this study.

Figure 6.4 Plots of mean $\mathrm{H} 1, \mathrm{H} 3$ and A2 mechanical work for the three matched speeds for the older (OLD) and young adult (YG) groups. 80

Figure 6.5 Schematic representation of the aging affect on K1 and K2 peak powers observed in the older adult gait in this study.

Figure 6.6 Schematic representation of the aging affect on K5 peak powers observed in the older adult gait in this study. 


\section{Abbreviations}

$\% \mathrm{GC} \quad$ percentage of the gait cycle

A1

ankle plantar flexor power absorption at midstance

A2

ankle plantar flexor power generation in late stance

APT

anterior pelvic tilt

ASIS anterior superior iliac spine

bpm beats per minute

CAD cadence

CSA cross-sectional area

DF dorsiflexion

FC foot clearance

FF foot flat

$\mathrm{F} \quad$ force

GS gait speed

GRF ground reaction force

HO heel off

$\mathrm{Hz} \quad$ hertz

HE hip extension

H1 hip extensor power generation in first half of stance

HF hip flexion

H2 hip flexor power absorption in midstance

H3 hip flexor power generation in late stance/initial swing

HROM hip range of movement

IC initial contact

IDS initial double support/stance

ISw initial swing

J Joules

$\mathrm{kg} \quad$ kilograms

K1 knee extensor power absorption during loading response

K4 knee extensor power absorption in late stance

K2 knee extensor power generation at the end of initial double support 


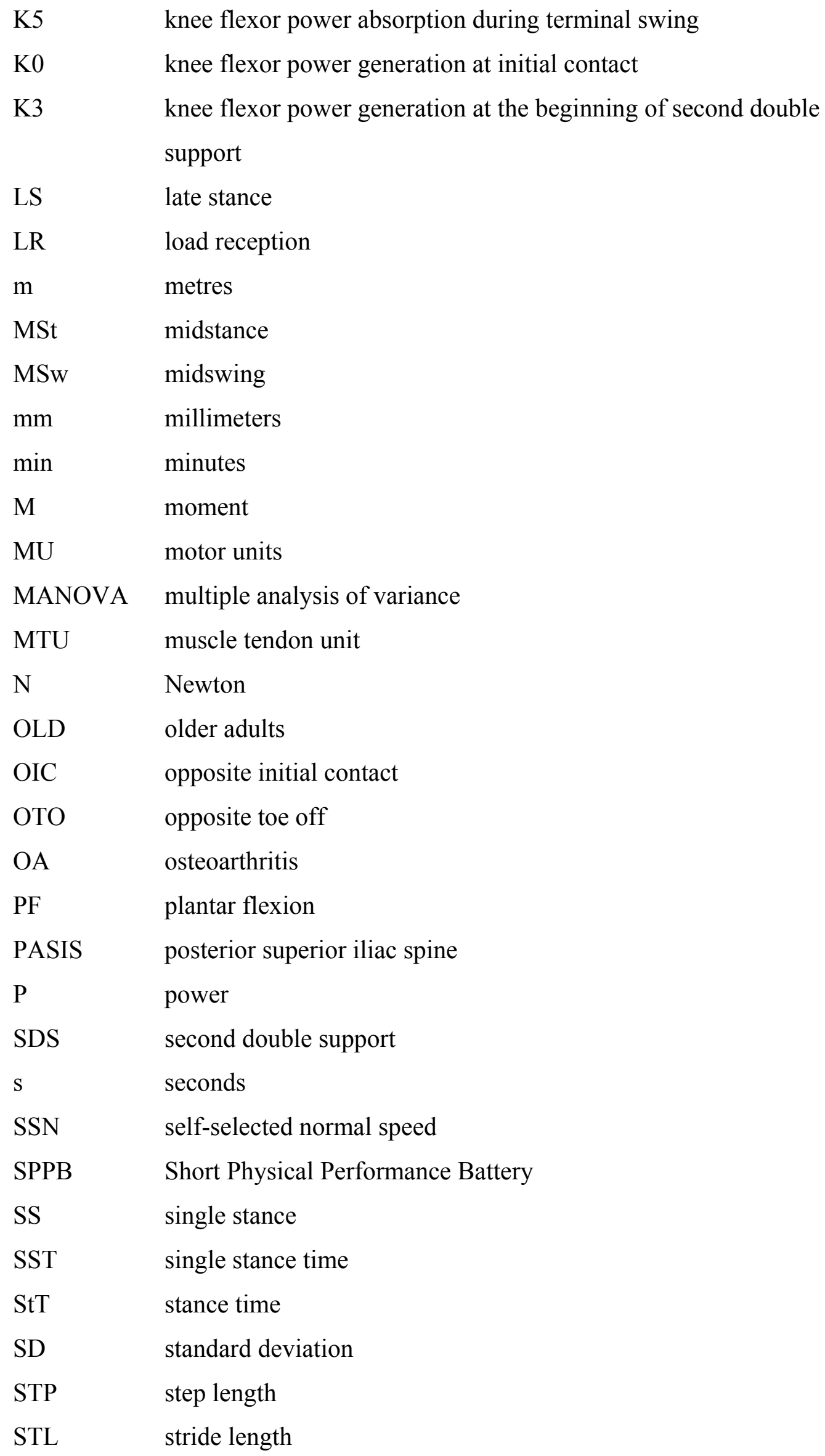




$\begin{array}{ll}\text { SWT } & \text { swing time } \\ \text { TT } & \text { tendinuos tissues } \\ \text { TSw } & \text { terminal swing } \\ \text { TV } & \text { tibia vertical } \\ \text { TO } & \text { toe off } \\ \text { VGRF } & \text { vertical ground reaction force } \\ \text { W } & \text { Watts } \\ \text { YG } & \text { young adults }\end{array}$




\section{Chapter 1: Introduction}

Gait dysfunctions become increasingly evident in the seventh decade of life (Prince et al., 1997, Hortobágyi et al., 2009). The most common manifestations are slower walking speed, shorter steps and increased cadence (Blanke and Hageman, 1989, McGibbon and Krebs, 2001, Oberg et al., 1994, Ostrosky et al., 1994, Winter et al., 1990, Shumway-Cook and Woollacott, 2001). Other signs of gait dysfunction include reductions in ankle, knee and hip joint angular motion (Judge et al., 1996a, McGibbon and Krebs, 2001, Oberg et al., 1994, Ostrosky et al., 1994) and increased anterior pelvic tilt (Kerrigan et al., 1998).

The emergence of gait changes in older adults is associated with a reduced ability to deal with perturbed environments (e.g. stairs or steps). This is demonstrated by a steady age-related rise in serious injuries resulting from pedestrian accidents and falls whilst walking (Campbell et al., 1981, Campbell et al., 1989, Hausdorff et al., 2001). These dysfunctions also impact on the physical health and mental well-being of older adults (Prince et al., 1994). Moreover, it can lead to a gradual loss of community engagement, followed by a period of falls and injury that may end in a loss of independence in daily living.

The emergence of gait changes with aging has been linked to physiological and mechanical changes in the neuromuscular system (McGibbon, 2003). It is thought that these changes lead to neuromuscular adaptations where the gait muscle activation pattern is reorganized (McGibbon and Krebs, 2004). However, it is not clear as to what are the causes and the compensatory actions in elderly gait. There is some agreement that age reduces ankle power or push-off during walking (Watelain et al., 2000, McGibbon, 2003). However, it still remains unclear as to what factors bring about this change with aging. For example, it may result from an attempt to increase stability during walking (Winter et al., 1990) or may be the result of weakness in the ankle plantar flexor muscles (Winegard et al., 1996). It is also possible that it is the direct outcome of a reduced walking speed with aging (Kerrigan et al., 1998, DeVita and Hortobágyi, 2000). Ankle plantar flexor function is important for trunk 
stabilization in early stance, forward progression of the body and leg swing initiation and is also a strong predictor of step length and walking speed in older adults (Neptune et al., 2001, McGibbon, 2003, Judge et al., 1996a).

There is some agreement about a shift in "the locus of function" or a redistribution of joint powers in aging gait (DeVita and Hortobágyi, 2000, Hortobágyi et al., 2009). That is, hip and knee propulsive powers increase in order to compensate for decreased ankle plantar flexor power. However, it is unclear as to how this affects hip and knee function. Evidence suggests that older adults increase activity in the hip flexors and extensors so as to assist leg swing and trunk stability in stance (DeVita and Hortobágyi, 2000, Silder et al., 2008, Watelain et al., 2000, McGibbon, 2003).

In attempts to investigate neuromuscular adaptations and compensatory actions in elderly gait, most studies have made direct comparisons to young adults. These studies have reported that healthy older adults adopt different compensatory actions to propel the body forward. These actions include increased hip extension power generation (H1), mechanical work at H1, hip flexor power generation (H3), mechanical work at H3, knee peak power generation (K2) and knee peak power absorption (K4) (DeVita and Hortobágyi, 2000, Graf et al., 2005, Judge et al., 1996a, Kerrigan et al., 1998, Monaco et al., 2009, Silder et al., 2008, Watelain et al., 2000, Winter et al., 1990).

The self-selected walking speed protocols employed in the majority of studies may account for the different findings since it is well known that speed has a significant effect on joint kinetics (Lelas et al., 2003, Stansfield et al., 2001). Moreover, some of these studies have reported significant speed differences between the young and older adult groups (Graf et al., 2005, Judge et al., 1996a, Kerrigan et al., 1998, Watelain et al., 2000, Winter et al., 1990). Hence, in order to investigate the compensatory actions made by older adults during gait, speed should be tightly controlled.

Another important issue in the study of aging gait is walking speed variability. The majority of aging gait studies have reported relatively high magnitudes of gait speed variability (i.e. standard deviation). This may have also contributed to the lack 
of agreement about the compensatory actions found in elderly gait (Judge et al., 1996a, Kerrigan et al., 1998, Neptune et al., 2001, Silder et al., 2008, Winter et al., 1990). Hip power generation (H1 and H3), for example, has been shown to increase by more than $20 \%$ with a small increase $\left(\approx 0.1 \mathrm{~m} \cdot \mathrm{s}^{-1}\right)$ in gait speed (Lelas et al., 2003). This may partly explain the failure by Silder et al. (Silder et al., 2008) to find significant differences in $\mathrm{H} 3$ and $\mathrm{A} 2$ peak power between young and older adults since speed variability for both groups fell around $0.12 \mathrm{~m} \cdot \mathrm{s}^{-1}$.

DeVita and Hortobágyi (2000) found older adults walking at the same speed (1.48 $\mathrm{m} \mathrm{s}^{-1}$ ) as young adults do so by redistributing the power generated at the hip, knee and ankle joints. Essentially, the older adults moved power generation away from the ankle to the hip joint so as to substitute hip flexor and extensor power for weak ankle plantar flexor power. This redistribution of joint powers was interpreted by DeVita and Hortobágyi as a change in the "locus of function" in the motor output.

In a recent study, Silder et al. (2008) found older adults generate more hip joint power than young adults when walking at self-selected slow $\left(1.1 \mathrm{~m} \cdot \mathrm{s}^{-1}\right)$, preferred $(1.3$ $\left.\mathrm{m} \cdot \mathrm{s}^{-1}\right)$ and fast speeds $\left(1.6 \mathrm{~m} \cdot \mathrm{s}^{-1}\right)$. This increased power was not found to be the result of increased hip joint stiffness or the return of more elastic energy through the passive joint elements. Interestingly, no aging effect in ankle joint power generation was found for the slow and preferred walking speeds. It is possible that this outcome was due to the fact that the older adults in Silder et al.'s study walked with relatively high speed variability when instructed to walk at self-selected speeds $\left(\approx 0.12 \mathrm{~m} \cdot \mathrm{s}^{-1}\right)$.

Joint kinetics have been shown to be successful and precise measures to identify subtle changes in elderly gait (Schmitz et al., 2009, Winter et al., 1995). Although it is well known that ankle joint power generation (A2) reduces with aging, there is no general consensus as to what fundamental or core compensatory actions occur at the knee and hip joints. This is probably due to the confounding influence of speed (Kerrigan et al., 1998).

Identifying how gait changes in healthy older adults is important since reductions in the ability to walk limits mobility, reduces living independence, diminishes the 
capacity to perform daily life tasks and affects socialization and well-being (Judge et al., 1996b, Salzman, 2010, Lopopolo et al., 2006, Watelain et al., 2000). All of these factors affect the quality of life of an older adult (Salzman, 2010, Wolfson, 2001). A better understanding of how neuromuscular changes emerge in healthy elderly gait will help develop interventions to prevent or partly reverse gait alterations and subsequent loss of mobility (Ko et al., 2009, Silder et al., 2008). 


\section{Chapter 2: Literature Review}

The emergence of gait changes with healthy aging generally signals deterioration in the systems that control movement. Age-related losses in the visual (Helbostad et al., 2009), vestibular (Deshpande and Patla, 2006), proprioceptive (Dietz and Duysens, 2000) and cardiopulmonary systems (Canavan et al., 2009) are known to affect gait. It is also thought that musculoskeletal conditions such as hip flexors contracture (Kerrigan et al., 1998, Kerrigan et al., 2003), weakness of the abdominal muscles (Røislien et al., 2009) and other non-specified postural modifications (Judge et al., 1996a) affect gait with aging. Other age-related changes in the neuromuscular system such as reduced muscle mass, power and strength are known to significantly impact on the normal walking pattern of healthy older adults (McGibbon, 2003, Vandervoort, 2002, Bean et al., 2003). This is demonstrated by reductions in gait speed, step and stride length, coupled with increases in double support time, base of support and cadence (Himann et al., 1988, Bendall et al., 1989, McGibbon, 2003, Prince et al., 1997, Shumway-Cook and Woollacott, 2001, Ko et al., 2009).

This literature review focuses on the neuromuscular adaptations and compensatory actions made by healthy young and older adults when walking. This chapter only reviews joint kinetic patterns of gait in the sagittal plane. The majority of lower limb joint power and mechanical work is produced in the sagittal plane (Eng and Winter, 1995, Neptune et al., 2008). Frontal and transverse plane kinetics are not reviewed. These are considered to be beyond the scope of this thesis. Throughout the thesis the term "basic" or "normal" gait refers to the walking pattern exhibited by healthy adults walking at steady-state speed along a straight, level and unobstructed path.

The format of this chapter is as follows. There are two major sections where the literature about the normal gait pattern and the effects of aging upon gait is reviewed. The first section is divided into three sub-sections: (1) gait cycle description, (2) kinematics, and (3) joint kinetics. The second section is divided into five sub-sections: (1) basic spatiotemporal gait parameters, (2) hip joint function, (3) 
knee joint function, (4) ankle joint function and (5) mechanisms underlying agerelated gait changes. A short summary is located at the end of this chapter. This summary critically assesses current knowledge and provides the rationale for this project. At the end of this section is a table that lists the relevant findings from published literature about aging gait (Table 2.2, page 42).

\subsection{Normal Gait}

\subsubsection{Gait Cycle Description}

The gait cycle (GC) is defined as the period between two successive footfalls of the same foot (figure 2.1). This cycle is divided in two phases: stance and swing phase (Rose, 1994). The stance phase is from heel contact to toe-off (or foot-off) whereas the swing phase is from toe-off (TO) to heel contact (or initial contact) of the same foot. The stance and swing phases are further divided into sub phases delineated by specific events. There are three sub phases of stance: (1) the initial double support (IDS) or loading response (LR). This is the period from initial contact (IC) to opposite toe-off (OTO) or foot flat (FF); (2) the single stance (SS) or midstance (MSt) from OTO to opposite initial contact (OIC) or heel-off (HO); and (3) the second double support (SDS) or late stance (LS) from OIC-HO to TO. The midpoint between OTO and OIC-HO during single stance is defined as midstance (MSt). The are three subphases of swing: (1) initial swing (ISw), that is the period from TO to foot clearance (FC); (2) midswing (MSw) from FC to tibia vertical (TV); and (3) terminal swing (TSw) from TV to HC (Perry, 1992, Rose, 1994, Whittle, 1993).

The gait cycle is commonly normalized to $100 \%$. The stance and swing phases last on average for $62 \%$ and $38 \%$ of the GC, respectively. Single stance lasts about $30 \%$ of the GC (Rose, 1994). These percentages vary with gait speed and cadence (Kirtley et al., 1985) (figure 2.1). 


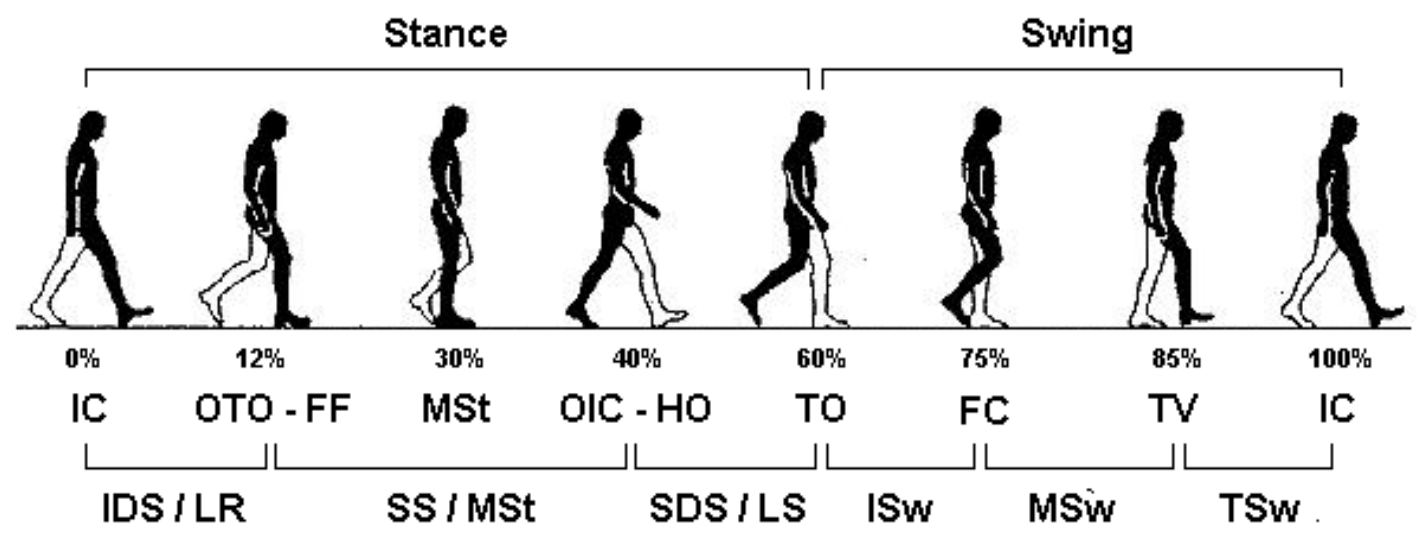

Figure 2.1 Phases, sub-phases, events and corresponding percentages of gait cycle. Refer to text on page 6 for abbreviations (Adapted from Whittle, 1993, p.53).

Linear measurements are also used to describe the gait cycle. The step length is the displacement between two sequential $\mathrm{HC}$ whereas stride length is the displacement between two successive HCs of the same foot (Rose, 1994, Sutherland et al., 1988). Step width is the medio-lateral displacement between the center points of the heels whereas foot angle is the angle formed between the midline of the foot and line of progression. This is defined as the line traced between two consecutive HCs of the same foot (Whittle, 1993) (figure 2.2). Cadence is commonly defined as the number of steps per minute (Whittle, 1993). These spatial measures are affected by gait speed (Kirtley et al., 1985). Gait speed is the average horizontal (anteriorposterior) speed and is commonly measured in $\mathrm{m} \cdot \mathrm{s}^{-1}$ (Rose, 1994).

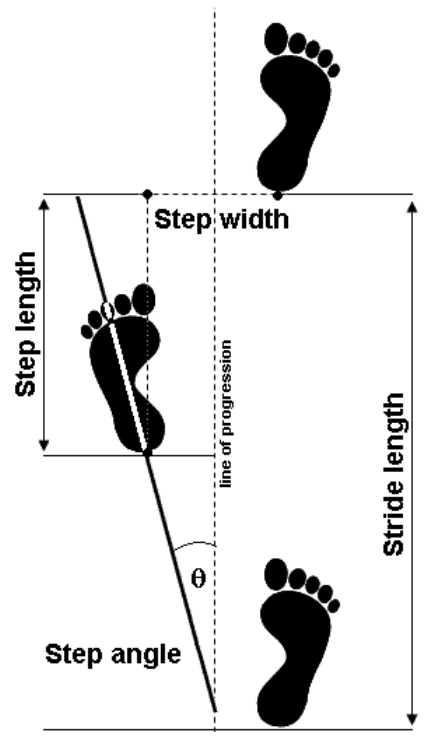

Figure 2.2 Basic spatiotemporal measures of gait. 


\subsubsection{Joint Angular Kinematics}

Kinematics is the study of the spatiotemporal aspects of motion. This section reviews the angular kinematics of the pelvis, hip, knee and ankle.

\subsubsection{Pelvis}

Pelvic motion in the sagittal plane is illustrated in figure 2.3. In a standing position, the pelvis is in about $11^{\circ}$ of anterior tilt (Lee et al., 2005). During normal gait the pelvic ROM ranges from $5^{\circ}$ to $15^{\circ}$ in young adults (Judge et al., 1996a). At TO, anterior pelvic tilt is minimized whereas it reaches a maximum value during double support and TSw (figure 2.3). This motion is mainly produced and controlled by two pairs of muscles. Firstly, the rectus abdominis and gluteus maximus muscles produce posterior pelvic tilt through concentric contraction and mediate anterior pelvic tilt through eccentric contraction. Secondly, the erector spinalis and rectus femoris produce anterior pelvic tilt through concentric contraction and mediate posterior pelvic tilt through eccentric contraction. However, biarticular muscles such as hamstrings and iliopsoas can also affect this motion.

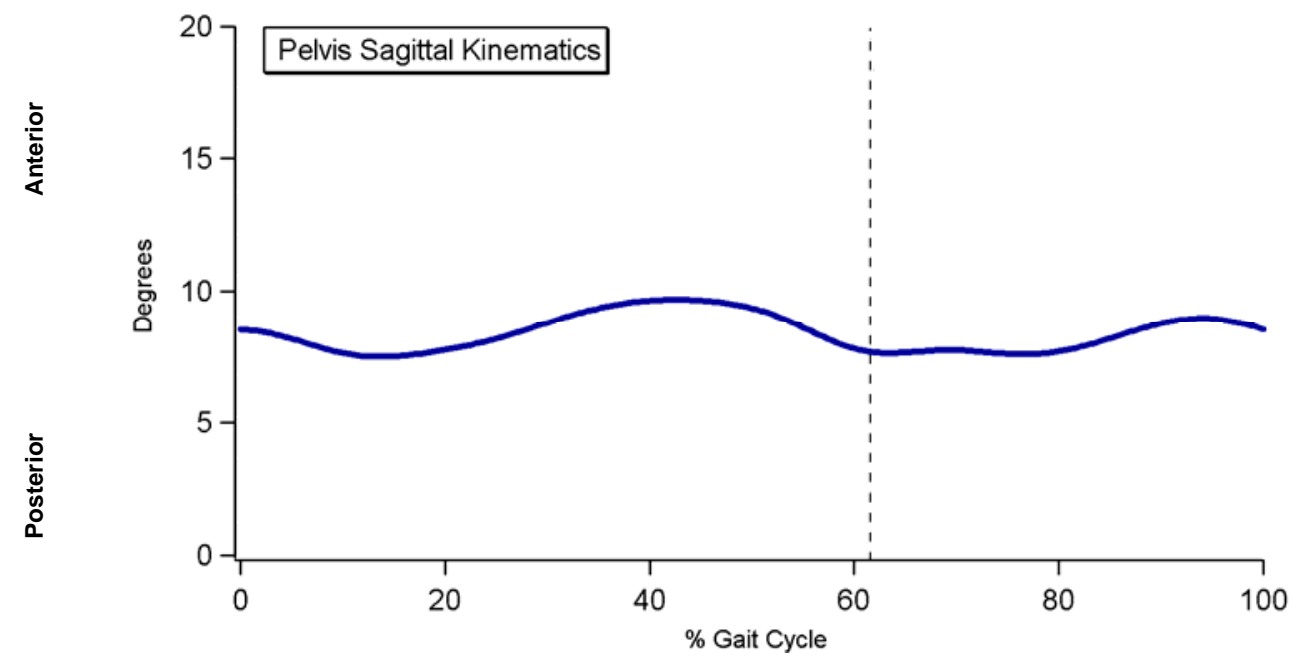

Figure 2.3 Example of sagittal kinematics of the pelvis in a young adult. 


\subsubsection{Hip}

Hip motion in the sagittal plane is illustrated in figure 2.4. It shows that peak extension is achieved at around $55 \%$ of the GC (near OHC) whereas peak flexion is achieved at around 90\% (near MSw). In adults peak extension reaches around $13^{\circ}$ to $15^{\circ}$ (Judge et al., 1996a, Ostrosky et al., 1994) whereas peak hip flexion reaches around $30^{\circ}$ (figure 2.4). Hip extension is produced by gluteus maximus and hamstrings whereas hip flexion is mainly produced by iliopsoas and rectus femoris.

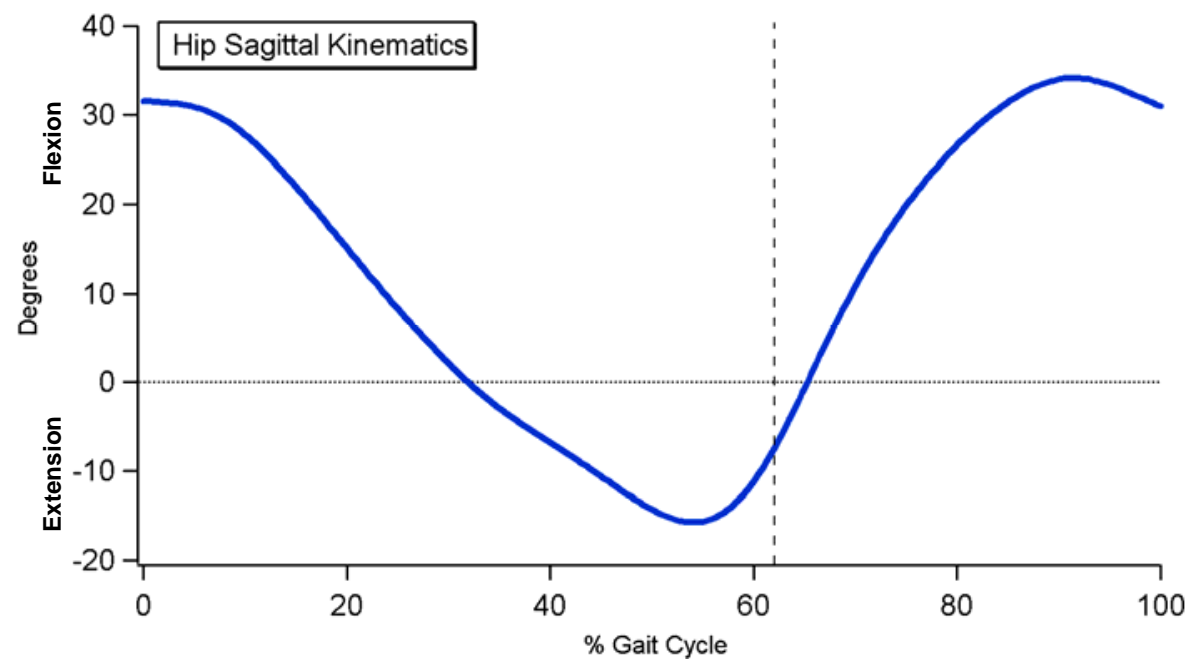

Figure 2.4 Example of sagittal kinematics of the hip in a young adult.

\subsubsection{Knee}

Knee motion in the sagittal plane is illustrated in figure 2.5. It shows peak flexion is achieved at around $15 \%$ of the gait cycle when the entire body weight is accepted during SS. This action has been defined as the "shock absorber", and is controlled by an eccentric contraction of the vastus lateralis, medialis and intermedius (Nene et al., 2004, Perry, 1992). The second peak flexion is produced at around $70 \%$ of the GC (near ISw). This shortens the limb when entering the swing phase which assists with toe clearance. Initially this action is produced by the concentric contraction of the gastrocnemius. After toe-off this movement is passive since it is produced by gravity (Perry, 1992), however, a study using simulation has suggested that knee flexion is also actively produced by hip flexors at this point of the GC (Fox and Delp, 2010) . 


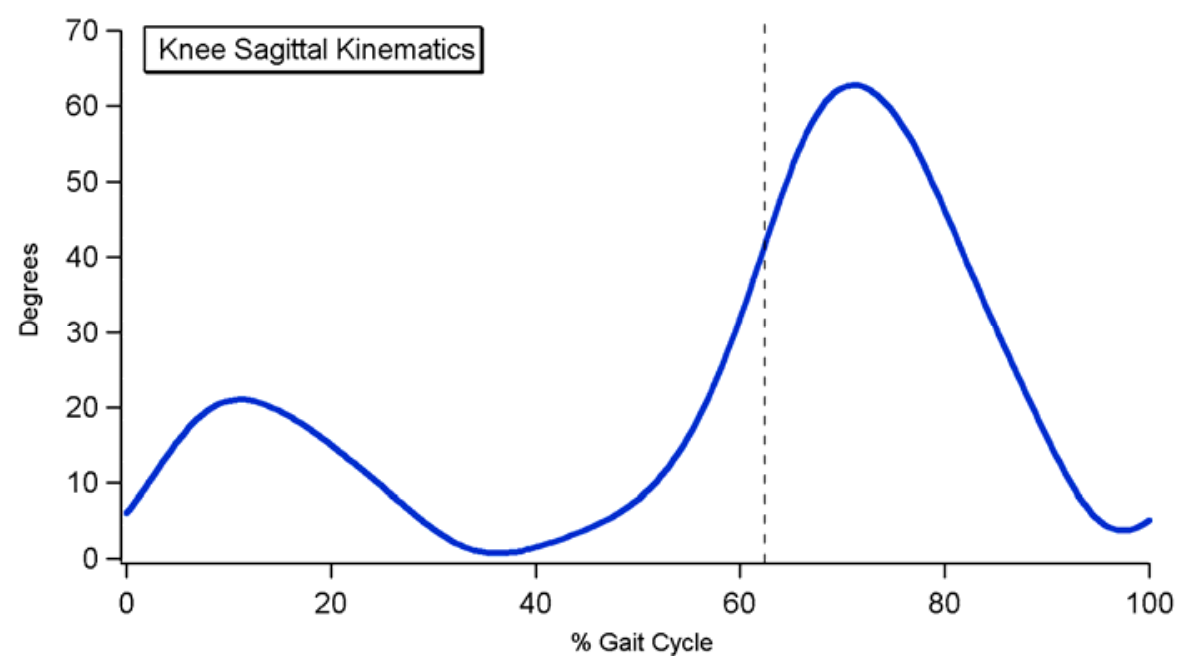

Figure 2.5 Example of sagittal kinematics of the knee in a young adult.

\subsubsection{Ankle}

Ankle motion in the sagittal plane is illustrated in figure 2.6. It shows an initial small plantar flexion peak at around $5 \%$ of the gait cycle which is eccentrically controlled by the dorsiflexors. This action prevents a rapid foot slap after HC. The period from $\mathrm{HC}$ to $\mathrm{FF}$ is defined as the "first rocker". A dorsiflexion peak occurs at around $50 \%$ of gait cycle (near HO). This motion is controlled by eccentric contraction of the ankle plantar flexors (around MS). This period is defined as the "second rocker". The maximum peak of plantar flexion is achieved at around $62 \%$ of the gait cycle (near TO). This motion produces push-off through concentric contraction of the triceps surae (gastrocnemius and soleus). The period from HO to TO is defined as the "third rocker". A second peak of dorsiflexion is achieved at around $80 \%$ of gait cycle. It is mainly produced by concentric contraction of the tibialis anterior. This action assists toe clearance by shortening the limb during swing (figure 2.6). 


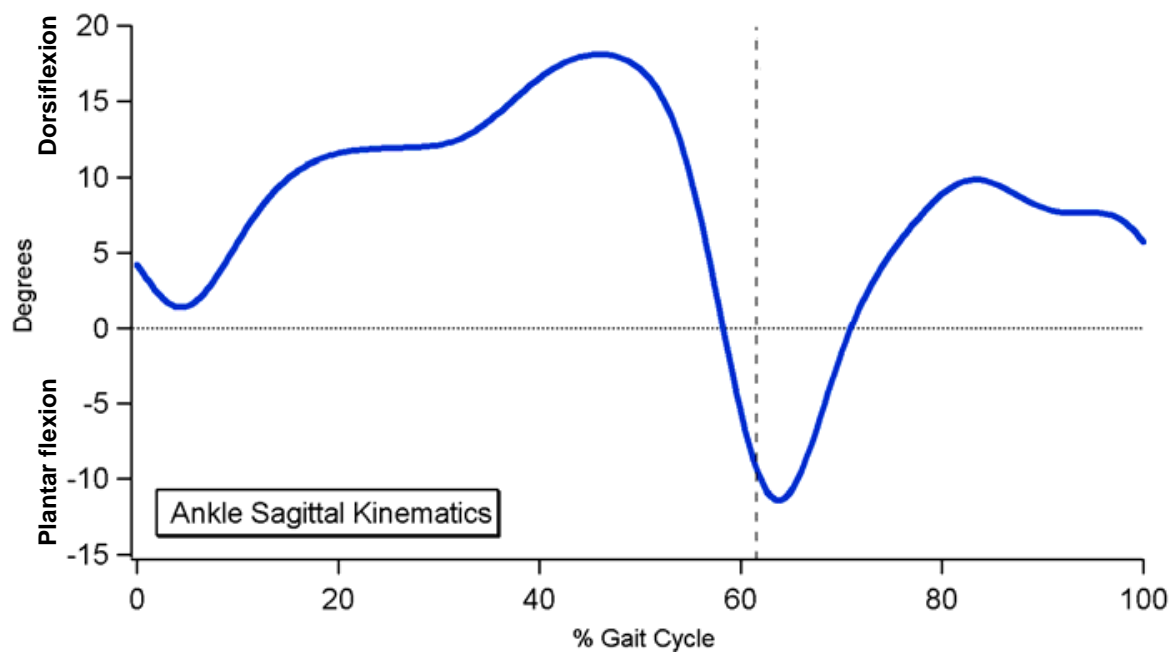

Figure 2.6 Example of sagittal kinematics of the ankle in a young adult. 


\subsubsection{Joint Angular Kinetics}

Human gait results from rotation of the lower limb segments. These rotations are determined by the need to balance external and internal forces (Enoka, 2002). During gait, these segmental movements support and propel the body, control dynamic equilibrium and help the body adapt to meet the demands of the environment (Patla, 1991). Muscles are the major actuators in gait. The muscular activation sequence is relatively constant throughout the GC but the role of the muscles is not constant (Winter, 2005). For instance, muscle function changes from propulsion to stabilization and vice versa, altering the muscle contraction velocity and type (concentric, eccentric, and isometric) which ultimately affects gait kinetics and kinematics.

Gait kinetics deals with the forces that produce movement (Winter, 1991). Generally, an inverse dynamics model is used to understand the interaction of the internal (muscles and soft tissue elastic properties) and external forces (i.e. gravitational and ground reaction forces) involved in gait. This technique uses anthropometric characteristics to estimate the joint reaction forces and moments (Winter, 2005). Through this approach, it is possible to gain insight into the neuromuscular patterns and the adaptive gait strategies implemented by the central nervous system (CNS) in response to a change in walking speed, pathology and aging (Winter and Eng, 1995).

It is important to describe some of the fundamental concepts of kinetics. Equations used to calculate peak joint powers and joint mechanical work are listed in table 2.1. A moment $(M)$ or torque is defined as the product of the magnitude of force $(F)$ and the perpendicular distance $(\perp d)$ from the axis of rotation (Seliktar and Bo, 1995). The product between the joint moment $(M)$ and joint angular velocity $(\omega)$ is joint power (eq.2) (Winter, 1991) whereas mechanical work $(W)$, or mechanical energy, is the power-time integral (eq.3) (Winter, 1991). Conversely, the rate of mechanical work done is joint power (Rodgers and Cavanagh, 1984). 
Table 2.1 Equations used to calculate joint peak powers and joint mechanical work.

\begin{tabular}{|l|l|}
\hline$M=F \cdot \perp d($ Newton $\cdot$ meters $)$ & Equation 1 \\
\hline$P=M \cdot \omega($ Watts $)$ & Equation 2 \\
\hline$W=\int P \cdot d t$ (Joules) & Equation 3 \\
\hline
\end{tabular}

In the literature joint power generation is commonly reported with positive magnitudes whereas joint power absorption is reported with a negative magnitude. Power generation can come from active muscle concentric contraction or from the return of the elastic energy stored in tissues including muscle, tendons, and possibly others (i.e. joint capsule and ligaments). On the other hand, power absorption is associated with elongation of the muscle-tendon complex which can be stored as elastic energy in tissues including muscle, tendons, and possibly others (i.e. joint capsule and ligaments) or dissipated as heat (Rose, 1994, Winter, 2005).

\subsubsection{Hip}

During gait, the majority of work produced in the sagittal plane is performed at the hip (Eng and Winter, 1995). Three main peak powers have been identified during the stance phase of gait (figure 2.7). The first peak is produced by the hip extensors (H1) and serves three functions. It prevents collapse of the body during single support (Eng and Winter, 1995, McGibbon and Krebs, 2004), propels the body forward (DeVita and Hortobágyi, 2000, Sadeghi, 2000, Vardaxis et al., 1998, Sadeghi et al., 2001) and controls trunk inclination (Allard et al., 1996, Eng and Winter, 1995) through active hip extension (Silder et al., 2008).

The second peak joint power (H2) is produced by the hip flexors. These act eccentrically to absorb some of the mechanical energy generated by $\mathrm{H} 1$. H2 slows the backward rotation of the thigh and produces forward inclination of the trunk (Allard et al., 1996, Eng and Winter, 1995). This peak joint power allows the storage of elastic energy that is utilized at the end of stance (McGibbon, 2003, Silder et al., 2008). H1 also facilitates the storage of this elastic energy (Chester, 2008, Whittington et al., 2008). 
At the end of stance a third joint peak power (H3) is generated by the action of hip flexors and the release of stored elastic energy. These actions propel the leg into the swing phase (Allard et al., 1996, Vardaxis et al., 1998, Sadeghi et al., 1997) by adding mechanical energy to the limb (Eng and Winter, 1995). A small generation peak observed during terminal swing may facilitate the next GC. This peak, however, has only been reported by Sadeghi et al (2000).

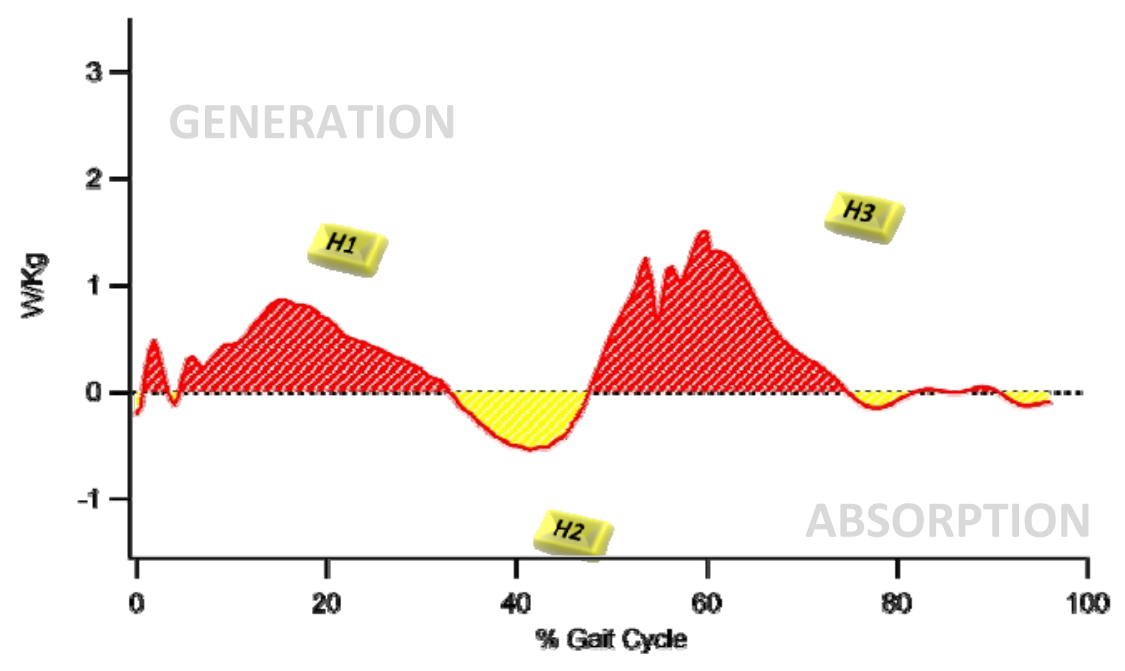

Figure 2.7 Hip joint power pattern in the sagittal plane.

\subsubsection{Knee}

It has been reported that around $85 \%$ of the total work done at knee is produced in the sagittal plane (Eng and Winter, 1995). The first peak knee power (K0) results in a small amount of knee flexion (figure 2.8). This ensures the knee is in a flexed position to absorb the impact of the foot with the ground (Eng and Winter, 1995, Sadeghi et al., 2004). At about $10 \%$ of GC, eccentric contraction of the quadriceps absorbs mechanical energy (K1) and controls knee flexion (Eng and Winter, 1995, Winter, 1983b, Winter, 1983a). This action allows the limb to accept full body weight (Rose, 1994, Sadeghi et al., 2004, Winter, 1991). 


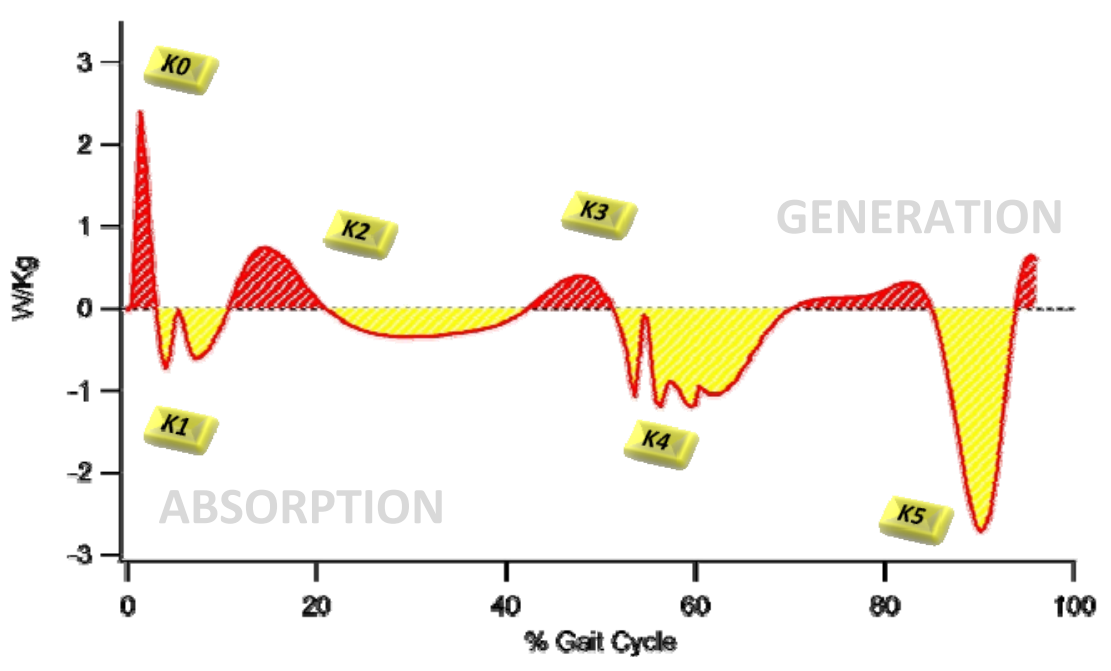

Figure 2.8 Knee joint power pattern in the sagittal plane.

At around $20 \%$ of GC, it is generally thought that concentric contraction of the quadriceps produces a small peak power (K2) that leads to knee extension (Sadeghi et al., 2004, Winter, 1991, Sadeghi et al., 1997, Allard et al., 1996). Nene et al. (2004), however, found that rectus femoris was not involved in knee extension at this time. It is also thought that $\mathrm{K} 2$ helps propel the body since positive mechanical work is done. Nevertheless, the main role of K2 appears to be knee extension prior to heel-off (Sadeghi et al., 2001).

In late stance a third knee peak joint power generation (K3) produces rapid knee flexion in late stance (McGibbon and Krebs, 2004). This power is generated through the release of elastic energy from the gastrocnemius. This energy is stored from foot-flat to heel-off (second half of midstance) when soleus and gastrocnemius eccentrically control the forward rotation of the tibia over the ankle (Ishikawa et al., 2005). To date, the role of K3 has not been fully understood. However, it is reasonable to suggest that it helps prepare the limb to be propelled into swing.

Between late stance and initial swing there is a power absorption phase (K4). This absorptive power has been commonly described as K3 in previous work (e.g. Sadeghi 2000, Winter 1990). In this thesis, however, the nomenclature adopted by McGibbon (1999) will be used. Hence this absorptive peak power will be described by the term "K4". This power prevents knee collapse from the beginning of late 
stance to the end of initial swing (tibia vertical event) through eccentric contraction of the rectus femoris (Eng and Winter, 1995).

At approximately $80 \%$ of GC, the monoarticular knee extensors (e.g. vastus lateralis) accelerate the tibia forward in preparation for the next footfall (Nene et al., 2004, Nene et al., 1999). In order to avoid hyperextension, K5 power absorption decelerates the shank during terminal swing (Watelain et al., 2000, Eng and Winter, 1995, Winter, 1983a). This power is produced by eccentric activation of the hamstrings that prepares the limb for initial contact with the ground (Rose, 1994, Neptune et al., 2008).

\subsubsection{Ankle}

Around $93 \%$ of the mechanical work performed by the ankle is produced in the sagittal plane (Eng and Winter, 1995). At heel contact, eccentric contraction of the dorsiflexors lowers the forefoot to the ground, which allows the absorption of mechanical energy. However, no absorption peak at this time of the GC has been described in the literature (Winter, 1983a). At around 40\% of GC, the ankle plantar flexors contract eccentrically (A1) (figure 2.9) to control the shank as it rotates over the ankle (Eng and Winter, 1995).

Following A1 power absorption, there is a significant burst of power generated (A2) by the ankle plantar flexors. This powerful push-off produces the majority of the total mechanical work generated by the joints during gait (Winter, 1991, Chen et al., 1997, Winter, 1983a, DeVita and Hortobágyi, 2000, Whittle, 1993, Sadeghi et al., 2004). This joint power is important for trunk stabilization in late stance, forward progression of the body and leg swing initiation (Judge et al., 1996a, Whittle, 1993, Winter, 1983a, Riley et al., 2001b). In contrast, A2 joint power has been described as a potential source of destabilization in older adults (Winter et al., 1990) since it has been shown they decrease A2 joint power in order to maintain dynamic balance. Other work suggests the main role of A2 peak power is to support and stabilize the upper body (Riley et al., 2001a, Riley et al., 2001b) since it has been found that ankle moments remain relatively constant over a range of walking speeds. This shows that 
any increase in ankle joint power may be partly due to an increase in angular velocity of the foot (Riley et al., 2001a, Riley et al., 2001b).

A2 peak power has commonly been associated with concentric action of the ankle plantar flexors. However, the EMG activity of soleus and gastrocnemius muscles has been shown to be reduced at this point of the gait cycle (Ishikawa et al., 2005). It is reasonable, therefore, to propose that A2 power is mainly produced by the release of the elastic energy stored in the Achilles tendon (prior to heel-off) during the A1 absorption period (Stewart et al., 2007). Since the gastrocnemius is a biarticular muscle that crosses both the ankle and knee joints, it probably plays a key role in $\mathrm{K} 3$ power generation at this point of the GC. On the other hand, since soleus is a monoarticular muscle that crosses the ankle joint, it probably plays a major role in A2 power generation (Stewart et al., 2007). Hence the storage and release of elastic energy probably reduces muscle work during gait (Neptune et al., 2008).

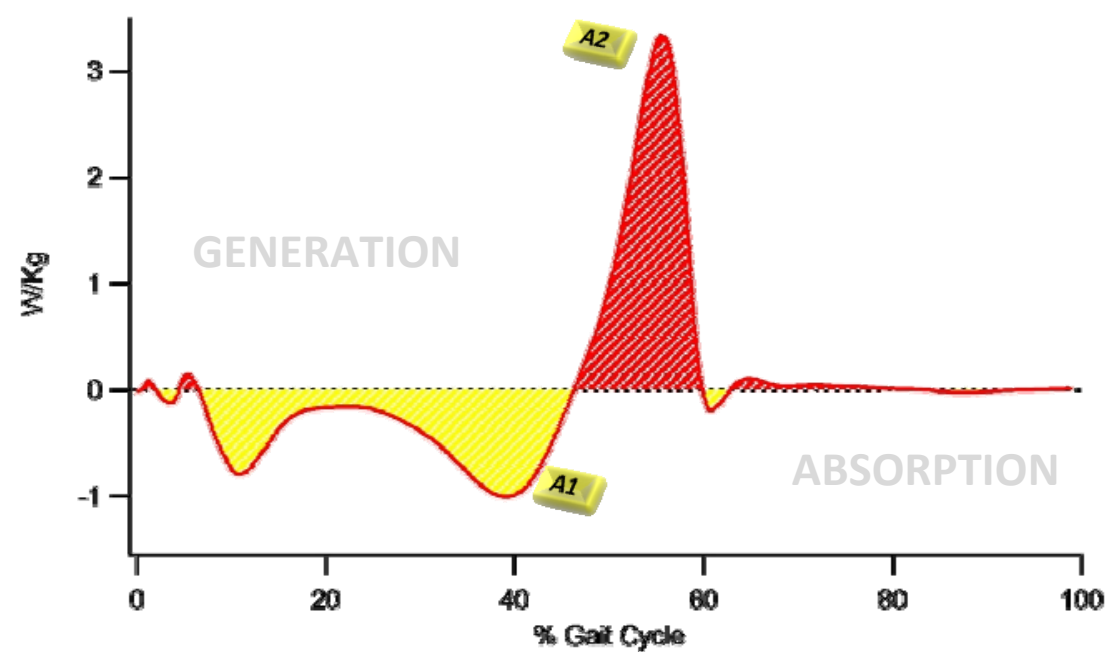

Figure 2.9 Ankle joint power pattern in the sagittal plane. 


\subsection{Aging Gait}

Gait changes with healthy aging are attributed to adaptations of the neuromuscular system that lead to compensatory actions that maintain gait functionality (i.e. gait speed and step length). The term "neuromuscular adaptation" has been defined as "a response to age-related impairment" (McGibbon, 2003). For the purposes of this thesis the term "compensatory action" is defined as the response produced by the neuromuscular system to generate a functional gait pattern. Compensatory actions driven by the neuromuscular system include increased activity of proximal muscles, specifically hip and knee muscles, and increased utilization of stored elastic energy in the lower limbs (DeVita and Hortobágyi, 2000, McGibbon, 2003). These compensatory actions are identified by changes in joint peak power generation (i.e. H3 peak power) and joint peak power absorption (i.e. H2 peak power). It is possible that when the neuromuscular system is unable to produce compensatory actions gait changes will emerge with aging which may also lead to gait dysfunctions

\subsubsection{Basic Spatiotemporal Gait Parameters}

The self-selected walking speed of older adults is commonly reported to be slower than young adults (Himann et al., 1988, Dobbs et al., 1993, Judge et al., 1996a, Chung and Wang, 2010, Kerrigan et al., 1998, McGibbon and Krebs, 2004, Ostrosky et al., 1994, Ko et al., 2009) and is associated with reduced step and stride length (figure 2.10) (Hageman and Blanke, 1986, Winter et al., 1990, Himann et al., 1988, Kerrigan et al., 1998, McGibbon and Krebs, 2004, Ostrosky et al., 1994, Ko et al., 2009) and increased cadence (Judge et al., 1996a, Watelain et al., 2000, Zijlstra, 2004). Reduced gait speed is an important issue since small decreases $\left(0.1 \mathrm{~m} \cdot \mathrm{s}^{-1}\right)$ have been linked to difficulty in performing simple daily life activities such as rising from a chair (Lopopolo et al., 2006, Judge et al., 1996b). Moreover, it has been reported that a minimum speed of $1.4 \mathrm{~m} \cdot \mathrm{s}^{-1}$ is needed to walk safely in the community (ShumwayCook and Woollacott, 2001). 


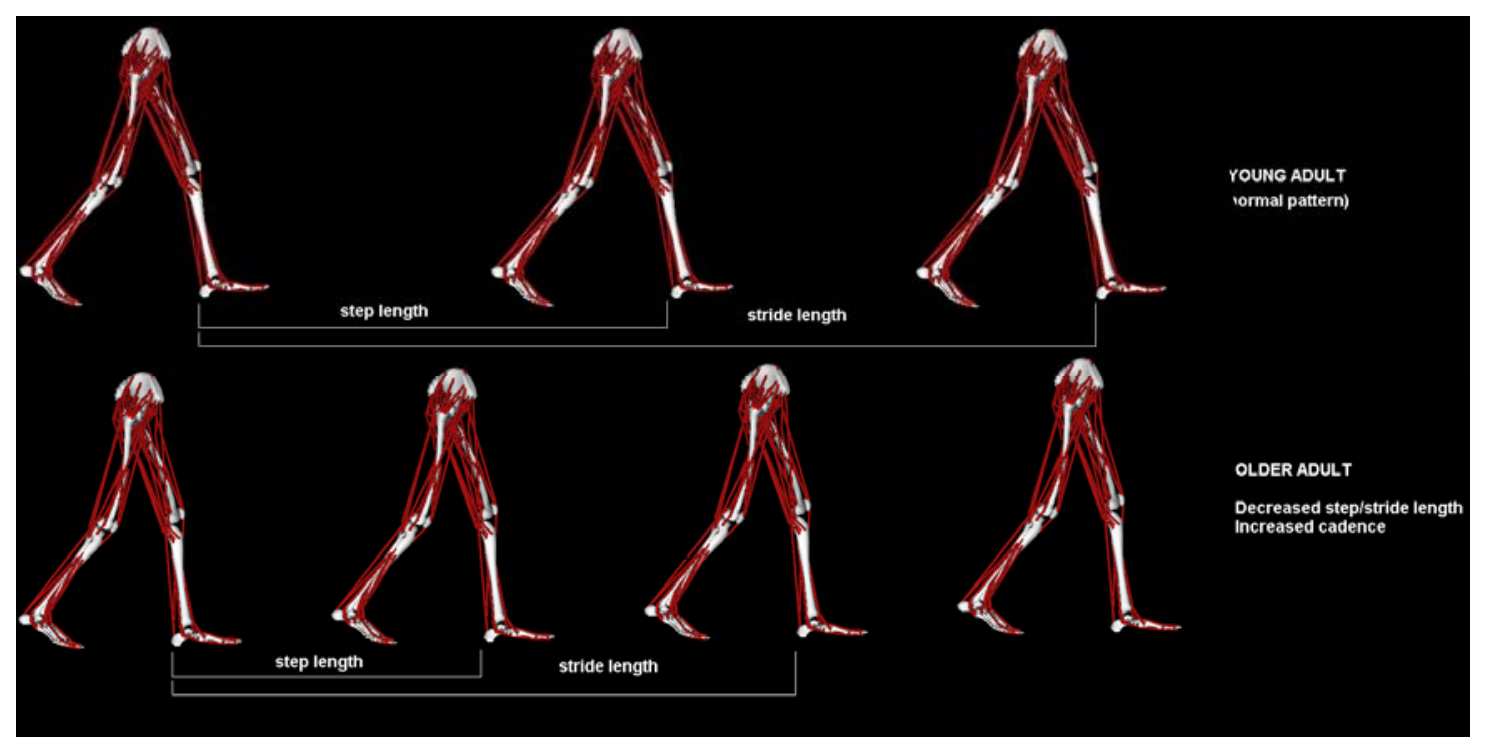

Figure 2.10 Changes in cadence, stride length and step length with aging (figure was produced using OpenSim 1.9.1).

Gait speed is determined by cadence and step length (Himann et al., 1988, Perry, 1992). The three strategies used to increase gait speed are (1) increasing cadence, (2) increasing step length and (3) increasing both. It has been shown that that children and older adults increase gait speed by mainly increasing cadence (DeVita and Hortobágyi, 2000, Crowinshield et al., 1978, Ganley and Powers, 2005), whereas young adults increase it by mainly increasing step/stride length (DeVita and Hortobágyi, 2000).

Temporal changes associated with aging (figure 2.11) include increased stance and double support time, and reduced single support and swing time (Winter et al., 1990, DeVita and Hortobágyi, 2000, Watelain et al., 2000, Begg and Sparrow, 2006). It is thought that these changes increase dynamic stability in the elderly (Winter et al., 1990, DeVita and Hortobágyi, 2000). Another strategy thought to increase stability with aging is a wider support base or step width (Shumway-Cook and Woollacott, 2001). This finding has not been supported by more recent studies (Ko et al., 2009, McGibbon and Krebs, 2004). 


\begin{tabular}{|l|c|c|c|c|}
\hline $\begin{array}{c}\text { double } \\
\text { support }\end{array}$ & single support & \multicolumn{1}{c|}{$\begin{array}{c}\text { double } \\
\text { support }\end{array}$} & swing phase \\
\hline \begin{tabular}{|c|c|c|c|} 
double \\
support
\end{tabular} & single support & \multicolumn{1}{c|}{$\begin{array}{c}\text { double } \\
\text { support }\end{array}$} & swing phase \\
\hline
\end{tabular}

Figure 2.11 Schematic representation of the effect of aging on temporal gait measures.

The variability of the basic gait spatiotemporal parameters (e.g. step width and length) has been shown to increase with aging. This increased variability has been linked to the deterioration of the fine motor control of gait (Maki, 1997, Hausdorff et al., 2001, Kang and Dingwell, 2008). It is thought that step width variability can predict falls in older adults (Maki, 1997). Increased variability of trunk motion has also been linked to gait dysfunction and increased falling behaviour (Kang and Dingwell, 2008, Moe-Nilssen and Helbostad, 2005). It is important to note, however, that the over-ground walk protocol used to assess gait can affect the variability of basic gait parameters (Paterson et al., 2009). In comparison to a repeated single overground walking protocol, a continuous over-ground walking protocol significantly reduced the variability of several basic spatiotemporal measures of gait in an older adult group (Paterson et al., 2009).

\subsubsection{Hip Joint Function}

In an early study, Crowinshield et al. (1978) found that older adults use less hip ROM than young adults during gait. Gait speed in this study, however, was not controlled since participants walked at self-selected speeds ranging from $0.3 \mathrm{~m} \cdot \mathrm{s}^{-1}$ to $1.5 \mathrm{~m} \cdot \mathrm{s}^{-1}$ (Crowinshield et al., 1978). More recently, DeVita and Hortobágyi (2000) found older adults use more hip ROM than young adults when walking at the same speed (DeVita and Hortobágyi, 2000). This finding is supported by a study that compared older and young adults walking at slow, preferred and fast speeds (Silder et al., 2008). The average speeds reported for the young and older adults were $1.06 \mathrm{~m} \cdot \mathrm{s}^{-}$ 1, $1.33 \mathrm{~m} \cdot \mathrm{s}^{-1}, 1.59 \mathrm{~m} \cdot \mathrm{s}^{-1}$ respectively (Silder et al., 2008). Increased hip flexion to compensate for decreased ankle function has been suggested as the cause of increased hip ROM in older adults gait during swing (Ostrosky et al., 1994, Silder et al., 2008). 


\subsubsection{Extension}

\subsection{Kinematics}

Studies have shown that healthy older adults exhibit less maximum hip extension (figure 2.12) than healthy young adults when walking at self-selected speed (Kerrigan et al., 2001, Ostrosky et al., 1994, Kerrigan et al., 1998). Kerrigan et al. (1998) found peak hip extension to be $21^{\circ}$ in a group of young adults $(\mathrm{n}=31)$ and $14.3^{\circ}$ in a group of older adults $(n=31)$ when walking at self-selected speed (Kerrigan et al., 2001, Kerrigan et al., 1998). The reduction in peak hip extension may be explained by the slower walking speed $(p<0.05)$ of the older adult group. The elderly walked at $1.19 \mathrm{~m} \cdot \mathrm{s}^{-1}$ whereas the young walked at $1.37 \mathrm{~m} \cdot \mathrm{s}^{-1}$. Interestingly, Kerrigan et al. (1998) found that when the older adults walked faster $\left(1.55 \mathrm{~m} \cdot \mathrm{s}^{-1}\right)$ than the young adults $\left(1.37 \mathrm{~m} \cdot \mathrm{s}^{-1}\right)$, peak hip extension only increased to a value of $14.5^{\circ}$ (Kerrigan et al., 1998). Therefore, it seems reasonable to conclude that older adults may use less maximum hip extension to walk than young adults.

Kerrigan et al. (1998) attributed the reduction in hip extension to the presence of a dynamic hip flexor contracture. Interestingly, however, the young adults in the study exhibited an unusually high amount of hip extension $\left(21^{\circ}\right)$ compared to the findings of other studies. Investigations of aging gait have typically reported about $15^{\circ}$ of hip extension in young adults during walking (Ostrosky et al., 1994, Winter, 1991, Silder et al., 2008). Therefore, it is possible that the difference in hip extension found by Kerrigan et al. may not be an aging effect.

McGibbon and Krebs (2004) also found that older adults walk with less hip extension than young adults (OLD: $11.9^{\circ}$; YG: $15.0^{\circ}$ ). As with previous investigations, however, speed was not controlled or matched since the healthy older adult group walked significantly $(p<0.05)$ slower $\left(1.1 \mathrm{~m} \cdot \mathrm{s}^{-1}\right)$ than the young adults $\left(1.3 \mathrm{~m} \cdot \mathrm{s}^{-1}\right)$. Recently a study by Monaco et al. (2009) compared the gait of young and older adults by controlling speed with a treadmill. A significant reduction $(p<0.05)$ in peak hip extension was found in the elderly when speeds were matched from $0.6 \mathrm{~m} \cdot \mathrm{s}^{-1}$ 
to $1.2 \mathrm{~m} \cdot \mathrm{s}^{-1}$. In contrast, Silder et al. (2008) found no significant difference in maximum hip extension between a group of older and young adults (e.g. OLD: $14^{\circ}$; YG: $15^{\circ}$ at fast speed) when walking over-ground at slow $\left(1.06 \mathrm{~m} \cdot \mathrm{s}^{-1}\right)$, preferred $(1.33$ $\left.\mathrm{m} \cdot \mathrm{s}^{-1}\right)$ and fast $\left(1.59 \mathrm{~m} \cdot \mathrm{s}^{-1}\right)$ speeds. It is reasonable to conclude, therefore, that there is currently no consensus about the effect of aging on maximum hip extension during gait.

Speed is an important factor when investigating maximum hip extension in aging gait. Chung and Wang (2010) and Silder et al. (2008) found walking speed to significantly affect maximum hip extension when young and older adults walked at different percentages of self-selected speed (ranging from $80 \%$ to $140 \%$ ). No aging effect, however, was found in this investigation (Chung and Wang, 2010). This effect has also been reported in earlier work by Silder et al. (2008) who compared the gait of young and older adults walking at slow $\left(1.06 \mathrm{~m} \cdot \mathrm{s}^{-1}\right)$, preferred $\left(1.33 \mathrm{~m} \cdot \mathrm{s}^{-1}\right)$ and fast speeds $\left(1.59 \mathrm{~m} \cdot \mathrm{s}^{-1}\right)$.

\subsection{Kinetics}

Aging has been found to affect hip joint kinetics during the first half of stance. DeVita and Hortobágyi (2000) found a significant increase in hip extension angular impulse coupled with a longer lasting period of hip extensor moment in older adults when walking at the same speed $\left(1.48 \mathrm{~m} \cdot \mathrm{s}^{-1}\right)$ as young adults (figure 2.12). The contribution of the extensor moment to the total support moment was $74 \%$ in the elderly and $37 \%$ in the young adults. McGibbon and Krebs (2004) have also reported higher hip extensor moments in older adults.

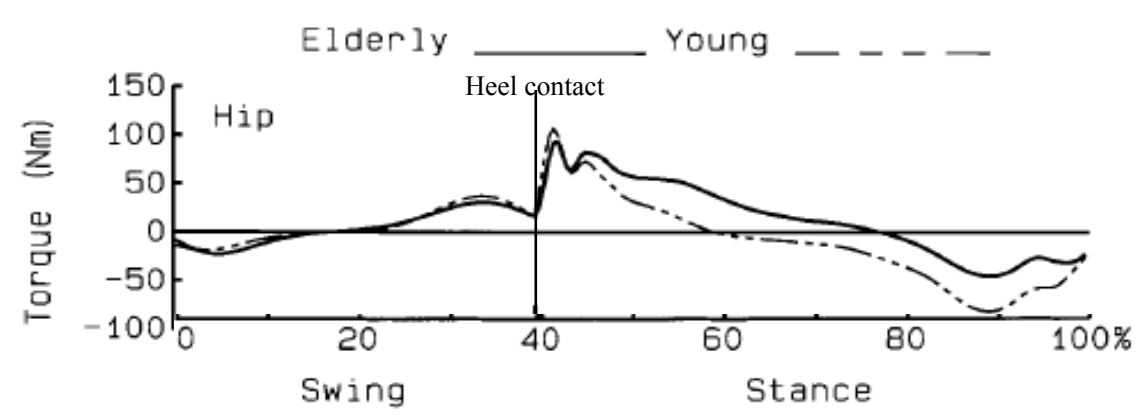

Figure 2.12 Mean hip joint torque curve for young and older adults (taken from DeVita and Hortobágyi, 2000, p.1808). 
It is known that $\mathrm{H} 1$ peak power and mechanical work are affected by gait speed (Chen et al., 1997, Lelas et al., 2003, Silder et al., 2008). This may partly explain the failure by earlier studies (Kerrigan et al., 1998, Winter et al., 1990, Watelain et al., 2000) to find significant aging differences in these measures since walking speed was not controlled or matched; that is, gait speed was significantly slower in the older adults compared to the young adults. It has been shown, however, that older adults, compared to young adults, generate greater $\mathrm{H} 1$ peak joint power and mechanical work (figure 2.13) at similar slow, preferred and fast gait speeds (Silder et al., 2008), when walking at around $1.48 \mathrm{~m} \cdot \mathrm{s}^{-1}$ (DeVita and Hortobágyi, 2000) and at a set cadence of 120 bpm (McGibbon and Krebs, 2004). Monaco et al. (2009) also found older adults generate greater $\mathrm{H} 1$ peak power than young adults walking on a treadmill at speeds ranging between 1.0 and $1.3 \mathrm{~m} \cdot \mathrm{s}^{-1}$ (Monaco et al., 2009).

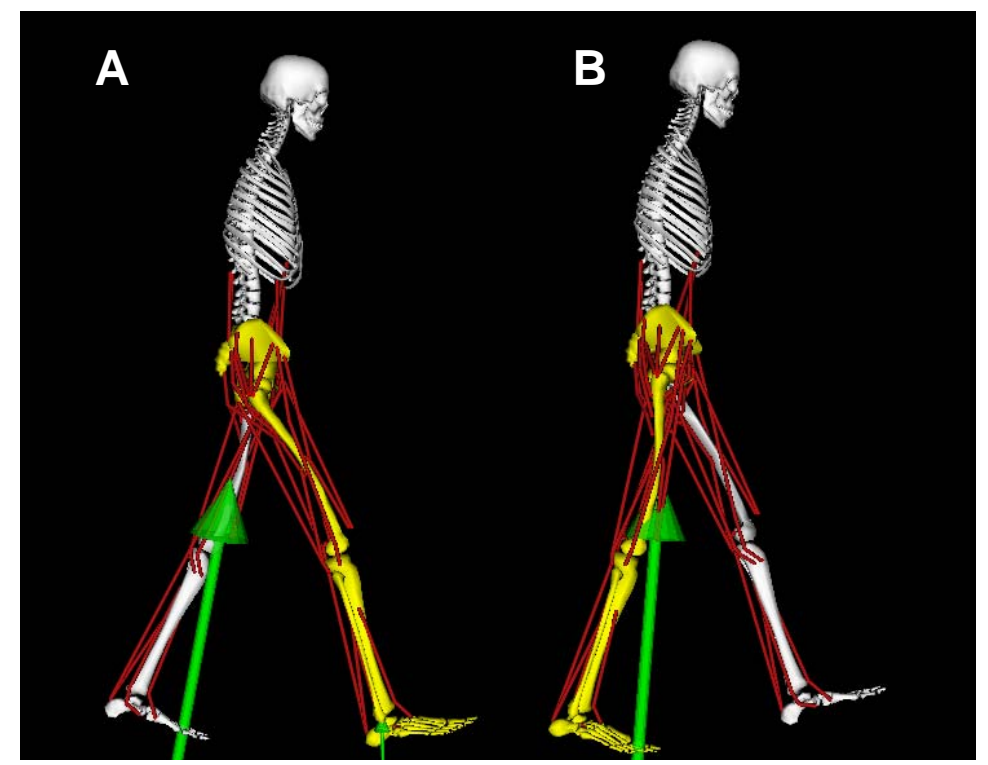

Figure 2.13 H1 joint power and maximum hip extension during gait. (A) H1 starts at $10 \%$ of GC. (B) $\mathrm{H} 1$ ends at $35 \%$ of GC (figure was produced using OpenSim 1.9.1).

The increased generation of $\mathrm{H} 1$ peak power and mechanical work by older adults is known to be partly produced by increased medial hamstrings activity (Schmitz et al., 2009). This activation has been reported to be significantly higher at fast speed $\left(1.58 \mathrm{~m} \cdot \mathrm{s}^{-1}\right)$ in older adults than young adults (Schmitz et al., 2009). During load reception, the gluteus maximus is activated to stabilize the trunk to prevent leg collapse (Winter, 1991, Neptune et al., 2004, Neptune et al., 2008, Sadeghi et al., 2004). Following this action, it generates the majority of the $\mathrm{H} 1$ mechanical work to 
propel the body forward (Sadeghi, 2000, Sadeghi et al., 2001, DeVita and Hortobágyi, 2000). This propulsive role has been shown to increase with walking speed in older adults (Monaco et al., 2008). Gait simulation studies, however, have shown the gluteus maximus contributes more to support than progression as speed increases (Liu et al., 2008, Neptune et al., 2008). Hence, the role of H1 in early stance is currently ambiguous.

Immediately after midstance, hip extension is slowed by a hip flexor torque through eccentric contraction of the hip flexors (refer to figure 2.12). This produces a hip flexor impulse that lasts until midswing. This impulse has been found to be greater in older adults than young adults when walking at a fixed cadence of $120 \mathrm{bpm}$ (McGibbon and Krebs, 2004) and significantly higher when older adults walk faster than young adults (Kerrigan et al., 1998). DeVita and Hortobágyi (2000), however, found that hip flexor impulse was significantly greater in young adults compared to older adults when walking around $1.48 \mathrm{~m} \cdot \mathrm{s}^{-1}$.

There is no consensus about the effect of aging on $\mathrm{H} 2$ peak power absorption and mechanical work. For example, older adults walking at slower speed than young adults have been shown to either increase (McGibbon and Krebs, 2004, Winter et al., 1990) or reduce (Kerrigan et al., 1998, McGibbon and Krebs, 1999) H2 peak power absorption and mechanical work compared to the young adults. When speed was controlled, older adults were found to have less $\mathrm{H} 2$ peak power and mechanical work than young adults (DeVita and Hortobágyi, 2000, Silder et al., 2008, Monaco et al., 2009). This finding, however, is contradicted by Watelain et al. (2000) who found higher $\mathrm{H} 2$ peak power absorption in a group of older adults than young adults when walking at similar speed (OLD: $1.34 \mathrm{~m} \cdot \mathrm{s}^{-1}$; YG: $1.35 \mathrm{~m} \cdot \mathrm{s}^{-1}$ ). An unknown yet potential confounding influence on the outcomes of these studies is tendon stiffness, which may affect the amount of energy return and the mechanical work generated by the iliopsoas (Neptune et al., 2008).

It is thought that increased $\mathrm{H} 2$ peak power absorption is important to maintain and increase stride length and walking speed in older adult gait (Watelain et al., 2000). A possible explanation for this relationship is that elastic energy stored during 
this period is returned to assist H3 power generation (McGibbon, 2003, McGibbon and Krebs, 2004). Recent work counters this idea since it found that older adults do not rely more than young adults on the energy stored in the passive hip structures (soft tissues) to produce greater $\mathrm{H} 2$ absorption, H3 peak power and mechanical work generation (Silder et al., 2008). However, in a gait simulation study elastic energy storage was found to increase in the ligaments and other joint structures, but not in the iliopsoas tendon as walking speed increased (Neptune et al., 2008).

\subsubsection{Flexion}

A rapid concentric contraction of the hip flexor muscles around terminal stance produces hip flexion that pulls the thigh forward to prepare the limb for the swing. This action generates hip power from late stance to initial swing (H3 peak power). Hip flexion has been found to be greater in older adults than young adults when walking over-ground at self-selected speeds (Silder et al., 2008, Ostrosky et al., 1994, Mills and Barrett, 2001). Monaco et al. (2009) also found older adults flex the hip more than young adults when walking on a treadmill at speeds ranging from 0.9 $\mathrm{m} \cdot \mathrm{s}^{-1}$ to $1.3 \mathrm{~m} \cdot \mathrm{s}^{-1}$.

Silder et al. (2008) found older adults, compared to young adults, generate more H3 peak power and mechanical work when walking over-ground at slow (1.06 $\left.\mathrm{m} \cdot \mathrm{s}^{-1}\right)$, preferred $\left(1.33 \mathrm{~m} \cdot \mathrm{s}^{-1}\right)$ and fast $\left(1.59 \mathrm{~m} \cdot \mathrm{s}^{-1}\right)$ speeds. The older adults relied more on $\mathrm{H} 3$ peak power generation than A2 peak power generation to increase speed from slow to fast (refer to section 2.2.5.4 "compensatory actions"). The H3 and A2 peak powers increased by $53 \%$ and $35 \%$ respectively in the older adults, whereas these powers increased by $49 \%$ and $43 \%$ in the young adults respectively. Judge et al. (1996a) also found older adults generate more H3 peak power (when normalized by step length). This effect has also been found for older adults walking on a treadmill at speeds ranging from $0.9 \mathrm{~m} \cdot \mathrm{s}^{-1}$ to $1.3 \mathrm{~m} \cdot \mathrm{s}^{-1}$ (Monaco et al., 2009) even though it is shown that less hip flexor power is generated when walking on a treadmill (Watt et al., 2010). 
It is thought that increased iliopsoas activation in older adults is the main contributor to H3 peak power generation (Neptune et al., 2008, Neptune et al., 2004, Silder et al., 2008), since it has been shown that rectus femoris activity near toe-off is unaffected by age and speed (Schmitz et al., 2009). In contrast, Chung et al (2010) found that rectus femoris activity increases with aging. This led to greater hip ROM and faster walking speed (Chung and Wang, 2010). A reason for the different findings in rectus femoris activity lies in the method of calculating the magnitude of the EMG signal. Schmitz et al. (2009) calculated the magnitude of the signal for specific gait cycle sub-phases (e.g. late stance), whereas Chung et al. (2010) calculated it for the entire gait cycle.

From midstance to heel-off, the rectus femoris is stretched by its proximal attachment (pelvis), yet later it is stretched by its distal attachment (tibia). During this period, hip flexion occurs as a result of both active contraction of the rectus femoris and the return of elastic energy from the stretched muscle (Whittington et al., 2008, Silder et al., 2007). This action increases the energy transferred from the knee to the hip resulting in greater $\mathrm{H} 3$ peak power generation for swing initiation and forward propulsion of the body (Neptune et al., 2008, Neptune et al., 2004).

McGibbon et al. (2003) proposed that older adults may take advantage of stiffer hip flexor muscles by storing and releasing more elastic energy. This increased return of elastic energy may increase H3 peak power generation (McGibbon, 2003). The contribution made by passive elements to the net joint work done has been found to increase with speed in both young and older adults (Silder et al., 2008). However, active elements produce most of the work done when speed increases, being significantly greater at preferred and self selected fast speeds (Silder et al., 2008, Whittington et al., 2008).

\subsection{Hip Flexor Contracture}

In early work, Judge et al. (1996) found that older adults walk with increased anterior pelvic tilt compared to young adults (figure 2.14). Increase pelvic tilt It is thought to be a marker of gait dysfunction in older adults (Kerrigan et al., 2001, Kerrigan et al., 1998). Although it is known that pelvic motion increases with gait 
speed (Schwartz et al., 2008, Røislien et al., 2009), Kerrigan et al. (1998) found older adults walk with significantly greater anterior pelvic tilt than young adults when walking at slower and faster speeds (Kerrigan et al., 1998, Kerrigan et al., 2003). Røislien et al. (2009) also found anterior pelvic tilt increases with aging and gait speed (Røislien et al., 2009).

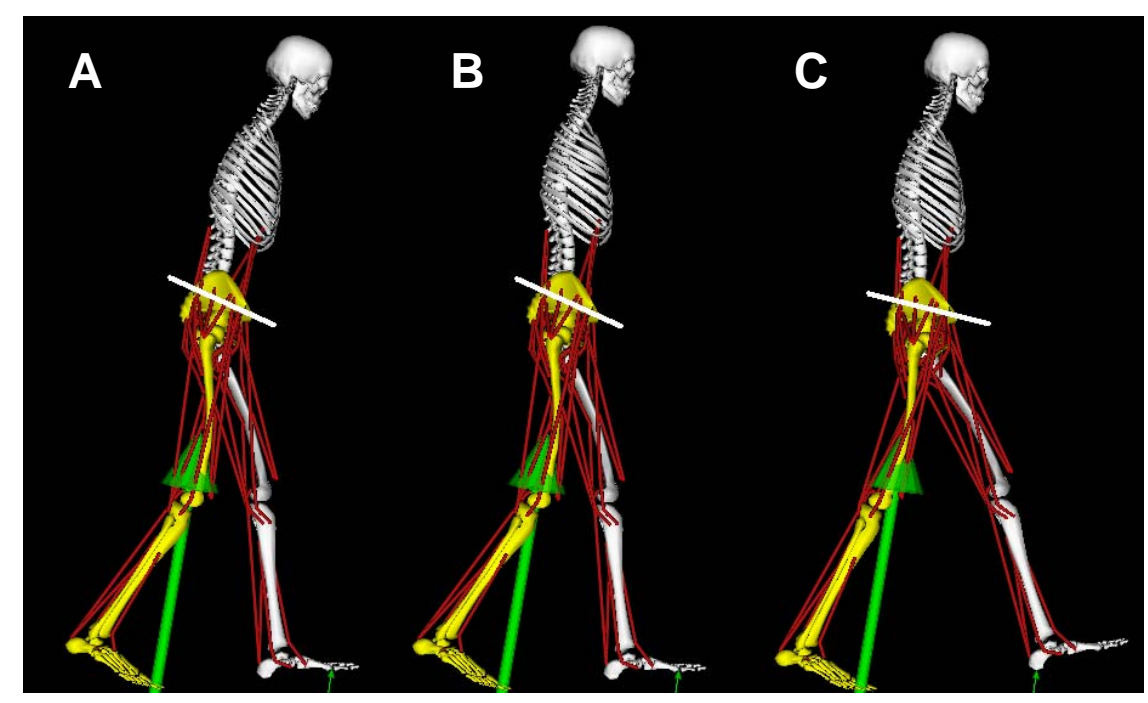

Figure 2.14 (A) A representation of hip flexor contracture and increased anterior pelvic tilt coupled with reduced hip extension and increased anterior trunk inclination. (B) Similar pattern to that shown in "A" but without increased anterior trunk inclination. (C) Young subject during the same period of the GC. Pelvic tilt shown by a line (white) drawn from the ASIS to PSIS (figure was produced using OpenSim 1.9.1).

Debility in the abdominal muscles and postural adaptation have been proposed as possible mechanisms behind increased anterior pelvic tilt in older adults (Judge et al., 1996a, Winter et al., 1990, Røislien et al., 2009). Another mechanism may be contracture in the hip flexors, particularly in the iliopsoas muscle. This restricts hip extension and increases anterior pelvic tilt (Kerrigan et al., 1998). It has been shown that in order to maintain contralateral step length in the presence of hip flexors contracture, older adults increase peak hip flexion (Kerrigan et al., 1998). Interestingly, this strategy has been observed in hip OA patients (Lee and Kerrigan, 1999, Watelain et al., 2001). Moreover, a restriction in hip extension and increased anterior pelvic tilt have been linked to fall in older adults (Kerrigan et al., 2001).

Lee et al. (2005) found hip flexor contracture is more evident during walking than standing in older adults. Hence, it is thought that it is not a postural adaptation (Lee et al., 2005). Even so, when a static stretching program was used over a 10 week 
training period by a group of older adults, hip extension increased and anterior pelvic tilt reduced (Kerrigan et al., 2003). Moreover, this was coupled with an increase in A2 peak power generation.

It has been shown that anterior tilt of the pelvis produces flexion of the lumbar spine during gait (Crosbie and Vachalathiti, 1997, Crosbie et al., 1997). Anterior pelvic tilt coupled with lumbar flexion has been shown to increase energy expenditure in disabled elders (McGibbon et al., 2001a, McGibbon et al., 2001b). It is thought these actions may lead to reduced stability and increased falls risk in older adults (McGibbon et al., 2001a).

\subsubsection{Knee Joint Function}

\subsubsection{Early Stance}

It is known that knee motion is altered with aging. DeVita and Hortobágyi (2000) found increased knee flexion at initial contact in older adults compared to young adults. This action most likely prepares the joint for load reception. Older adults have also been shown to exhibit less peak knee flexion in early stance (around $15 \%$ GC) compared to young adults (DeVita and Hortobágyi, 2000, Begg and Sparrow, 2006). On the other hand, Monaco et al. (2009) found older adults exhibited more peak knee flexion in early stance than young adults whilst walking on a treadmill. Similarly, McGibbon and Krebs (2004) found older adults exhibited more peak knee flexion than young adults in early stance. The latter outcome is unexpected, since it was reported that the young adults walked significantly faster than the older adults. Moreover, it is known that knee flexion in early stance increases with speed (Lelas et al., 2003, Winter, 1991, Røislien et al., 2009, Schwartz et al., 2008, Kirtley et al., 1985). It is possible, however, that the fixed cadence (120 bpm) used by McGibbon and Krebs (2004) altered the natural gait pattern of the participants in the study.

Knee joint kinetics are known to be altered by aging. Kerrigan et al. (1998) found a group of older adults produced $60 \%$ less $\mathrm{K} 1$ power absorption when walking $0.18 \mathrm{~m} \cdot \mathrm{s}^{-1}$ slower $(p<0.05)$ than a group of young adults. Interestingly, only $28 \%$ 
more $\mathrm{K} 1$ power absorption was found when the older adults walked $0.18 \mathrm{~m} \cdot \mathrm{s}^{-1}$ faster than the young adults (Kerrigan et al., 1998). When walking at the same speed (1.48 $\mathrm{m} \cdot \mathrm{s}^{-1}$ ), DeVita and Hortobágyi (2000) found the older adults produced less K1 peak power absorption and mechanical work than the young adults. Similarly, when walking at the same cadence $(120 \mathrm{bpm})$, older adults compared to young adults, produced less K1 power absorption and mechanical work (McGibbon and Krebs, 1999).

$\mathrm{K} 1$ power absorption is produced by eccentric contraction of monoarticular knee extensors (Nene et al., 2004). During early stance, Schmitz et al. (2009) found older adults exhibit less activity in the vastus lateralis muscle compared to young adults (Schmitz et al., 2009). This reduction in activity diminishes eccentric knee extensor power leading to less K1 peak power absorption (Røislien et al., 2009, Lelas et al., 2003). This may increase hip and knee joint loading and predispose an older adult to pathology such as OA (McGibbon and Krebs, 2002, Watelain et al., 2001).

Loading response is followed by rapid knee extension that is produced by concentric contraction of the monoarticular knee extensors (K2 peak power generation). It has been shown that older adults exhibit more K2 peak power generation than young adults $(p<0.05)$ when walking at the same speed (DeVita and Hortobágyi, 2000, Monaco et al., 2009). K2 power of older adults has also been found to increase significantly with speed (Judge et al., 1996a, Kerrigan et al., 1998). Monaco et al. (2009) argues that increased K2 power generation in older adults results from increased and prolonged knee flexion during stance. It is also thought that increased $\mathrm{K} 2$ power in older adults assists forward progression of the body (Monaco et al., 2009); yet Sadeghi et al (2001) argue its main function is to prepare the leg for push-off.

\subsubsection{Midstance to Final Swing}

Immediately prior to the heel-off event in gait, older adults have been shown to exhibit greater knee extension than young adults (Ostrosky et al., 1994, Judge et al., 1996a). It is reasonable to propose that greater knee extension affects K3 peak power 
and mechanical work generation. Disappointingly, however, little is known about K3 power generation in human gait. The study by McGibbon et al. (2004) appears to be the only work to report age-related changes in $\mathrm{K} 3$ power generation. K3 peak power generation was found to be lower in a group of older adults than a group of young adults. The older adults, however, walked at a slower speed. Interestingly, diminished $\mathrm{K} 3$ peak power generation has been found in older adults with disabilities such as knee and hip OA (McGibbon and Krebs, 2002, McGibbon and Krebs, 2004, Watelain et al., 2001). It may be that a reduction in gastrocnemius activity near heel-off in older adults reduces K3 power generation (Schmitz et al., 2009) and leads to less knee flexion in late stance. In order to compensate for this loss of $\mathrm{K} 3$ power, older adults probably increase $\mathrm{H} 3$ power generation to help pull the leg into swing.

$\mathrm{K} 4$ peak power absorption and mechanical work around toe-off is greater in older adults, even when walking slower than young adults (Kerrigan et al., 1998, McGibbon and Krebs, 2004, Winter et al., 1990). This adaptation may increase H3 power by transferring mechanical energy from the knee to the hip through the rectus femoris (Neptune et al., 2008, Silder et al., 2008). The study by Chung and Wang (2010) supports this idea since rectus femoris activity has been found to increase with age (20 to 60 years of age) over a range of walking speeds. Schmitz et al. (2009), however, found no significant differences in rectus femoris activity between young and older adults walking at a range of self selected speeds. The reported increase in rectus femoris activity with speed (Hof et al., 2002, Schwartz et al., 2008) may partly explain why $\mathrm{K} 4$ peak power is greater when older adults increase walking speed. Interestingly, no age-related changes in K4 were found when gait speed was controlled for a group of young and older adults (DeVita and Hortobágyi, 2000).

A reduction in the range of motion of the knee over the gait cycle has been reported in older adults (Judge et al., 1996a). However, it is relatively unknown as to whether older adults use more knee flexion than young adults during swing. Studies have found older adults, compared to young adults, either increase (Ostrosky et al., 1994) or decrease (Begg and Sparrow, 2006) knee flexion during swing. A possible reason for the different findings is most likely the failure to control walking speed in these studies. 
Older adults have been found to produce less K5 power absorption and mechanical work than young adults (Winter et al., 1990, Watelain et al., 2000). This is probably due to less activity by the hamstrings resulting in greater knee extension in final swing. This may help to increase or maintain stride length in older adults (Watelain et al., 2000); however, it also increases foot speed at initial contact which heightens the risk of a slip-induced fall (Watelain et al., 2000, Espy et al., 2010). It is possible that the observed reduction in $\mathrm{K} 5$ with aging may simply be the result of a slower gait speed in older adults (Lelas et al., 2003, Watelain et al., 2000).

\subsubsection{Ankle Joint Function}

Ankle dorsiflexion during stance has been shown to increase with walking speed and aging (Røislien et al., 2009, Lelas et al., 2003, Caravaggi et al., 2010, McGibbon and Krebs, 2004, Silder et al., 2008). Increased dorsiflexion in older adults has been associated with longer stance and foot flat time. This strategy is probably used to increase stability during stance (Maki, 1997).

No age-related differences in ankle peak power absorption (A1) and mechanical work have been found during ankle dorsiflexion in stance (McGibbon and Krebs, 2004, Silder et al., 2008). Interestingly, soleus activity from midstance to heeloff is reduced in older adults compared to young adults (Schmitz et al., 2009). This may reduce the elastic energy stored in the ankle plantar flexors during stance, which will lessen the contribution of elastic energy to A2 peak power generation (Ishikawa et al., 2005, Neptune et al., 2008, Stewart et al., 2007).

A reduction in peak ankle plantar flexion with aging (figure 2.15) is commonly reported in the literature (Prince et al., 1997, Judge et al., 1996a, DeVita and Hortobágyi, 2000, Begg and Sparrow, 2006, Kerrigan et al., 1998, Ostrosky et al., 1994, Silder et al., 2008, Ko et al., 2009). It is associated with reduced plantar flexor moments and impulse (DeVita and Hortobágyi, 2000). More importantly, it has been directly linked to a significant loss in A2 peak power generation which is a strong predictor of step length and gait speed in older adults (DeVita and Hortobágyi, 2000, Judge et al., 1996a, Kerrigan et al., 1998, McGibbon and Krebs, 2004). 


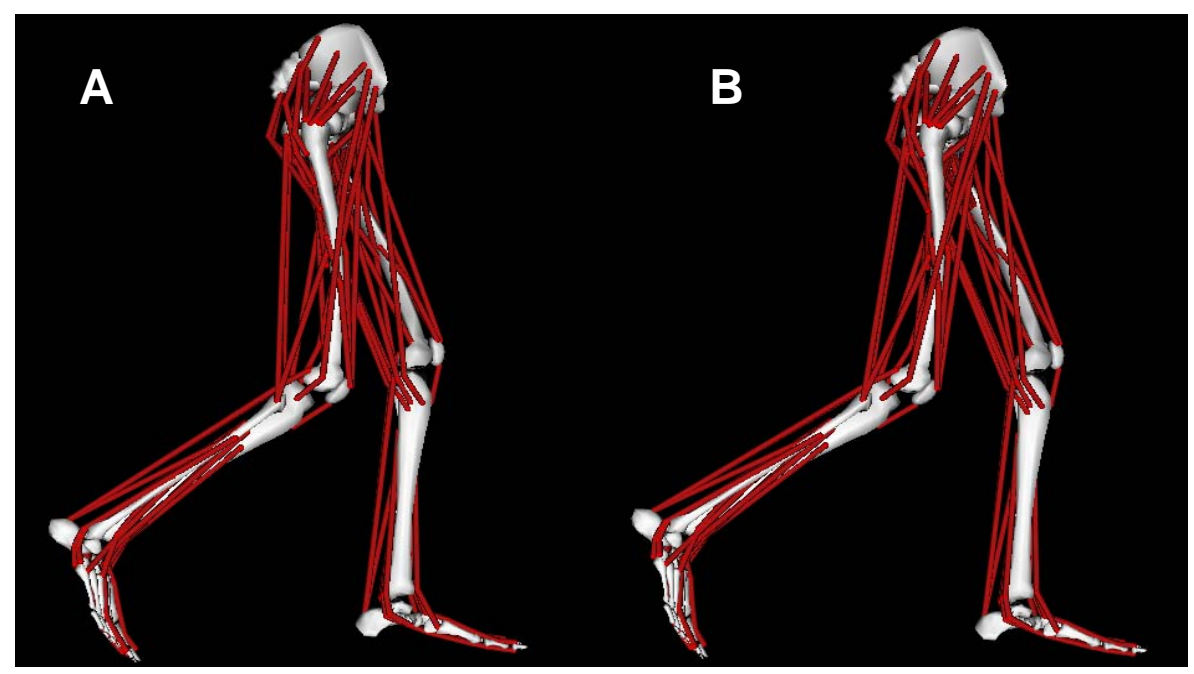

Figure 2.15 (A) Example of push-off for an older adult with reduced ankle plantar flexion and A2 joint power generation. (B) Example of ankle plantar flexion and A2 power generation for a young adult (figure was produced using OpenSim 1.9.1).

It is well known that $\mathrm{A} 2$ peak power generation and mechanical work reduce with aging (figure 2.15) (McGibbon, 2003). Significant reductions have been found when older adults walk: $(1)$ slower $(p<0.05)$ and with shorter steps and strides than young adults (Kerrigan et al., 1998, Judge et al., 1996a, Watelain et al., 2000, Winter et al., 1990); (2) faster than young adults (Kerrigan et al., 1998); (3) at the same speed as young adults but with shorter steps (DeVita and Hortobágyi, 2000); (4) at a range of similar self-selected speeds as young adults (Silder et al., 2008); and, (5) at the same speeds as young adults on a treadmill (Monaco et al., 2009).

The reduction in A2 peak power generation and mechanical work found with aging is probably due to less soleus activity during late stance (Schmitz et al., 2009) and greater co-activation of the ankle plantar and dorsiflexors (Hortobágyi et al., 2009). Although it is known that older adults with increased co-activation can reach the same speed (i.e. $1.8 \mathrm{~m} \cdot \mathrm{s}^{-1}$ ) as young adults (Hortobágyi et al., 2009), it is not known how increased co-activation affects A2 peak power generation. With these observations in mind, it is reasonable to suggest that neuromuscular adaptations are made at the hip and knee to compensate for a loss of ankle function with aging. 


\subsubsection{Mechanisms Underlying Age-related Gait Changes}

The term "neuromuscular adaptation" is often used in the literature when referring to aging gait. It describes the impact of aging upon the neural system that drives the activation patterns of the muscles (McGibbon and Krebs, 2004, DeVita and Hortobágyi, 2000). It is unknown, however, as to what extent aging affects the major components of the neuromuscular system (e.g. muscle, motor neurons) or how these components contribute to known age-related gait adaptations (Zatsiorsky, 2000).

Neuromuscular gait adaptations are brought about by the interplay of the nervous (peripheral and central) and musculoskeletal systems (mechanical and physiological). These adaptations involve a spatiotemporal reorganization of muscular activity patterns (Kwon et al., 2010) in order to achieve functionality. Deterioration in these systems, particularly with aging, leads to motor output changes during walking. Nevertheless, the relationship between neuromuscular gait adaptations and gait functionality is not fully understood (McGibbon, 2003). A representation of the possible neural and muscular factors affecting gait is shown in figure 2.16.

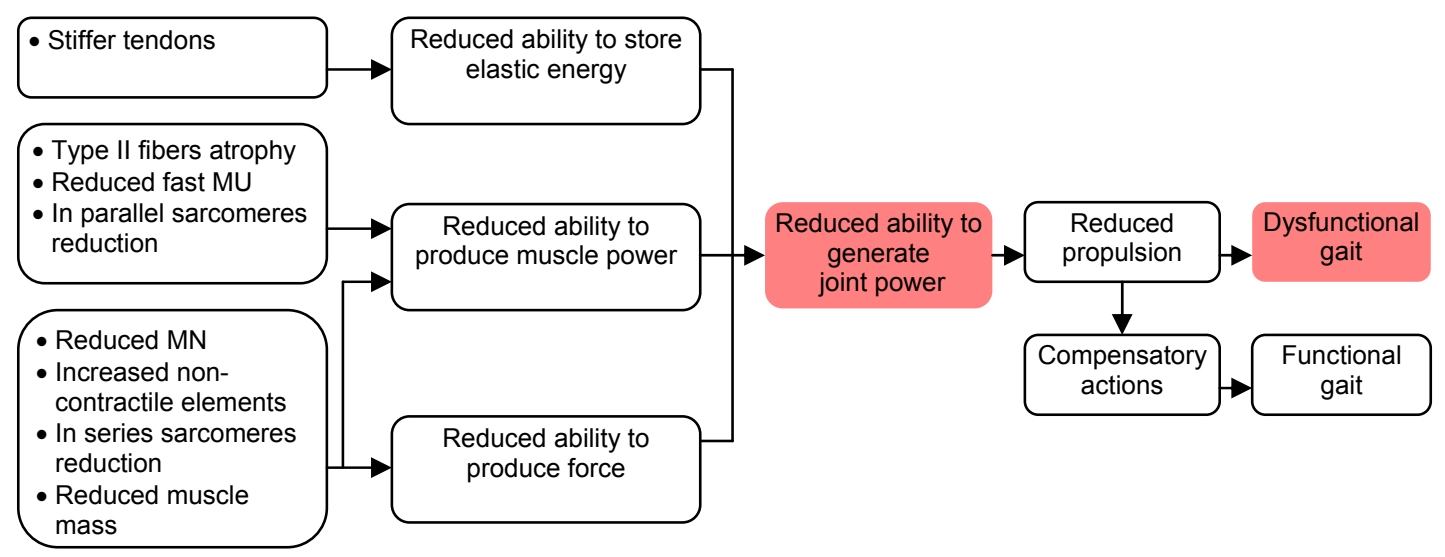

Figure 2.16 Flow chart illustrating the neuromuscular factors that may affect gait functionality. MN: motor neurons; MU: motor units. 


\subsubsection{Neural Factors}

It is well known that the nervous system deteriorates with aging which may partly explain some of the changes observed in elderly gait. Changes in the nervous system include a decrease in the number of motor units (Chan et al., 2001), a reduction in the axonal conduction velocity (Xi et al., 1999), loss of the largest and fastest motor units (Wang et al., 1999), a loss and size reduction of myelinated nerve fibers (Verdu et al., 2000), and an increase in the ratio of nerve- to-muscle fiber or innervations ratio (Kadhiresan et al., 1996). A reduction in the number of motor neurons $(\mathrm{MN})$ in the lumbar and sacral (L1-S3) segments has also been reported in older adults (Tomlinson and Irving, 1977). These alterations of the nervous system, coupled with a reduction in sensorimotor inputs (Callisaya et al., 2010a) reduce the ability to adapt the motor output during gait. The loss of the fast motor units reduces the ability for rapid muscular action, leading to a reduction in joint power production.

\subsubsection{Muscular Factors}

Age-related changes in the mechanical and physiological properties of the muscles and tendons affect motor output during walking. Muscle mass and strength decrease with aging, commonly known as sarcopenia (Rosenberg, 1989). Generally, sarcopenia affects the postural muscles (Ryan et al., 2002) but it is known to have a greater effect upon the leg musculature (Janssen et al., 2000), particularly the musculature essential for walking (Narici and Maffulli, 2010).

Typically, the measurement of the cross-sectional area (CSA) of the muscle has been used to investigate muscle mass reduction (sarcopenia) and atrophy in older adults (Doherty, 2003). A reduction in CSA with aging is associated with increased deposition of intramuscular fat (myostatosis) and an increase in connective noncontractile tissues (Narici and Maffulli, 2010, Kent-Braun et al., 2000).

Muscle fiber size, particularly the type II or fast-twitch fibers, have been reported to reduce or atrophy with aging (Coggan et al., 1992). Apoptosis of myocytes has also been reported to increase sarcopenia or muscular mass loss (Dirks and Leeuwenburgh, 2005, Siu, 2009). There is also a reduction in the number of motor 
units (MU) with aging (Lexell et al., 1983). All of these factors reduce the ability of an older adult to generate muscular force and power and therefore to perform functional tasks (Doherty, 2003, Janssen et al., 2002).

Muscle architecture is also affected by aging with decreases in the pennation angle and fascicle length (Narici et al., 2003). There is also a loss of force due to reductions in the number of sarcomeres in parallel and slower shortening velocity due to reductions in the number of sarcomeres in series (Thom et al., 2007). All of these factors reduce the capacity of the muscle to generate force and power during walking.

Tendons become mechanically stiffer (Tuite et al., 1997) and thicker (Magnusson et al., 2003) with aging. Increased intermolecular cross-linking causes collagen stiffness, resulting in greater tendon stiffness (Kjaer, 2004). In order to compensate for increased tendon stiffness, there is an increase in muscle energy absorption. However, this can affect stability and locomotion in older adults (Gajdosik et al., 2005). Since the integrity of the muscle-tendon unit is important for the recovery of elastic energy and joint power generation during walking (Ishikawa et al., 2005), any structural or mechanical alteration of the unit will affect the gait pattern (figure 2.17).

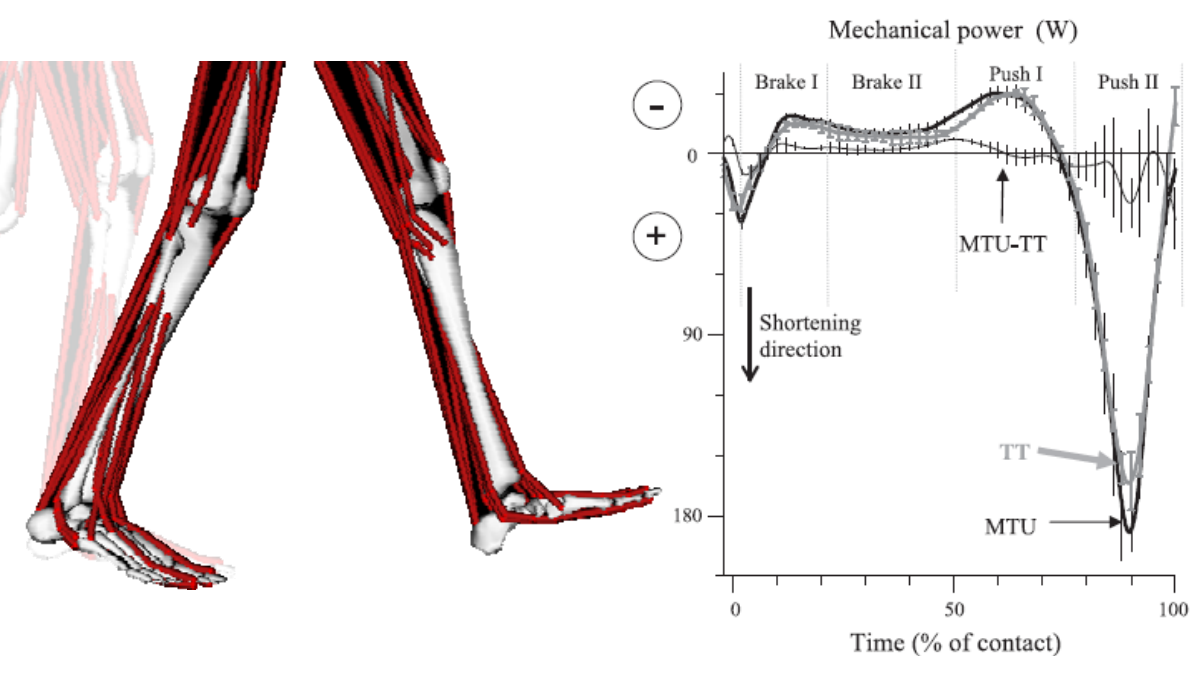

Figure 2.17 Left panel shows phase of stance where elastic energy is absorbed and recovered. Right panel shows a plot of the elastic energy absorbed ("Push I") and recovered ("Push II") by the muscletendon unit (MTU) and tendinuous tissues (TT) (Adapted from Ishikawa 2005, p.607). 


\subsubsection{Neuromuscular Co-activation}

The function (i.e. support and propulsion) of the lower limb musculature has been shown to vary with speed (Monaco et al., 2008, Neptune et al., 2008, Liu et al., 2008). It has also been shown that the activity level of the muscles is different between young and older adults as speed increases (Schmitz et al., 2009). Despite these differences, the activation patterns remain relatively stable with aging; that is, the timing and sequencing of the muscle EMG (electromyography) bursts remain unchanged. However, muscle activation time is prolonged with aging which results in greater co-activation between the agonist and antagonist (figure 2.18) muscles during walking (Hortobágyi et al., 2009). Although prolonged co-activation is thought to increase the energy cost (Mian et al., 2006, Peterson and Martin, 2010, Hortobágyi et al., 2009) and stability of walking (Hortobágyi et al., 2009, Shumway-Cook and Woollacott, 2001, Schmitz et al., 2009), Malatesta et al. (2003) did not find a relationship between stability and the higher energy cost of walking in older adults. Even though there is no current agreement about the role of co-activation with aging, it is argued that it probably accounts for the altered gait patterns discussed (Peterson and Martin, 2010, Donelan et al., 2004, Malatesta et al., 2003). Moreover, it is still not clear whether central mechanisms in the spinal or cortical circuitry are responsible for increased co-activation. Currently the neural mechanisms behind co-activation and its effect on aging gait remain unknown (Hortobágyi and DeVita, 2006).

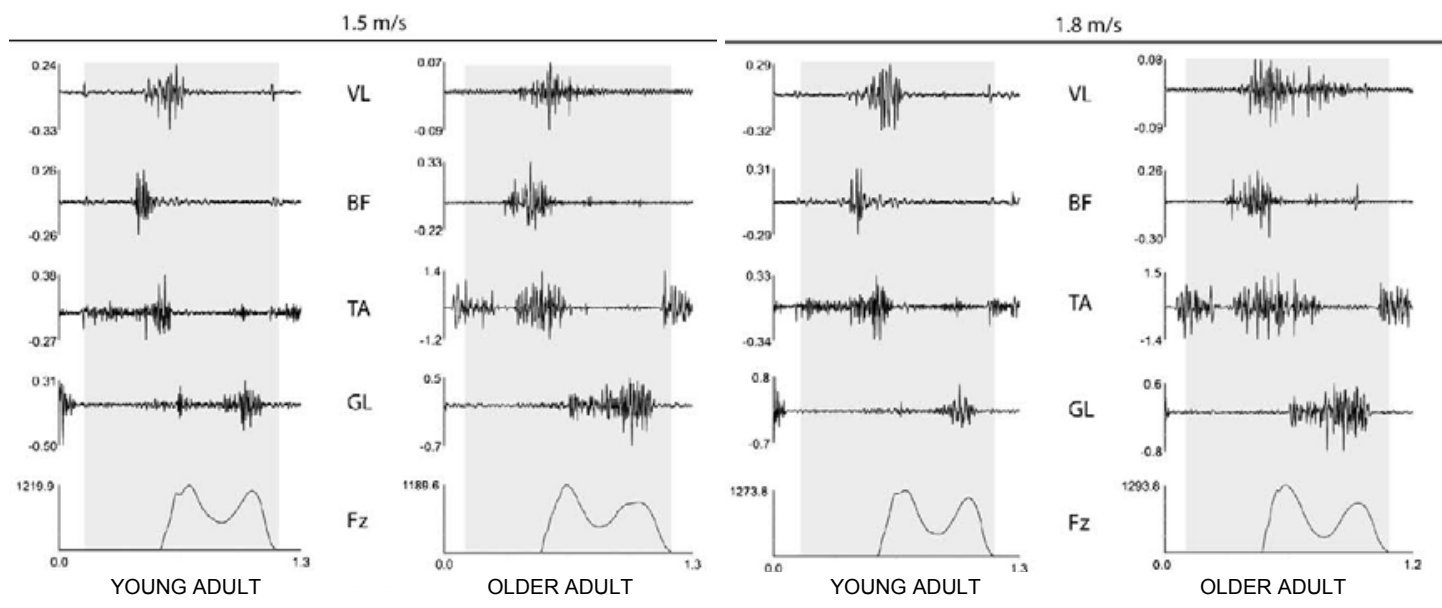

Figure 2.18 Muscle co-activation EMG patterns. The two panels on the left show (from top to bottom) muscle activity for vastus lateralis (VL), biceps femoris (BF), TA (tibialis anterior), gastrocnemius lateralis (GL) and vertical ground reaction force (Fz) in a young (left column) and older adult (right column) walking at $1.5 \mathrm{~m} \cdot \mathrm{s}^{-1}$. The two panels on the right show the EMG plots for the same muscles when walking at $1.8 \mathrm{~m} \cdot \mathrm{s}^{-1}$ (adapted from Hortobágyi et al., 2009, p.559). 


\subsubsection{Compensatory Actions}

Figure 2.19 shows the main neuromuscular and compensatory actions made by older adults when walking. Ankle power generation and mechanical work decrease with aging (DeVita and Hortobágyi, 2000, Judge et al., 1996a, McGibbon, 2003). The loss of ankle function has been shown for a wide range of walking speeds and cadences (DeVita and Hortobágyi, 2000, McGibbon and Krebs, 2004, Monaco et al., 2009). However, it remains unclear as to what compensatory actions are made at the hip and knee when ankle function is compromised by aging. De Vita and Hortobágyi (2000) found older adults compensate for this loss by increasing H1 peak power generation and mechanical work. This has been supported by Silder et al (2008) in a study involving three different self-selected speeds.

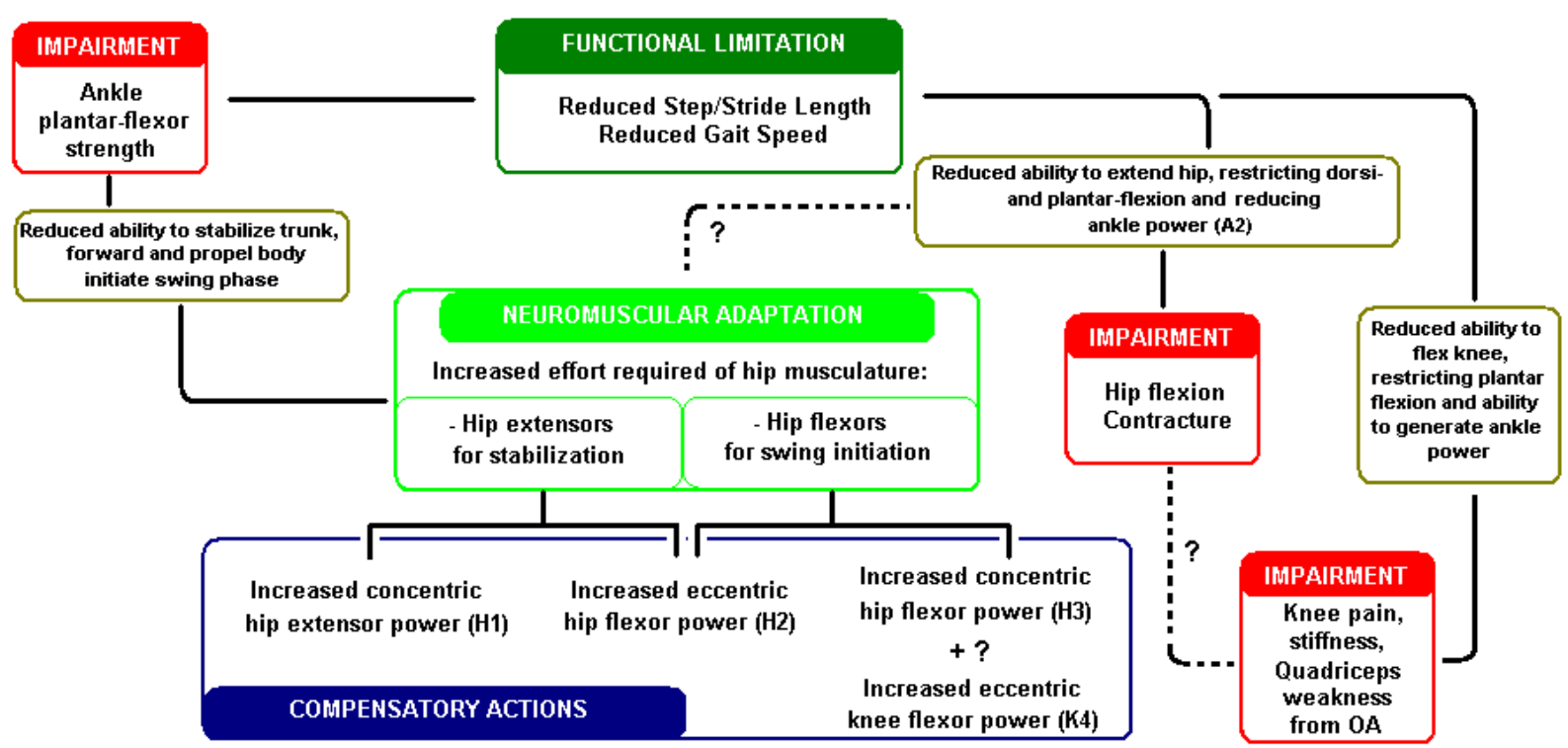

Figure 2.19 Schematic representation of the neuromuscular adaptations in gait with aging. The diagram links the gait impairments to the functional limitation, and the neuromuscular adaptation, and its compensatory action. The dashed line with "?" indicate possible situations not completely supported by current literature (adapted from McGibbon 2003, p. 103).

There are two possible mechanisms that explain how H1 peak power generation contributes to forward propulsion of the body. Firstly, a "pushing from behind" mechanism that accelerates the body forward (Winter and Eng, 1995) and secondly a "pulling backward" mechanism that pulls the contralateral limb into swing through the backward rotation of the pelvis (McGibbon, 2003). H1 power generation also plays an important role in preventing the collapse of the body during single 
support. Hence, it is possible that increased $\mathrm{H} 1$ power found in older adults serves to increase stability more so than propulsion (Eng and Winter, 1995, McGibbon and Krebs, 2004).

The increased H3 peak power generation and mechanical work found in older adults may be a compensatory action for decreased ankle function (Judge et al., 1996a, Silder et al., 2008, Ko et al., 2009). These increases, although not significant, have also been reported by Watelain et al. (2000) for an older adult group that walked at similar speed to young adults (OLD: $1.34 \mathrm{~m} \cdot \mathrm{s}^{-1}$, YG: $1.35 \mathrm{~m} \cdot \mathrm{s}^{-1}$ ). These compensatory actions have also been observed in older adults walking on a treadmill (Monaco et al., 2009). Increased H3 peak power and mechanical work may be due to increased iliopsoas activity (Schmitz et al., 2009) but it is possible that increased rectus femoris activity may also contribute (Whittington et al., 2008). The increase in hip flexor activity in older adults may be due to decreased soleus activity (Schmitz et al., 2009) and increased co-activation between gastrocnemius and tibialis anterior (Hortobágyi et al., 2009). It seems reasonable to conclude, therefore, that increased $\mathrm{H} 3$ peak power is the core compensatory action for decreased A2 peak power with aging (Lewis and Ferris, 2008).

Increased H3 power is partly brought about by the storage and return of more energy (during $\mathrm{H} 2$ peak power absorption) by the passive muscle elastic components of older adults (Kerrigan et al., 1998, Monaco et al., 2009, Silder et al., 2008, Watelain et al., 2000). K4 peak power absorption may also contribute to increased H3 peak power since it is also known to increase with aging (Kerrigan et al., 1998, McGibbon and Krebs, 2004, Winter et al., 1990). It is possible that this action helps maintain forward propulsion of the body by transferring mechanical energy from the knee joint (K4 peak power absorption) to the hip joint (H3 peak power generation).

Lewis and Ferris (2008) investigated how joint powers of young adults walking on a treadmill $\left(1.25 \mathrm{~m} \cdot \mathrm{s}^{-1}\right)$ were modified in response to voluntary alterations in ankle push-off. The study showed that voluntary decreases in A2 peak power generation were associated with increased $\mathrm{H} 3$ peak power generation whereas voluntary increases in A2 were associated with decreased H3. Interestingly, when 
ankle push-off was voluntarily reduced or increased, H1 peak power generation remained unchanged. An inverse relationship between A2 and K4 power was also found (Lewis and Ferris, 2008). The study supports the work by Judge et al. (1996) that found A2 peak joint power to be a strong predictor of step length. Therefore, if the loss of A2 power is not compensated for by actions at the knee and hip (mainly H3 peak power), older adults will walk slower and take shorter steps.

\subsubsection{Summary}

It is thought that $\mathrm{H} 1$ and $\mathrm{H} 3$ peak joint powers and associated mechanical work are the major compensatory actions used by older adults to overcome a loss in ankle function. It is also thought that $\mathrm{H} 1$ peak power increases forward propulsion of the body through increased concentric hip extensors activity (gluteus maximus and hamstrings) whereas $\mathrm{H} 3$ peak power increases forward propulsion through increased concentric hip flexors activity (iliopsoas and rectus femoris). It is also thought that increased $\mathrm{K} 4$ and $\mathrm{H} 2$ peak power absorption through increased eccentric hip flexors activity (iliopsoas and rectus femoris) also contributes to forward propulsion of the body. It is likely that this is achieved by older adults through greater energy storage and return (iliopsoas muscle-tendon unit) and through the transfer of energy from the knee to the hip (rectus femoris) (figure 2.20).

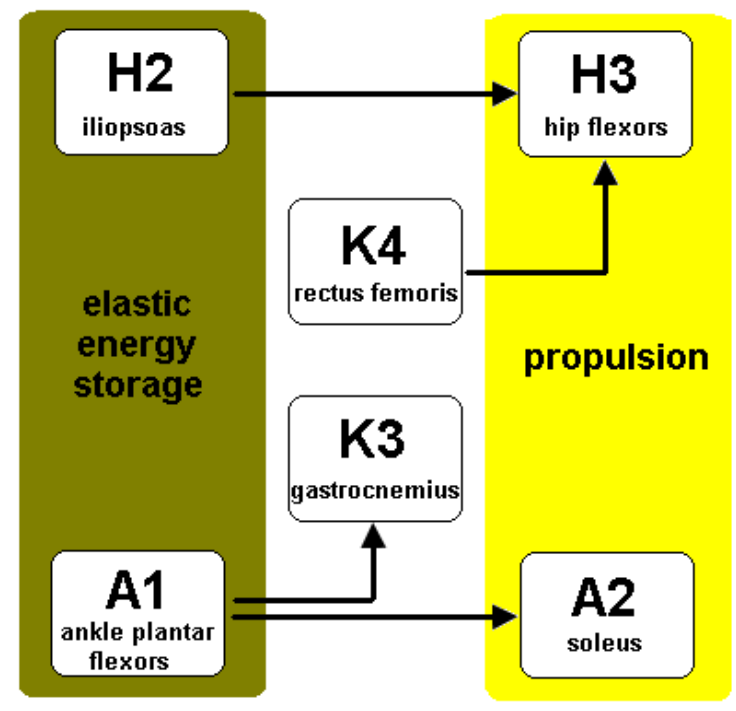

Figure 2.20 Proposed relationship between power absorption and generation in order to produce propulsion when ankle function is compromised by aging. 
Although gait studies have reported a loss in ankle power generation and mechanical work with aging (DeVita and Hortobágyi, 2000, Judge et al., 1996a, McGibbon, 2003), there is no general consensus as to what core compensatory actions are made at the knee and hip when ankle function is compromised in older adults. It is well known that gait speed has a significant effect upon joint powers and mechanical work (Schwartz et al., 2008, Lelas et al., 2003). Hence, it is reasonable to conclude that this lack of consensus is partly due to the failure to control walking speed. When comparing older and young adult gait patterns, it is crucial that gait speed is controlled in order to match and reduce speed variability. This is an important issue to prevent the confounding influence of speed on joint kinetics.

In summary, the aim of this project was to understand the neuromuscular mechanisms underlying age-related gait dysfunction. In order to better identify compensatory actions in older adult gait, this study used fixed matched gait speeds in order to reduce speed variability and minimize the confounding effect of speed upon joint kinetic variables. 


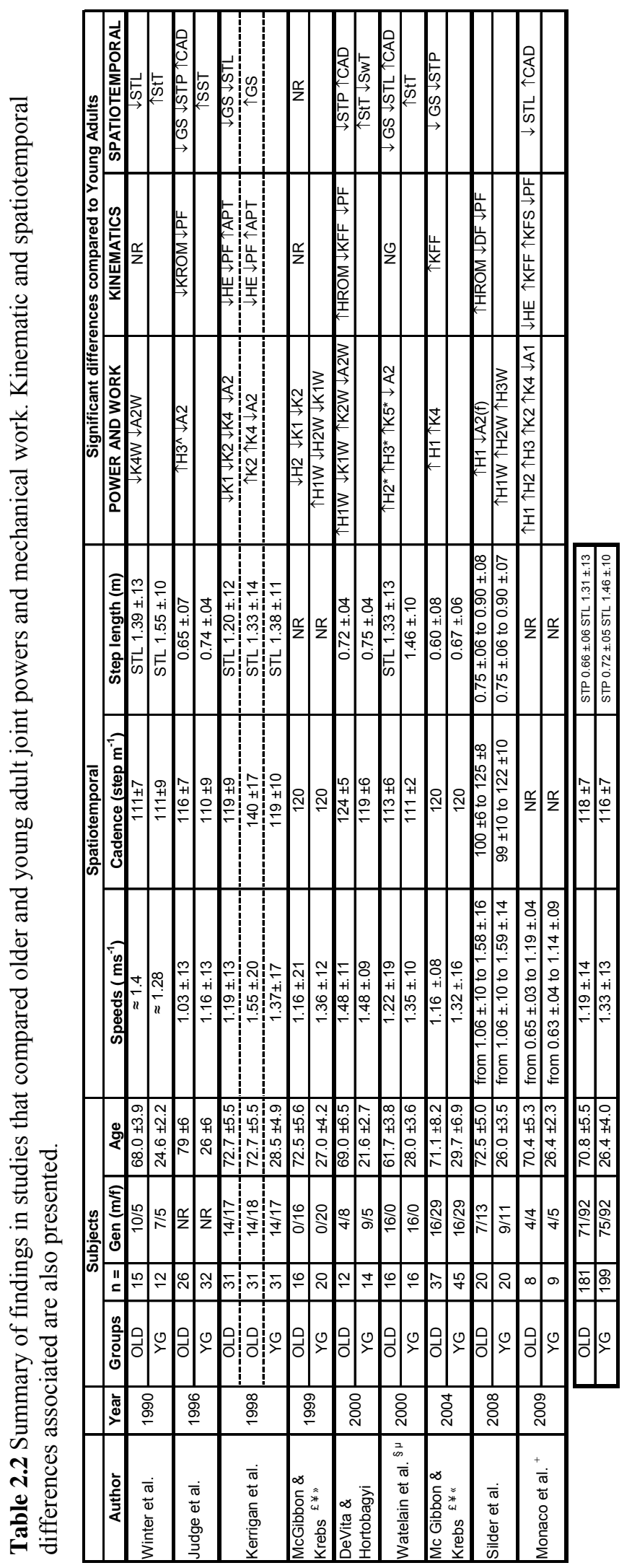

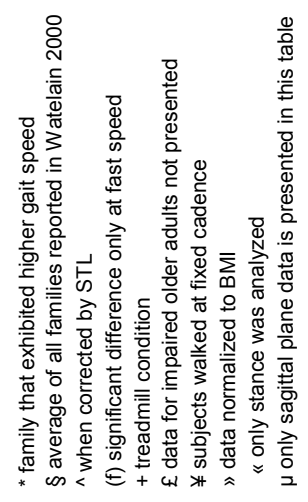

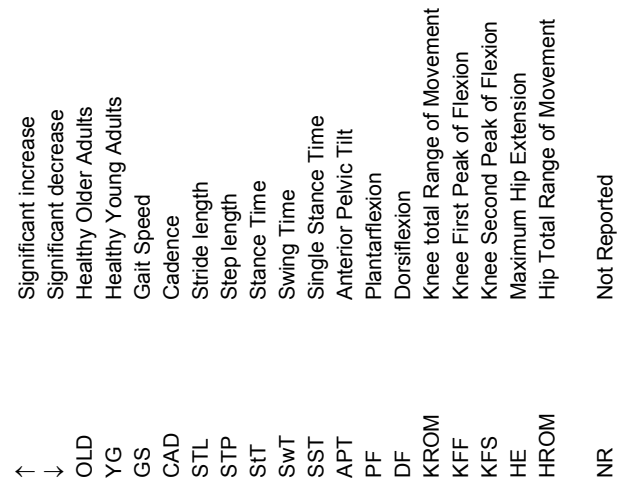




\section{Chapter 3: Methods}

\subsection{Participants}

Twelve healthy older adults and twelve healthy young adults participated in this investigation. A statistical power calculation using hip (H1) and ankle joint power (A2) data from previous relevant work (DeVita and Hortobágyi, 2000) showed that a minimum group size of eight participants to be sufficient to achieve $80 \%$ power (Vincent, 1995).

The older adults were aged between 60 and 80 years (4 female, 8 male), whereas the young adults were aged between 20 and 30 years ( 5 female, 7 male). Participant demographics are listed in table 3.1. Ethics approval was obtained from The Human Research Committee at The University of Melbourne. Written informed consent was obtained from the participants.

Table 3.1 Participant demographics.

\begin{tabular}{lccc|ccc} 
& \multicolumn{2}{c|}{ OLDER ADULTS } & \multicolumn{3}{c}{ YOUNG ADULTS } \\
& \multicolumn{2}{c|}{$\mathbf{n}=\mathbf{1 2}$} & \multicolumn{3}{c}{$\mathbf{n}=\mathbf{1 2}$} \\
\hline Height (m) & 1.67 & \pm & 0.06 & 1.71 & \pm & 0.06 \\
Mass (kg) & 74.0 & \pm & 12.9 & 71.0 & \pm & 10.3 \\
Leg length (cm) & 88.3 & \pm & 3.4 & 89.8 & \pm & 3.1 \\
\hline Age (yrs) & 66.8 & \pm & 4.5 & 26.6 & \pm & 2.9 \\
\hline
\end{tabular}

\subsubsection{Recruitment Process}

The participants were recruited from the university and local community. The project was advertised through local media and advertisements placed around the university. 


\subsubsection{Screening}

Exclusion criteria were any neurological, musculo-skeletal or other medical condition to affect gait. These included low back pain, lower limb joint replacement, recent lower limb joint sprain or contusion, stroke and a self-reported history of falling within the last 12 months. This information was obtained through an interview (Appendix 2). The Short Physical Performance Battery (SPPB) was also used to screen the older adults (Guralnik JM et al., 1994) . This battery assesses gait speed over a 3 to $4 \mathrm{~m}$ walkway, balance (feet together, semi tandem position and tandem position) and sit-to-stand ability at maximum speed (5 times) (Please refer to Appendix 3 for a detailed description of the screening procedures). Older adults were excluded if they failed to achieve a maximum score of 12 on the Short Physical Performance Battery (table 3.2).

Table 3.2 Time thresholds to score maximum points in the SPPB.

\begin{tabular}{lc}
\multicolumn{1}{c}{ Task } & Time \\
\hline Side-by-side stand & $>10 \mathrm{sec}$ \\
Semi-tandem stand & $>10 \mathrm{sec}$ \\
Tandem stand & $>10 \mathrm{sec}$ \\
\hline Gait speed (4 m) & $<4.82 \mathrm{sec}$. \\
Chair stand test (5 repetitions) & $<11.19 \mathrm{sec}$.
\end{tabular}

\subsection{Experimental Setup}

The experimental set up is shown in figure 3.1. Bilateral kinematic and kinetic data were recorded by an 8-camera VICON MX System (Oxford, UK) sampling at $200 \mathrm{~Hz}$ and three OR6-7 AMTI force plates (Watertown, MA) sampling at $2000 \mathrm{~Hz}$. The plates were embedded in the centre of a $12 \mathrm{~m}$ level walkway and covered with carpet tiles ( $5 \mathrm{~mm}$ thickness) that were fixed to the force plates and surrounding floor. This precluded any deliberate targeting of the plates which is known to perturb the natural gait pattern (Wearing et al., 2000, Hirokawa, 1989). The high sample rates were used to minimize error in the data (e.g. joint power) extracted by the method of the inverse dynamics (McGibbon, 2006). 
Timing gates (NAM7R Takenaka Co., Ltd) positioned in the middle of the walkway (3 m apart) were used to monitor gait speed (figure 3.1). The gate sensors were positioned at shoulder height for each participant. Gait data were collected in the central $3 \mathrm{~m}$ portion of the walkway. A 4.0 to $4.5 \mathrm{~m}$ approach and $4.5 \mathrm{~m}$ departure distance ensured the participants achieved a steady-state walking speed over the $3 \mathrm{~m}$ capture area (Lindemann et al., 2008, Macfarlane and Looney, 2008). The approach distance was determined by a grid system that is described in the "Experimental Protocol" in section 3.3.

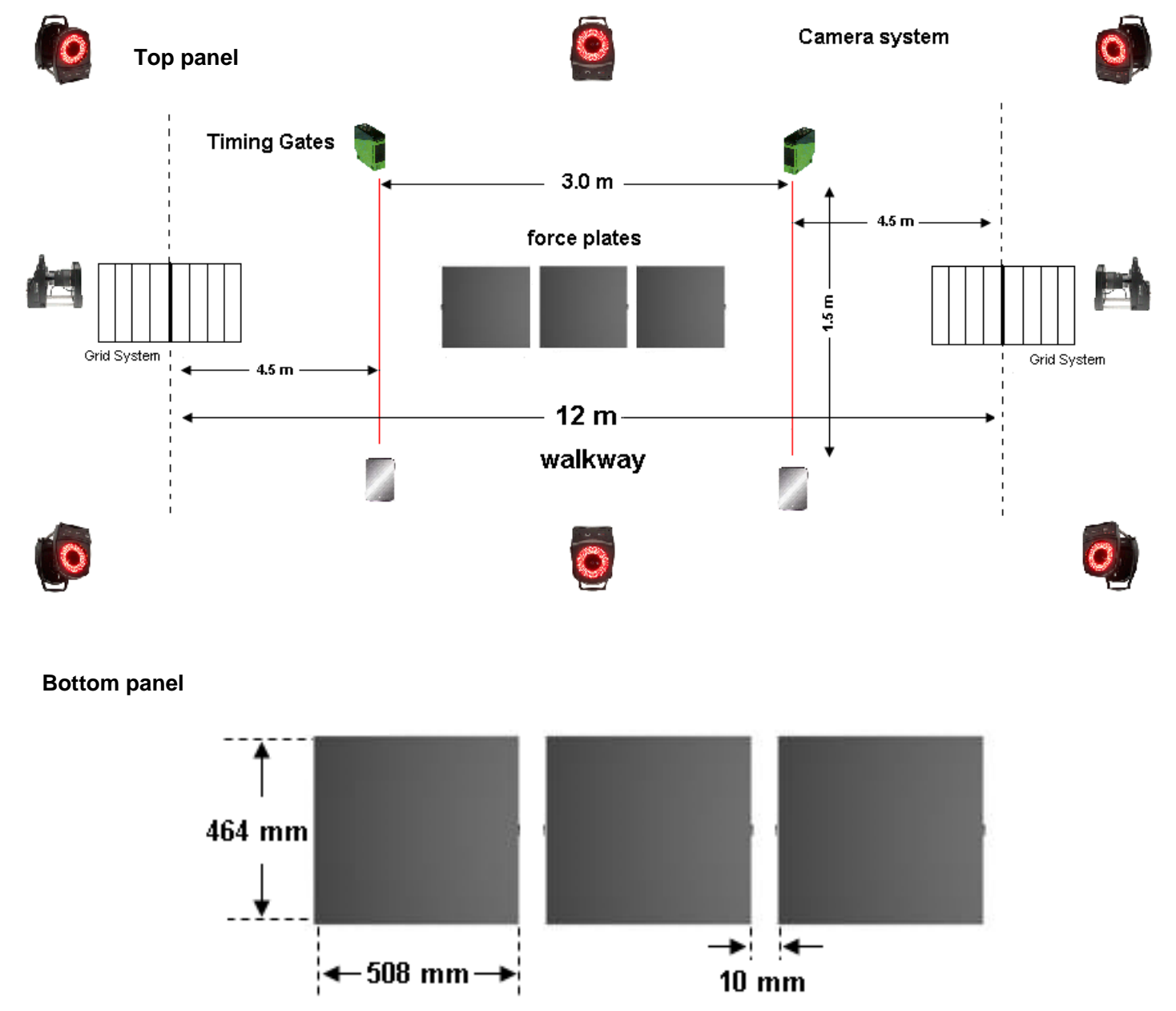

Figure 3.1 Experimental setup showing walkway dimensions (top panel), force plate dimensions and positioning (bottom panel). 


\subsection{Experimental Protocol}

\subsubsection{Physical Assessment}

Participants attended the Movement Laboratory at Rehabilitation Science Research Centre (RSRC) for about 2 to 3 hours. The SPPB was only used to assess the older adults. The participants were assessed for hip flexor contracture (figure 3.2) with the Thomas test (Peeler and Anderson, 2007) since it is thought to affect gait (Kerrigan et al., 1998). Participants wore shorts, t-shirt and walked barefoot. The barefoot condition removed the effect of shoes on the walking pattern. Shoes significantly affect gait measures such as speed, stride length and cadence (Lythgo et al., 2009).
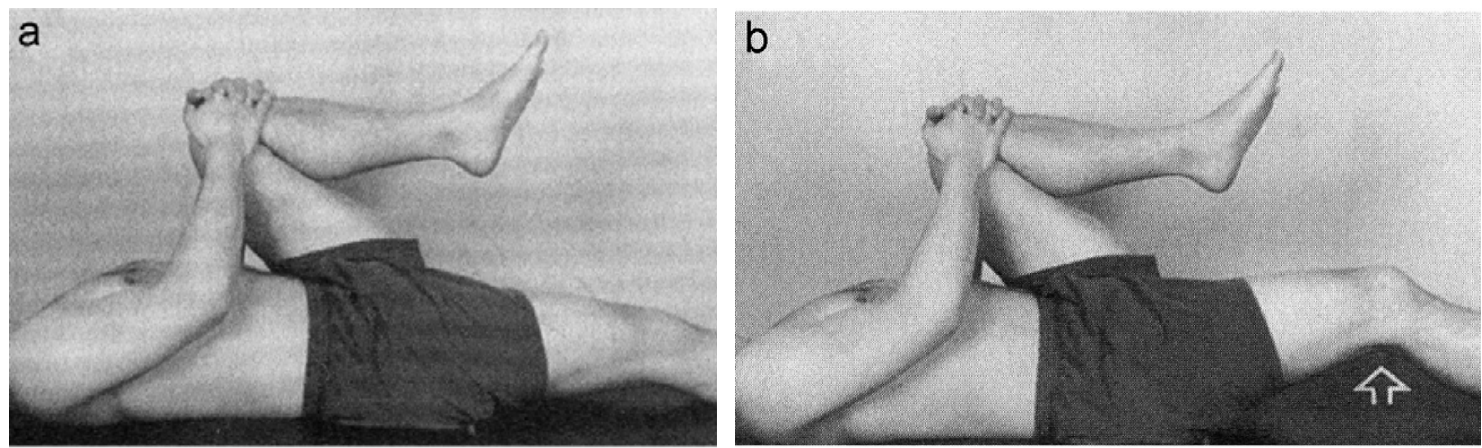

Figure 3.2 Thomas test for the assessment of hip flexors contracture. (a) No elevation of the right thigh when the left leg is maximally flexed at the hip; no hip flexors contracture (pass). (b) Right thigh raised when the left leg is maximally flexed at the hip; hip flexors contracture present (fail). (Adapted from Peeler, 2007, p.16).

\subsubsection{Gait Assessment}

The following anthropometric measures were recorded: height, mass and inter ASIS (anterior superior iliac spine) distance. Bilateral knee width, ankle width and leg length (from ASIS to medial malleolus) were also recorded. Fifteen passive spherical reflective markers (14 mm diameter) were placed on known anatomical landmarks on the lower extremities. Marker placement was in accordance with the Vicon Plug-inGait marker setup (figure 3.3). 


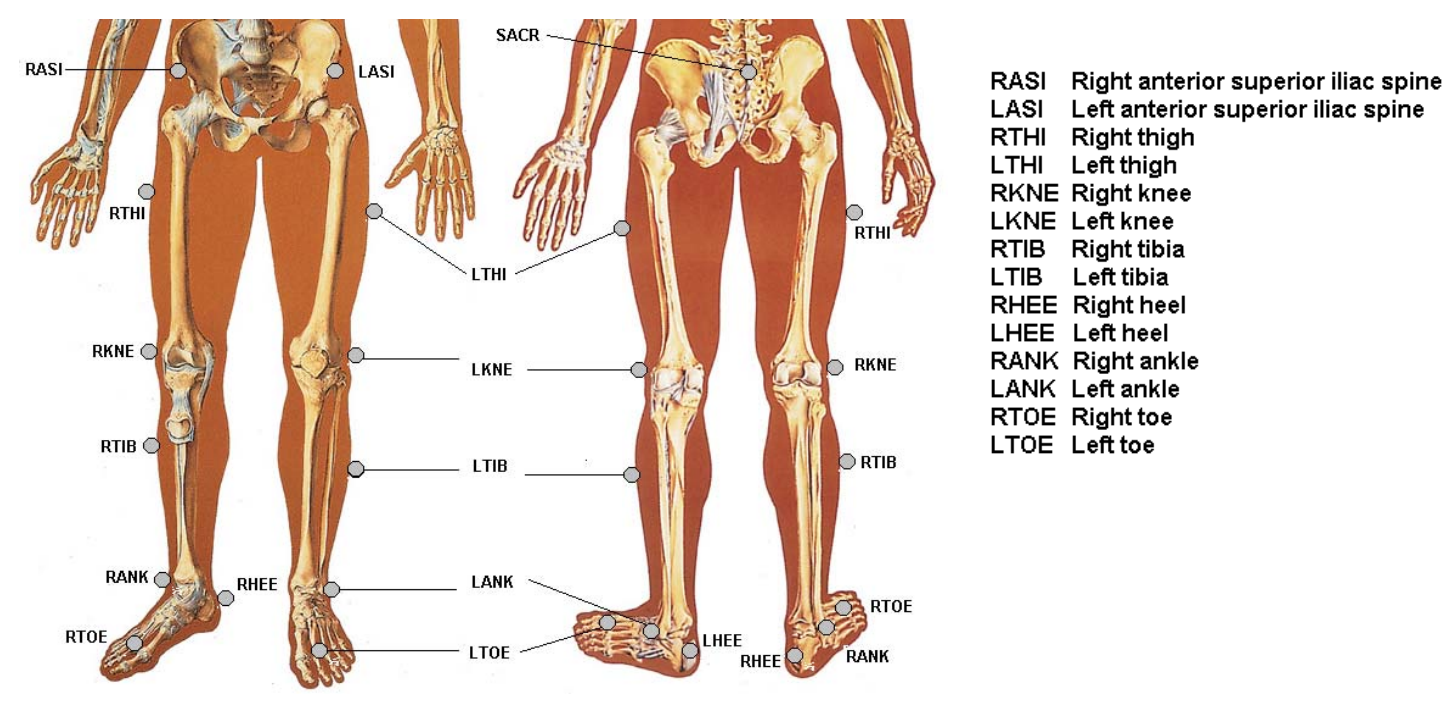

Figure 3.3 Marker placement.

A walking trial was considered successful when an entire foot landed on a force plate. Participants performed 5 successful trials (for each leg) at self-selected speed (SSN). The self-selected speed condition was adopted in order to obtain baseline gait data. These were followed by 5 successful trials (for each leg) at speeds of $1.0 \mathrm{~m} \cdot \mathrm{s}^{-1}, 1.3 \mathrm{~m} \cdot \mathrm{s}^{-1}$ and $1.6 \mathrm{~m} \cdot \mathrm{s}^{-1}$. Previous work has shown these speeds to be representative of slow, normal and fast walking in adults (Allard et al., 1996, Eng JJ and Winter DA, 1995, Kerrigan et al., 1998, Silder et al., 2008, Vardaxis et al., 1998). Visual inspection of the VICON output at the end of each trial was used to determine whether the trial was successful or not. To reduce the number of trials necessary to obtain 5 successful trials, a grid system was fixed to the floor at each end of the walkway. This system consisted of 11 lines spaced $10 \mathrm{~cm}$ apart. Participants began the trial from the line marked " 0 ". If the trial was unsuccessful the starting position was adjusted. For example, if the participant's footfall fell short of the first plate, they repeated the trial starting on the line marked " 1 " (please refer to figure 3.4). 


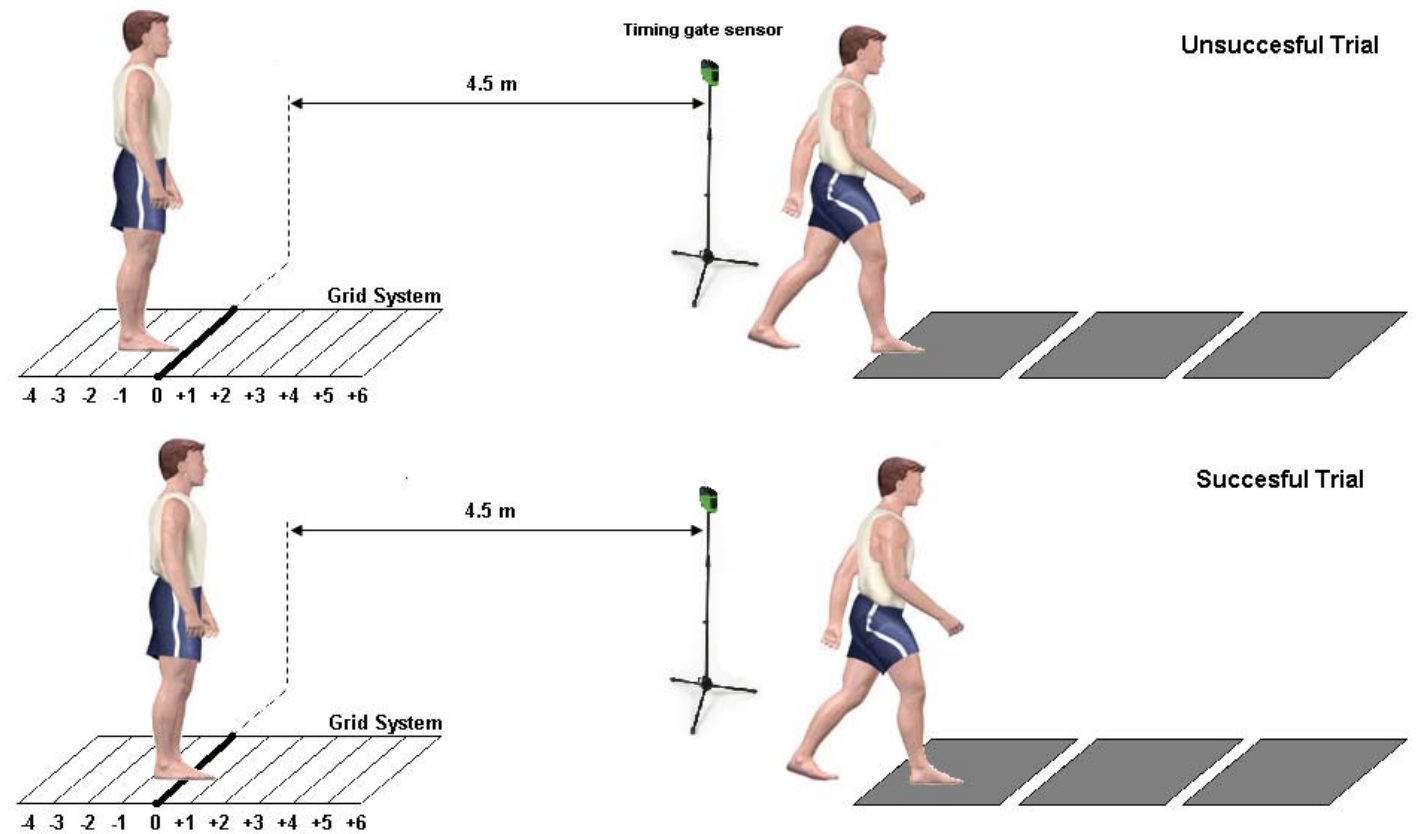

Figure 3.4 Grid system used to adjust start position. (A) Unsuccessful trial in which foot does not successfully land on the force plate. (B) Adjusted start point to obtain a successful foot landing.

Participants completed 4 blocks of walking trials at self-selected speed, 1.0 $\mathrm{m} \cdot \mathrm{s}^{-1}, 1.3 \mathrm{~m} \cdot \mathrm{s}^{-1}$ and $1.6 \mathrm{~m} \cdot \mathrm{s}^{-1}$. Prior to the first block of walking trials, participants were given the following instructions: "Walk at your normal or comfortable speed". After this block of trials, the participant's average gait speed was calculated. The participants were then told their average gait speed. This information was used to instruct participants to decrease or increase gait speed for the fixed speed conditions. The instructions given were "Walk slower" or "Walk faster". Verbal feedback about speed was given at the end of each trial. A trial was discarded and repeated if the speed fell 5\% above or below the required speed. Speeds were not set by a timer or metronome as this can constrain the natural gait pattern (Bertram and Ruina, 2001). On average, a typical session required between 60 to 80 trials which is equivalent to a walking distance of 720 to 960 metres. No participants required rest, reported fatigue or discomfort. 


\subsection{Data Processing}

Bilateral data were extracted by Nexus software (Vicon, Oxford, UK) using the Vicon Plug-in-Gait model (version 1.3.109, Oxford, UK) and a Woltring filter $(\mathrm{MSE}=20)$. Joint kinematic, joint kinetic (normalized to body mass) and vertical ground reaction force (VGRF) data were exported and processed by in-house software written in Igor Pro version 6.0.0.0 (Wavemetrics Inc., Oregon, USA). This software identified the stance and swing phases of the gait cycle from key events (i.e. initial heel contact, toe-off and second heel contact of the same limb). For the stance phase, the events of initial heel contact and toe-off were found. For the swing phase the second heel contact was found. Initial heel contact was identified when the vertical ground reaction force exceeded $10 \mathrm{~N}$ whereas toe-off was identified when the VGRF fell below $10 \mathrm{~N}$ (force plate threshold). Two methods were used to identify the second heel contact. Firstly, if the second footfall was successful (i.e. entire footfall on a force plate), heel contact was identified when the vertical ground reaction force exceeded 10 N. However, if the second footfall fell outside the force plate or partly on it, the minimum vertical displacement of the heel marker was used to identify second heel contact.

The following data were extracted from a gait cycle: peak joint powers, joint work and basic spatiotemporal measures of gait speed, cadence, step length, stride length, step width, and gait cycle phases expressed as a percentage of the gait cycle (\%GC). Peak angular displacement of the pelvis, hip and ankle were also extracted. These measures are commonly used to investigate the effect of aging upon lower limb joint power during gait (DeVita et al., 2007, Kerrigan et al., 1998, Silder et al., 2008, Judge et al., 1996a, Kerrigan et al., 2003, Winter et al., 1990) 


\subsection{Statistical Analysis}

Statistical analyses were conducted with SPSS (version 17.0). Normality was assessed by measures of skewness and kurtosis. Descriptive statistics were calculated for all gait parameters and participant demographics. Between-group MANOVAs were used to investigate the effect of age on the basic spatiotemporal gait parameters; 4 spatial (step length, stride length and step width) and 6 temporal measures (stance, swing, single stance, initial double support and final double support times). Separate between-group MANOVAs were used for the spatial and temporal measures. Bonferroni adjustments (Vincent, 1995) were made to the $\alpha$ level for these analyses. For spatial measures to achieve significance at 0.05 , the $p$-value had to fall below $0.016(0.05 / 3)$ whereas for the temporal measures the $p$-value had to fall below 0.01 $(0.05 / 5)$. Gait speed and cadence measures were analysed separately, therefore, no further adjustments were necessary. Age group effects on the 4 joint kinematic measures were also assessed by between-group MANOVAs. In this group of measures, Bonferroni adjustments (Vincent, 1995) were made to the $\alpha$ level; to achieve significance at 0.05 , the $p$-value for these measures had to fall below 0.0125 (0.05/4). A flow chart presented in figure 3.5 illustrates how statistical analyses were performed for the spatiotemporal and kinematic measures.

In total there were 11 measures of peak joint power recorded for each of the four speed conditions. These measures were grouped as follows: powers occurring in the first half of stance $(\mathrm{H} 1, \mathrm{~K} 0, \mathrm{~K} 1, \mathrm{~K} 2)$ and powers occurring between the second half of stance and initial swing $(\mathrm{H} 2, \mathrm{H} 3, \mathrm{~K} 3, \mathrm{~K} 4, \mathrm{~A} 1, \mathrm{~A} 2)$. In total, eight betweengroup MANOVAs were used to investigate the effect of age on these measures for each speed. Bonferroni adjustments (Vincent, 1995) were made to the $\alpha$ level for these analyses. For the first grouping of peak power measures to achieve significance at 0.05 , the $p$-value had to fall below $0.0125(0.05 / 4)$ whereas for the second grouping of power measures the $p$-value had to fall below $0.0083(0.05 / 6)$. K5 joint peak power was analysed separately, therefore, no adjustment was made to the $\alpha$ level. The effect of age on K5 joint peak power was assessed by a between-group ANOVA. The flow chart shown in figure 3.6 illustrates the statistical analyses performed. 
In total there were 11 measures of joint mechanical work recorded for each of the four speed conditions. These measures were grouped as follows: mechanical work occurring in the first half of stance $(\mathrm{H} 1, \mathrm{~K} 0, \mathrm{~K} 1, \mathrm{~K} 2)$ and mechanical work occurring between the second half of stance and initial swing (H2, H3, K3, K4, A1, A2). In total, eight between-group MANOVAs were used to investigate the effect of age on these mechanical works for each speed. Bonferroni adjustments (Vincent, 1995) were made to the $\alpha$ level for these analyses. For the first grouping of mechanical work measures to achieve significance at 0.05 , the $p$-value had to fall below $0.0125(0.05 / 4)$ whereas for the second grouping of mechanical work measures the $p$-value had to fall below $0.0083(0.05 / 6)$. K5 mechanical work was analysed separately, therefore, no adjustment was made to the $\alpha$ level. The effect of age on K5 mechanical work was assessed by a between-group ANOVA. The flow chart shown in figure 3.6 illustrates the statistical analyses performed.

Multiple regressions for spatiotemporal, kinematic and kinetic parameters were calculated as a function of gait speed in both groups separately. Statistical significance was set at $p<0.01$ for all regression analyses. Linear correlations using Pearson's coefficient were made between peak joint powers/mechanical work and spatiotemporal measures (speed, cadence, step length and stride length) for the entire sample and for the young and older adults. A very high correlation had to reach an $r$ value greater than 0.9 , a high correlation had to reach a value between 0.7 and 0.9 and a moderate correlation between 0.4 and 0.7 . 


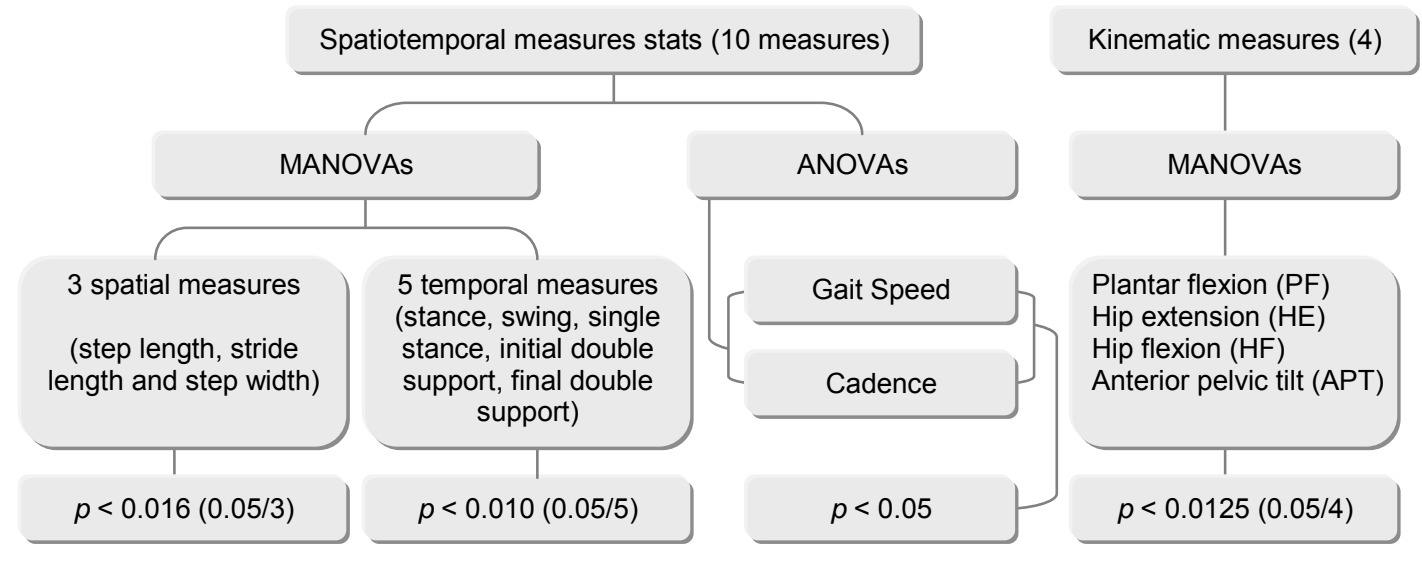

Figure 3.5 Flow chart shows inferential statistics $(\alpha$ level $=0.05)$ used to investigate the effect of aging on the spatiotemporal and kinematic measures. The Bonferroni adjustment to the $\alpha$ level is shown.

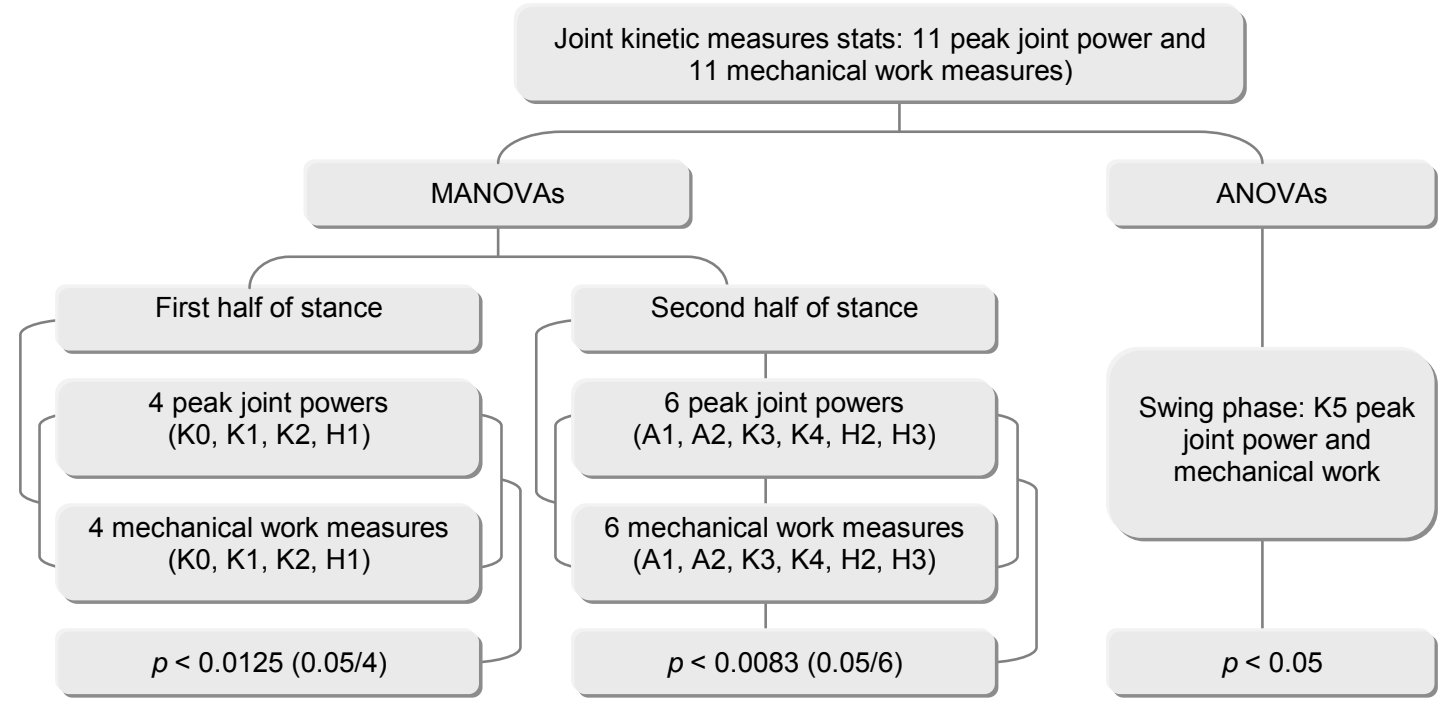

Figure 3.6 Flow chart shows inferential statistics $(\alpha$ level $=0.05)$ used to investigate the effect of aging on the kinetic measures. The Bonferroni adjustment to the $\alpha$ level is shown. Peak powers and mechanical work are identified with letters and numbers. The letter represents the joint $(\mathrm{A}=$ ankle, $\mathrm{H}=\mathrm{hip}, \mathrm{K}=\mathrm{knee})$ and the numeral represents the peak of interest $(1,2,3$, etc.) 


\section{Chapter 4: Objectives of Investigation}

\subsection{General Aim}

The aim of this study was to identify and better understand the neuromuscular adaptations and core compensatory actions made by older adults when walking at self-selected speed and at a range of matched speeds as young adults.

\subsection{Hypotheses}

1. Older adults increase hip flexor peak joint power generation (H3) to compensate for a loss in ankle peak joint power generation (A2) when walking at the same speed as young adults.

2. Older adults increase hip flexor joint mechanical work at $\mathrm{H} 3$ to compensate for a loss in ankle mechanical work at A2 when walking at the same speed as young adults.

3. Older adults exhibit similar hip extensors peak joint power generation (H1) and mechanical work when walking at the same speed as young adults.

4. Older adults increase power absorption at the knee (K4) during late stance to transfer energy to the hip and increase H3 peak power and mechanical work when walking at the same speed as young adults.

5. Older adults rely more on hip flexor muscles than ankle plantar flexor muscles to propel the body forward when walking at the same speed as young adults. 


\section{Chapter 5: Results}

The results are reported in four sections. The first section presents the basic spatiotemporal data. The second section presents the joint angular kinematic data. The third section presents the joint kinetic data in the following order: effect of age on peak powers and mechanical work followed by effect of speed on peak powers and mechanical work. The final section presents correlation data about the relationships between six key joint kinetic measures (H1, H3 and A2 powers and mechanical works) and four key basic spatiotemporal parameters of gait (speed, step length, stride length and cadence). It also presents correlation data about the relationships between joint peak powers during late stance and initial swing. This phase of the gait cycle is important for forward propulsion of the body. All data sets were normally distributed.

\subsection{Basic Spatiotemporal Measures}

The descriptive statistics for the basic spatiotemporal data are listed in table 5.1. Plots of cadence, step length and stride length are shown in figure 5.1. There were no speed differences between the groups for the matched speed conditions. On average, speed variability fell below $0.04 \mathrm{~m} \cdot \mathrm{s}^{-1}$ for the matched speeds, and was around $0.18 \mathrm{~m} \cdot \mathrm{s}^{-1}$ for the self-selected speed. There were no significant age differences in cadence for the $1.0 \mathrm{~m} \cdot \mathrm{s}^{-1}$ and $1.3 \mathrm{~m} \cdot \mathrm{s}^{-1}$ speeds. Nonetheless, the older adult group had significantly higher cadence than the young adults at the SSN and 1.6 $\mathrm{m} \cdot \mathrm{s}^{-1}$ speeds $(p<0.05)$. Stride length and step length were shorter in the older adults for the $1.6 \mathrm{~m} \cdot \mathrm{s}^{-1}$ speed $(p<0.05)$. Although not significant, older adults had greater step widths at all speeds. 


\begin{tabular}{|c|c|c|c|c|c|c|c|c|c|c|c|c|c|c|c|}
\hline & & $\frac{\infty}{a}$ & 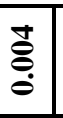 & 。ㅇ & 。․ & $\stackrel{n}{\mathfrak{0}}$ & $\stackrel{\stackrel{J}{I}}{\stackrel{5}{0}}$ & 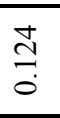 & $\begin{array}{l}\tilde{H} \\
\stackrel{8}{0} \\
0\end{array}$ & $\vec{a}$ & $\begin{array}{l}0 \\
\stackrel{0}{0} \\
0\end{array}$ & $\begin{array}{l}\overline{8} \\
0 \\
0\end{array}$ & 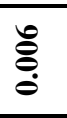 & $\exists$ & ְे \\
\hline & 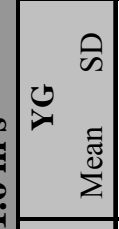 & $\begin{array}{l}\vec{\delta} \\
\dot{0} \\
\tilde{\delta} \\
\stackrel{0}{-}\end{array}$ & $\begin{array}{l}\stackrel{\infty}{i} \\
\stackrel{\sim}{\sim} \\
\stackrel{\Xi}{\Xi}\end{array}$ & $\begin{array}{l}\stackrel{t}{0} \\
\stackrel{0}{0} \\
\stackrel{0}{0}\end{array}$ & $\hat{n}$ & 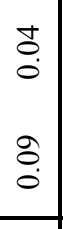 & $\begin{array}{l}\stackrel{0}{-} \\
n \\
\text { nn }\end{array}$ & $\stackrel{\circ}{-}$ & $\stackrel{n}{q}$ & $\begin{array}{l}\sim \\
\ddot{n}\end{array}$ & $\stackrel{m}{m}$ & $\begin{array}{l}0 \\
\dot{n} \\
\infty \\
\infty \\
1 \\
1\end{array}$ & $\hat{a}$ & $\stackrel{m}{m}$ & 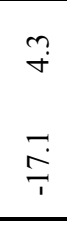 \\
\hline & 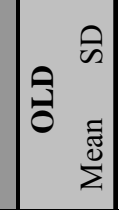 & $\begin{array}{l}0 \\
0 \\
0 \\
0 \\
\stackrel{0}{0} \\
-\end{array}$ & 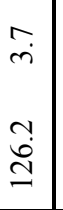 & \begin{tabular}{l}
\multirow{2}{0}{} \\
0 \\
$\hat{a}$ \\
0
\end{tabular} & \begin{tabular}{l}
3 \\
\hdashline
\end{tabular} & 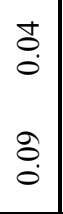 & $\begin{array}{l}\tilde{m} \\
\tilde{8}\end{array}$ & $\stackrel{\infty}{\stackrel{m}{m}}$ & $\hat{\check{m}}$ & 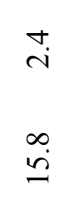 & $\stackrel{\sim}{+}$ & $\begin{array}{l}\stackrel{+}{+} \\
\stackrel{a}{i} \\
\stackrel{1}{1}\end{array}$ & $\begin{array}{l}\dot{0} \\
\dot{ } \\
\dot{=}\end{array}$ & $\begin{array}{l}n \\
\stackrel{n}{m} \\
\dot{m}\end{array}$ & $\begin{array}{l}\stackrel{0}{\sim} \\
\stackrel{1}{1}\end{array}$ \\
\hline & 2 & $\begin{array}{l}0 \\
0 \\
0 \\
0\end{array}$ & $\begin{array}{l}\text { \& } \\
\text { ڤ. }\end{array}$ & $\hat{\kappa}$ & 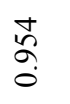 & in & $\vec{n}$ & $\vec{n}$ & $\stackrel{?}{\Xi}$ & बे & $\begin{array}{l}\stackrel{\infty}{\infty} \\
\stackrel{+}{0}\end{array}$ & 宮 & $\stackrel{m}{\circ}$ & $\stackrel{\circ}{\circ}$ & $\stackrel{+}{ \pm}$ \\
\hline 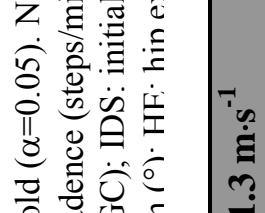 & 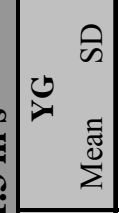 & $\begin{array}{l}\tilde{0} \\
0 \\
0 \\
0 \\
0 \\
i\end{array}$ & $\begin{array}{l}\stackrel{\infty}{n} \\
\stackrel{n}{\Xi} \\
\stackrel{n}{\Xi}\end{array}$ & 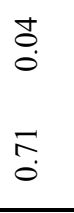 & $\begin{array}{l}\stackrel{\infty}{0} \\
\stackrel{f}{-}\end{array}$ & $\begin{array}{l}0 \\
0 \\
0 \\
0 \\
0 \\
0 \\
0\end{array}$ & $\begin{array}{l}\stackrel{9}{-} \\
\dot{8}\end{array}$ & $\begin{array}{l}9 \\
\overrightarrow{9}\end{array}$ & $\begin{array}{l}\stackrel{\infty}{-} \\
\stackrel{m}{\dot{m}}\end{array}$ & $\begin{array}{l}\stackrel{+}{i} \\
\stackrel{\infty}{\leftrightarrows}\end{array}$ & $\nabla$ & $\begin{array}{l}\overrightarrow{6} \\
\dot{n} \\
\frac{1}{1}\end{array}$ & 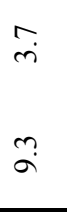 & $\begin{array}{l}\hat{i} \\
\dot{a} \\
\ddot{i}\end{array}$ & $\simeq$ \\
\hline 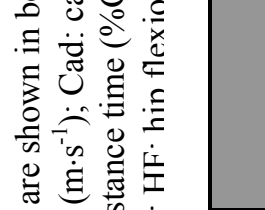 & 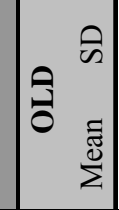 & $\begin{array}{l}0 \\
0 \\
0\end{array}$ & $\begin{array}{l}\tilde{n} \\
\stackrel{\Xi}{\Xi}\end{array}$ & $\begin{array}{l}\because \\
0 \\
0\end{array}$ & $\begin{array}{l}\stackrel{\infty}{\circ} \\
\stackrel{0}{+}\end{array}$ & $\begin{array}{l}0 \\
0 \\
0 \\
0 \\
\dot{0} \\
0\end{array}$ & $\begin{array}{l}\vec{i} \\
\overrightarrow{0}\end{array}$ & $\begin{array}{l}\vec{i} \\
\dot{a} \\
\dot{\infty}\end{array}$ & ஓ̆. & $\begin{array}{l}\stackrel{0}{i} \\
\stackrel{a}{a}\end{array}$ & $\stackrel{\infty}{\infty}$ & $\begin{array}{l}\stackrel{b}{+} \\
\stackrel{m}{i} \\
\stackrel{m}{T}\end{array}$ & $\begin{array}{l}n \\
\ddot{n} \\
\ddot{0}\end{array}$ & $\begin{array}{l}\stackrel{i}{r} \\
\stackrel{\infty}{m}\end{array}$ & $\ddot{n}$ \\
\hline 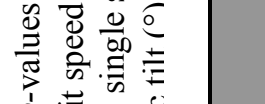 & 2 & $\begin{array}{c}\infty \\
\substack{\infty \\
n \\
0}\end{array}$ & 8 & సై & $\vec{\infty}$ & $\overrightarrow{0}$ & $\cong$ & & $\begin{array}{l}\hat{\kappa} \\
\stackrel{0}{0}\end{array}$ & $\stackrel{\circ}{\circ}$ & $\begin{array}{l}\hat{0} \\
\stackrel{0}{0}\end{array}$ & $\overrightarrow{8}$ & $\stackrel{0}{0}$ & ڤ̊ & I \\
\hline T' & 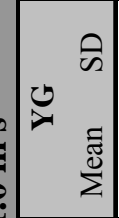 & $\mid \begin{array}{l}\stackrel{t}{0} \\
0 \\
0 \\
\stackrel{0}{-}\end{array}$ & $\begin{array}{l}\stackrel{\infty}{r} \\
\stackrel{\infty}{\sigma}\end{array}$ & $\begin{array}{l}\qquad 0 \\
0 \\
0 \\
\tilde{0} \\
0\end{array}$ & $\stackrel{\overbrace{}}{\beth}$ & $\begin{array}{l}\infty \\
0 \\
0\end{array}$ & $\begin{array}{l}\hat{i} \\
0 \\
i \\
\dot{b}\end{array}$ & $\begin{array}{l}\stackrel{n}{i} \\
\underset{m}{\pi}\end{array}$ & $\underset{n}{n}$ & $\begin{array}{l}\stackrel{\infty}{i} \\
0 \\
\stackrel{0}{i}\end{array}$ & 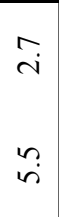 & 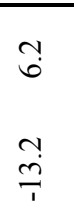 & $\dot{m}$ & $\stackrel{F}{F}$ & $\stackrel{\widehat{i}}{\simeq}$ \\
\hline 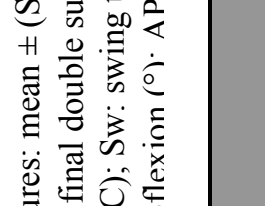 & 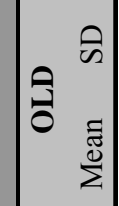 & $\begin{array}{l}\stackrel{\circ}{\circ} \\
\overrightarrow{0}\end{array}$ & $\begin{array}{l}\stackrel{m}{r} \\
\stackrel{\grave{\sigma}}{\sigma}\end{array}$ & $\begin{array}{l}\stackrel{0}{0} \\
0 \\
0 \\
0\end{array}$ & $\begin{array}{l}\stackrel{0}{0} \\
\stackrel{0}{0}\end{array}$ & $\stackrel{0}{0}$ & 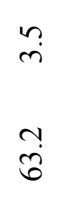 & $\begin{array}{l}n \\
m \\
\infty \\
\infty \\
\dot{m} \\
m\end{array}$ & $\underset{m}{\stackrel{m}{m}}$ & $\stackrel{\nabla}{i}$ & $\stackrel{m}{+}$ & $\begin{array}{l}n \\
n \\
\tilde{0} \\
\dot{0}\end{array}$ & $\stackrel{0}{\circ}$ & $\stackrel{\text { ̀े }}{\text { m. }}$ & $\stackrel{m}{\rightarrow}$ \\
\hline t & 2 & $\overline{0}$ & $\overline{8}$ & 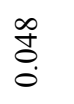 & $\tilde{n}$ & 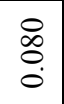 & 8 & 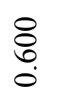 & $\begin{array}{l}\hat{o} \\
\stackrel{0}{o}\end{array}$ & $\stackrel{m}{\vec{\jmath}}$ & $\begin{array}{l}\infty \\
\stackrel{\infty}{0} \\
0\end{array}$ & $\overline{8}$ & 웅 & $\stackrel{0}{\partial}$ & $\begin{array}{l}\vec{J} \\
\stackrel{0}{0} \\
\dot{0}\end{array}$ \\
\hline Z & 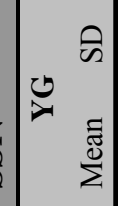 & 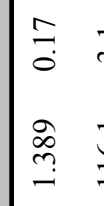 & $\begin{array}{l}\vec{m} \\
\vec{\bullet} \\
=\end{array}$ & $\begin{array}{l}5 \\
0 \\
0 \\
0 \\
0\end{array}$ & $\stackrel{?}{q}$ & $\begin{array}{l}\infty \\
0 \\
0\end{array}$ & $\begin{array}{l}\stackrel{9}{-} \\
0 \\
\dot{8}\end{array}$ & 9 & $\vec{i}$ & 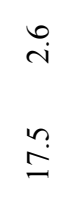 & $\begin{array}{l}\dot{r} \\
\dot{r}\end{array}$ & $\begin{array}{l}\hat{n} \\
\infty \\
\dot{n}\end{array}$ & $\tilde{a}$ & $\begin{array}{l}0 \\
\stackrel{\infty}{n}\end{array}$ & $\stackrel{\infty}{\underset{+}{\dagger}}$ \\
\hline$\dot{\dot{v}}$ & 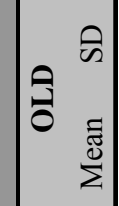 & $\begin{array}{l}\stackrel{\sigma}{\circ} \\
\stackrel{\sigma}{\sigma} \\
\stackrel{\sigma}{-}\end{array}$ & $\stackrel{+}{i}$ & $\begin{array}{l}\stackrel{8}{0} \\
\stackrel{0}{0} \\
0\end{array}$ & 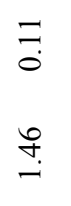 & $\stackrel{d}{0}$ & $\begin{array}{l}r \\
\hat{8}\end{array}$ & & $\vec{i}$ & $\begin{array}{l}0 \\
i\end{array}$ & त̃ & $\stackrel{\vec{r}}{ }$ & $\stackrel{\infty}{\stackrel{0}{\ominus}}$ & $\stackrel{+}{\sim}$ & $\hat{\sigma}$ \\
\hline & & क्षँّ. & $=$ & के & $\vec{D}$ & & $\bar{\omega}$ & $v$ & ss & 百 & 全 & A & & $\bar{I}$ & $\underline{\underline{y}}$ \\
\hline
\end{tabular}




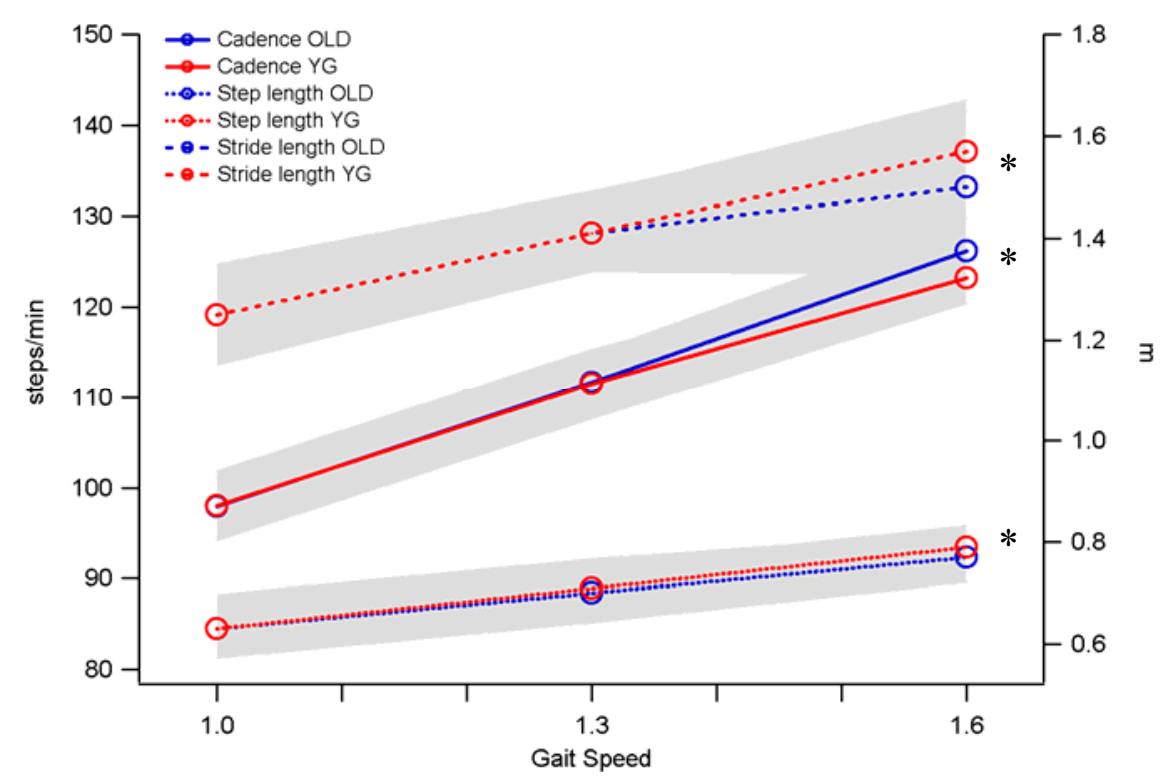

Figure 5.1 Plots of cadence, step and stride length for both age groups across the three matched speeds. The shaded region indicates \pm SD from mean. * Indicates significant differences $(p<0.05)$.

No significant age differences were found for the durations of stance, single stance, initial single stance, terminal single stance and swing across the speed conditions. Although not significant, the young adults exhibited more swing time and less stance time than older adults as speed increased.

From $1.0 \mathrm{~m} \cdot \mathrm{s}^{-1}$ to $1.6 \mathrm{~m} \cdot \mathrm{s}^{-1}$ speed, older adults increased cadence by $29 \%$ and collectively increased step and stride length by $21 \%$. The young adults increased cadence by $26 \%$ and collectively increased step and stride length by $26 \%$ from 1.0 $\mathrm{m} \cdot \mathrm{s}^{-1}$ to $1.6 \mathrm{~m} \cdot \mathrm{s}^{-1}$.

Compared to the $1.0 \mathrm{~m} \cdot \mathrm{s}^{-1}$ speed condition, young and older adults reduced stance time ( $\% \mathrm{GC})$ by $5 \%$ and increased swing and single stance time (\%GC) by $8 \%$ at the $1.6 \mathrm{~m} \cdot \mathrm{s}^{-1}$ walking speed. Single stance period increased more in young adults than in older adults at $1.6 \mathrm{~m} \cdot \mathrm{s}^{-1}$ compared to $1.0 \mathrm{~m} \cdot \mathrm{s}^{-1}$ speed condition. Single stance time increased by $6 \%$ in the older adults whereas in the young adults it increased by $8 \%$. 


\subsection{Joint Angular Kinematics}

The descriptive statistics for the joint angular kinematics data are listed in table 5.1. Hip maximum extension and flexion plots are shown in figure 5.2. Average plots of peak ankle plantar flexion and peak anterior pelvic tilt are shown in figure 5.3. No significant age differences were found for peak hip extension (HE) for all speeds. Significant age differences $(p<0.05)$ were found for peak hip flexion (HF) for the $1.0 \mathrm{~m} \cdot \mathrm{s}^{-1}$ and $1.3 \mathrm{~m} \cdot \mathrm{s}^{-1}$ but not for the SSN and $1.6 \mathrm{~m} \cdot \mathrm{s}^{-1}$ speeds. At the ankle joint, significant age differences $(p<0.05)$ were found for peak ankle plantar flexion (PF) for all speeds. Significant age differences were found for peak anterior pelvic tilt (APT) for all speeds except the $1.3 \mathrm{~m} \cdot \mathrm{s}^{-1}$ speed $(p<0.05)$. On average (combining all speed conditions), the OLD exhibited $4^{\circ}$ less PF, $2^{\circ}$ more HF and $2^{\circ}$ more APT than the YG. These differences were more notable at $1.6 \mathrm{~m} \cdot \mathrm{s}^{-1}$ for APT $\left(2^{\circ}\right)$ and PF $\left(5^{\circ}\right)$ and at $1.0 \mathrm{~m} \cdot \mathrm{s}^{-1}$ for $\operatorname{HF}\left(2.2^{\circ}\right)$.

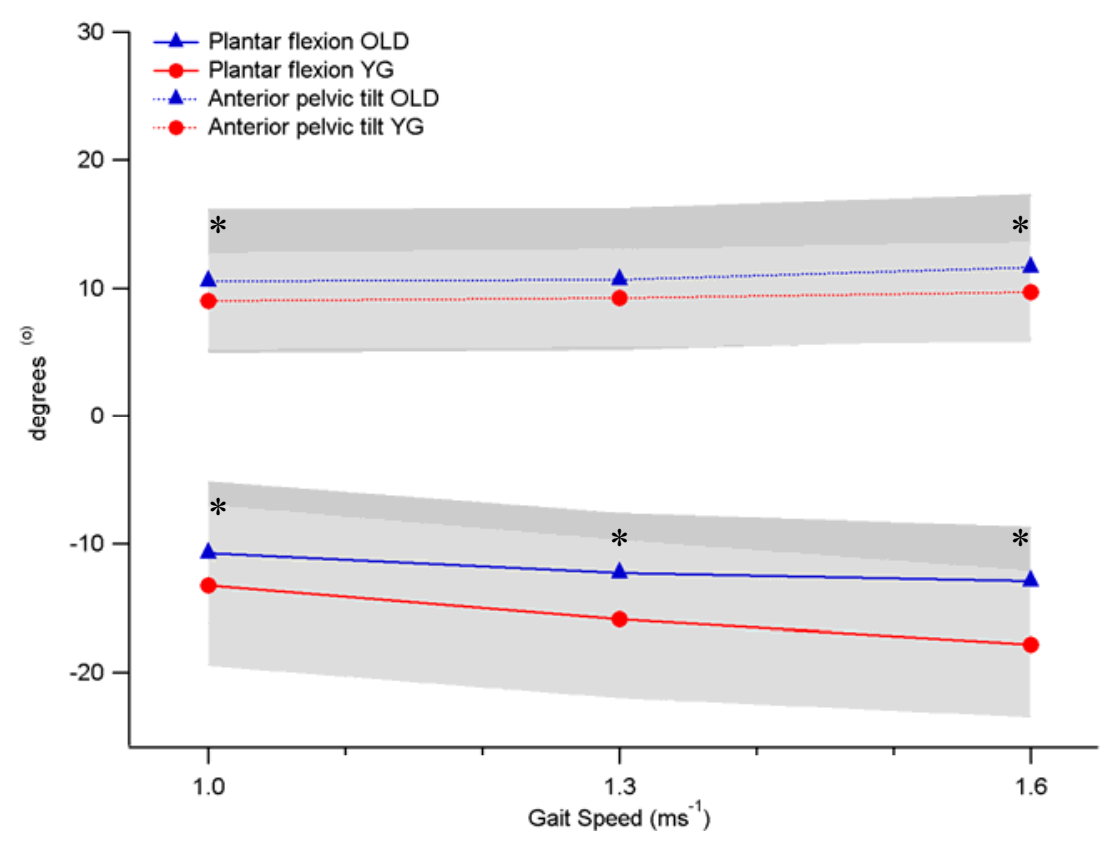

Figure 5.2 Plot shows mean peak ankle plantar flexion and mean peak anterior pelvic tilt for both groups at matched speed conditions. The shaded region indicates $\pm \mathrm{SD}$ from mean. * Indicates significant differences $(p<0.05)$. 


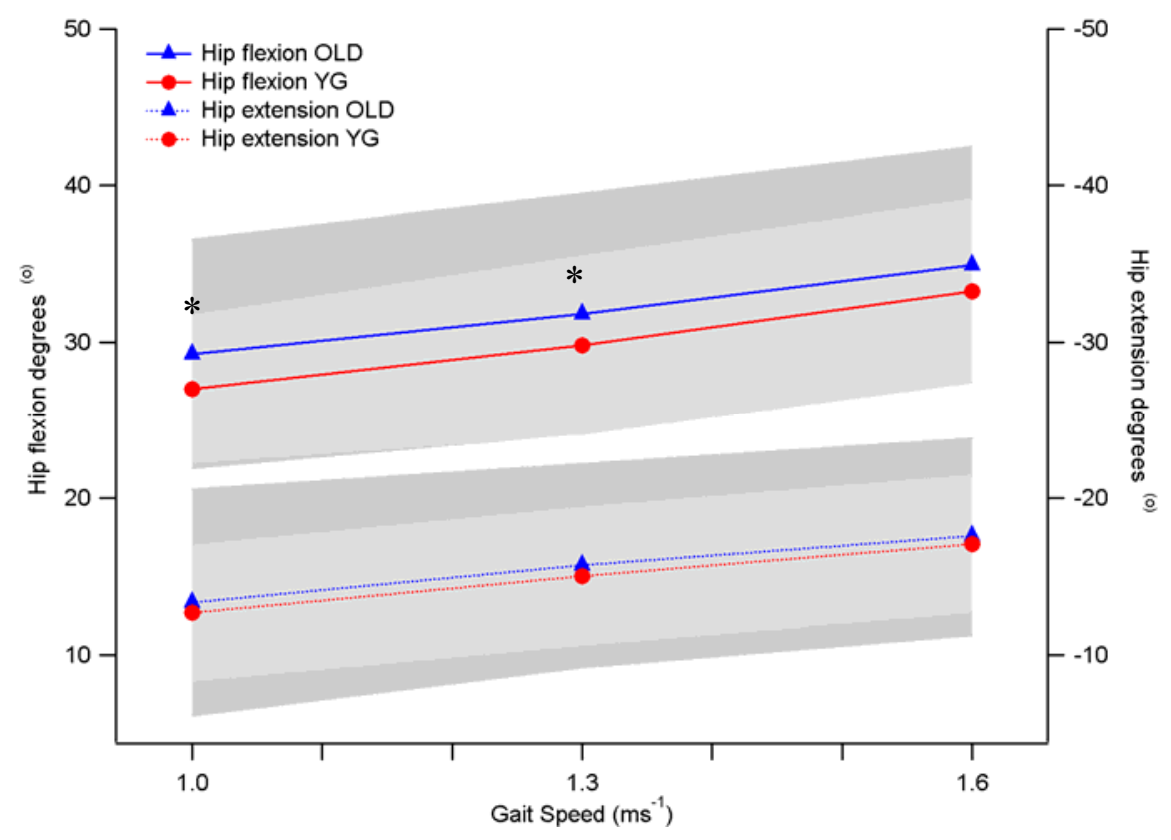

Figure 5.3 Plot shows hip flexion and extension means and standard deviation for both groups at matched speed conditions. The shaded region indicates \pm SD from mean. . * Indicates significant differences $(p<0.05)$.

On average (combining all group data), peak hip extension (HE) increased by $33 \%$ from $1.0 \mathrm{~m} \cdot \mathrm{s}^{-1}$ to $1.6 \mathrm{~m} \cdot \mathrm{s}^{-1}$. The young adults increased by $35 \%$ whereas the older adults increased it by $32 \%$. Peak hip flexion (HF) increased from $1.0 \mathrm{~m} \cdot \mathrm{s}^{-1}$ to $1.6 \mathrm{~m} \cdot \mathrm{s}^{-1}$ for both groups $(\mathrm{OLD}=19.4 \%, \mathrm{YG}=23 \%)$. Peak ankle plantar flexion $(\mathrm{PF})$ increased $14 \%$ more in the young adults than the older adults from $1.0 \mathrm{~m} \cdot \mathrm{s}^{-1}$ to 1.6 $\mathrm{m} \cdot \mathrm{s}^{-1}$ (YG: $34.4 \%$; OLD: 20.6\%). The effect of speed on APT was similar for both groups. On average it increased by $21 \%$ from $1.0 \mathrm{~m} \cdot \mathrm{s}^{-1}$ to $1.6 \mathrm{~m} \cdot \mathrm{s}^{-1}$. 


\subsection{Joint Angular Kinetics}

Representative plots of joint powers for a young and older adult for the matched speeds are shown in figure 5.4 (page 64), and schematically represented in figure 5.5 (page 65). These plots and figure are presented so as to help the reader. The descriptive statistics for the peak powers and mechanical work are listed in tables 5.2 and 5.3 respectively.

\subsubsection{Hip Kinetics}

On average (combining all speeds), H1 peak power was $11 \%$ higher in the older adults than the young adults. No significant age differences, however, were found for each speed. The greatest age group difference was $16 \%$ for the $1.0 \mathrm{~m} \cdot \mathrm{s}^{-1}$ speed. Significant age differences $(p<0.05)$ were found for $\mathrm{H} 2$ peak power at all speeds. On average, combining only matched speed data, the older adults produced $45 \%$ more $\mathrm{H} 2$ peak power absorption than the young adults. At the self-selected speed this difference reached $74 \%$. Significant age differences $(p<0.05)$ were found for H3 peak power generation for the SSN and $1.6 \mathrm{~m} \cdot \mathrm{s}^{-1}$ speeds. On average, combining matched speed data, the older adults generated 7\% more $\mathrm{H} 3$ peak power than the young adults. At the self-selected speed this difference reached $34 \%$.

No significant age differences were found for $\mathrm{H} 1$ mechanical work. On average, the older adults exhibited 21\% more H1 mechanical work (combining all speeds). At the $1.0 \mathrm{~m} \cdot \mathrm{s}^{-1}$ speed this difference reached $35 \%$. Significant age differences $(p<0.05)$ were found for $\mathrm{H} 2$ mechanical work at all speeds. On average (combining all speeds), H2 work was $49 \%$ higher in the older adults. The difference in $\mathrm{H} 2$ mechanical work was greatest $(60 \%)$ for the self-selected speed. On average (combining all speeds), the older adults exhibited 9\% more $\mathrm{H} 3$ mechanical work than the young adults. However, significant age differences $(p<0.05)$ were only found for the $1.6 \mathrm{~m} \cdot \mathrm{s}^{-1}$ and self-selected speeds. The difference in $\mathrm{H} 3$ mechanical work generation was greatest (22\%) for the self-selected speed but only differed by $1.1 \%$ for the $1.0 \mathrm{~m} \cdot \mathrm{s}^{-1}$ speed. 


\begin{tabular}{|c|c|c|c|c|c|c|c|c|c|c|c|c|}
\hline \multirow{5}{*}{\begin{tabular}{l}
$\Xi$ \\
0 \\
\hdashline \\
-
\end{tabular}} & & 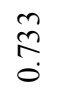 & 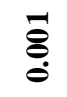 & $\overline{8}$ & $\begin{array}{l}\infty \\
\stackrel{8}{0} \\
0\end{array}$ & ò & 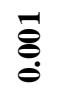 & $\overrightarrow{8}$ & 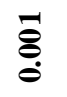 & $\stackrel{\Delta}{\overrightarrow{0}}$ & 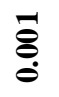 & 官 \\
\hline & के & 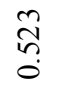 & $\overrightarrow{\widetilde{\pi}}$ & $\stackrel{n}{f}$ & $\stackrel{+}{\infty} \underset{-}{=}$ & $\begin{array}{l}\widetilde{\Omega} \\
0 \\
0\end{array}$ & $\hat{\tilde{n}}$ & $\begin{array}{l}0 \\
\text { ñ } \\
0\end{array}$ & के & $\begin{array}{l}\hat{0} \\
\tilde{0}\end{array}$ & $\begin{array}{l}n \\
\infty \\
\infty \\
0\end{array}$ & $\begin{array}{l}\hat{a} \\
\hat{0}\end{array}$ \\
\hline & $\stackrel{\text { हाँ }}{\sum^{\circ}}$ & ڤ̊. & $\begin{array}{l}\infty \\
\stackrel{\infty}{i} \\
\stackrel{i}{i}\end{array}$ & 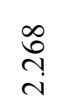 & $\begin{array}{l}\sqrt{n} \\
b \\
i\end{array}$ & $\stackrel{\text { aे }}{\rightarrow}$ & 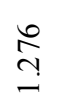 & $\begin{array}{l}\stackrel{0}{\circ} \\
\stackrel{\sigma}{\sigma}\end{array}$ & 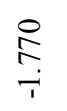 & $\begin{array}{l}0 \\
\hat{6} \\
i \\
i\end{array}$ & $\stackrel{8}{\stackrel{8}{\prime}}$ & $\begin{array}{l}\hat{\infty} \\
\hat{n} \\
i\end{array}$ \\
\hline & के & $\begin{array}{l}\text { I } \\
0 \\
0\end{array}$ & $\stackrel{m}{\exists}$ & $\vec{n}$ & $\begin{array}{l}\tilde{O} \\
\stackrel{2}{0} \\
0\end{array}$ & $\stackrel{5}{0}$ & $\stackrel{1}{m}$ & $\frac{\mathfrak{n}}{3}$ & 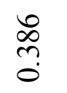 & $\begin{array}{l}8 \\
\infty \\
0 \\
0\end{array}$ & $\overrightarrow{\tilde{\vartheta}}$ & $\begin{array}{l}0 \\
\infty \\
\infty \\
0\end{array}$ \\
\hline & 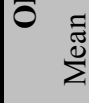 & $\stackrel{\infty}{\stackrel{\infty}{=}}$ & $\underset{+}{\stackrel{\infty}{+}}$ & $\frac{\bar{n}}{i}$ & 京 & $\stackrel{\infty}{\stackrel{\infty}{+}}$ & $\stackrel{\circ}{\circ}$ & 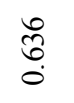 & $\begin{array}{l}+ \\
\stackrel{0}{0} \\
\stackrel{i}{i}\end{array}$ & 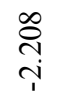 & 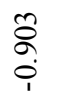 & $\stackrel{\text { ले }}{\stackrel{+}{+}}$ \\
\hline \multirow{4}{*}{ } & 8 & $\begin{array}{l}\text { Tे } \\
\text { లై } \\
0\end{array}$ & $\vec{\delta}$ & $\stackrel{\hat{\delta}}{0}$ & 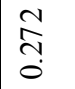 & $\overrightarrow{8}$ & 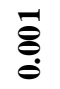 & $\overrightarrow{8}$ & $\overline{8}$ & $\begin{array}{l}n \\
8 \\
0\end{array}$ & 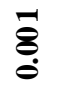 & $\overline{8}$ \\
\hline & $\stackrel{\text { ฐू๊ }}{\Sigma}$ & 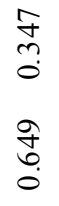 & $\begin{array}{l}\infty \\
\infty \\
\\
\infty \\
\infty \\
\infty \\
\stackrel{0}{0}\end{array}$ & $\begin{array}{l}? \\
n \\
0 \\
n \\
n \\
n \\
n\end{array}$ & $\begin{array}{l}0 \\
\stackrel{\infty}{0} \\
0 \\
2 \\
\hat{n} \\
-2\end{array}$ & 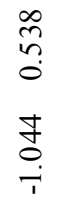 & $\begin{array}{l}2 \\
\text { యे. } \\
\hat{0} \\
\hat{0} \\
0\end{array}$ & 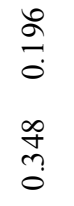 & 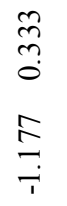 & 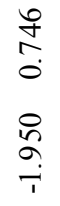 & 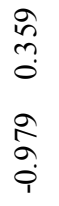 & 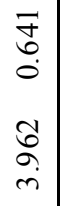 \\
\hline & है & $\begin{array}{c}\hat{\widehat{N}} \\
0\end{array}$ & \begin{tabular}{l}
\multirow{+}{*}{} \\
ڤ్
\end{tabular} & $\underset{O}{\vec{\sigma}}$ & $\frac{\mathfrak{I}}{\stackrel{N}{0}}$ & $\stackrel{n}{\tilde{n}}$ & $\stackrel{\overbrace{}}{\overparen{N}}$ & $\stackrel{\check{N}}{\tilde{0}}$ & ڤึ) & $\begin{array}{l}n \\
\frac{n}{0} \\
0 \\
0\end{array}$ & $\begin{array}{l}\text { In } \\
\text { İ }\end{array}$ & $\begin{array}{l}\vec{Q} \\
\stackrel{0}{0}\end{array}$ \\
\hline & $\sum^{\bar{\Xi}}$ & $\begin{array}{l}\stackrel{2}{0} \\
0\end{array}$ & $\underset{\mathbb{i}}{\vec{i}}$ & $\underset{-}{\stackrel{8}{0}}$ & $\stackrel{\text { fơ }}{\stackrel{\sim}{\longrightarrow}}$ & $\begin{array}{c}\stackrel{0}{+} \\
\stackrel{i}{i}\end{array}$ & $\begin{array}{l}n \\
n \\
n \\
0\end{array}$ & $\stackrel{n}{\stackrel{n}{f}}$ & $\stackrel{\circ}{\stackrel{m}{i}}$ & $\underset{\stackrel{\overrightarrow{0}}{+}}{-}$ & 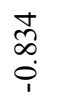 & $\begin{array}{l}\stackrel{n}{+} \\
\stackrel{n}{n} \\
n\end{array}$ \\
\hline \multirow{3}{*}{$\begin{array}{l}\stackrel{\varphi}{\dot{\Xi}} \\
\stackrel{\Xi}{-}\end{array}$} & 8 & $\begin{array}{l}0 \\
\stackrel{0}{0}\end{array}$ & $\overrightarrow{8}$ & $\begin{array}{l}\text { ते } \\
\tilde{3}\end{array}$ & $\hat{\sigma}$ & $\begin{array}{l}\stackrel{t}{0} \\
\stackrel{0}{0}\end{array}$ & $\begin{array}{l}\stackrel{\leftrightarrow}{0} \\
\stackrel{0}{0}\end{array}$ & $\overrightarrow{8}$ & $\begin{array}{l}n \\
\text { co } \\
0 \\
0\end{array}$ & $\stackrel{\overline{8}}{0}$ & $\begin{array}{l}0 \\
0 \\
0\end{array}$ & $\stackrel{\leftrightarrow}{\stackrel{0}{0}}$ \\
\hline & 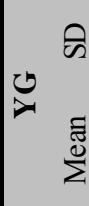 & 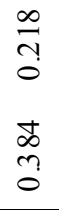 & 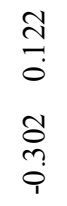 & 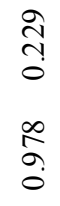 & \begin{tabular}{l}
8 \\
\multirow{+}{0}{} \\
0 \\
$m$ \\
$\tilde{0}$ \\
$\stackrel{0}{0}$
\end{tabular} & 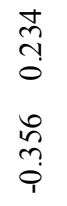 & 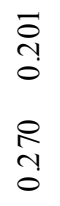 & $\begin{array}{l}\stackrel{\infty}{n} \\
\stackrel{0}{0} \\
\frac{n}{n} \\
0\end{array}$ & \begin{tabular}{l} 
वे \\
तु \\
J \\
\multirow{2}{i}{}
\end{tabular} & 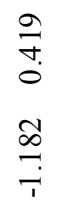 & 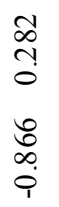 & 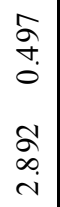 \\
\hline & 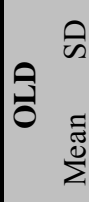 & 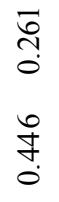 & $\begin{array}{l}\frac{\partial}{0} \\
\dot{0} \\
0 \\
\stackrel{0}{+} \\
0 \\
1\end{array}$ & $\begin{array}{l}\hat{\hat{N}} \\
\text { ○े } \\
0 \\
0 \\
0\end{array}$ & $\begin{array}{l}\infty \\
\infty \\
0 \\
0 \\
0 \\
0 \\
\infty \\
0\end{array}$ & 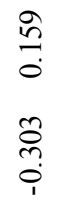 & $\begin{array}{l}\cong \\
ٍ \\
0 \\
\circ \\
\stackrel{1}{0} \\
0\end{array}$ & $\frac{+}{\infty}$ & 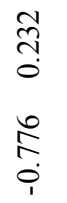 & 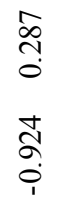 & 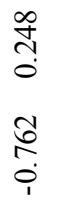 & $\begin{array}{l}8 \\
\stackrel{0}{0} \\
0 \\
\vec{b} \\
i \\
i\end{array}$ \\
\hline \multirow{4}{*}{ Z } & R & $\stackrel{+}{\stackrel{+}{0}}$ & $\overline{8}$ & $\overline{8}$ & $\begin{array}{l}a \\
\vec{J} \\
0\end{array}$ & $\stackrel{\Xi}{\stackrel{5}{0}}$ & $\begin{array}{l}\infty \\
\hat{\sigma} \\
0\end{array}$ & $\overrightarrow{\tilde{s}}$ & $\overrightarrow{8}$ & $\stackrel{a}{0}$ & تَّ & 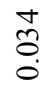 \\
\hline & $\underset{\nu}{0}$ & $\begin{array}{l}7 \\
n \\
0 \\
0 \\
0 \\
\infty \\
0\end{array}$ & 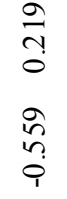 & 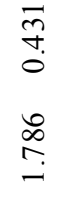 & $\begin{array}{l}\stackrel{ \pm}{\sigma} \\
\stackrel{-}{-} \\
\tilde{n} \\
2 \\
\stackrel{2}{-}\end{array}$ & 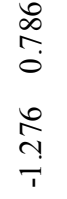 & 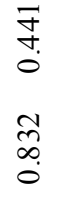 & $\begin{array}{l}\vec{\infty} \\
\tilde{0} \\
0 \\
n \\
\tilde{y} \\
\tilde{0}\end{array}$ & 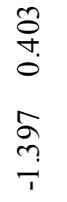 & 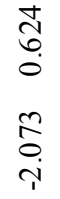 & $\begin{array}{l}\hat{n} \\
\hat{n} \\
0 \\
o \\
\stackrel{0}{0} \\
i\end{array}$ & 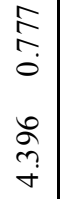 \\
\hline & है & $\begin{array}{l}\text { ô: } \\
\stackrel{0}{0}\end{array}$ & $\stackrel{m}{\stackrel{f}{+}}$ & $\begin{array}{l}\text { बे. } \\
\text { : }\end{array}$ & $\vec{n}$ & $\begin{array}{l}n \\
\infty \\
n \\
0\end{array}$ & 훙 & ڤે & $\begin{array}{l}\overrightarrow{\tilde{b}} \\
\stackrel{0}{0}\end{array}$ & $\begin{array}{l}0 \\
\infty \\
0 \\
0\end{array}$ & $\begin{array}{l}\stackrel{\partial}{\hat{~}} \\
\stackrel{0}{0}\end{array}$ & $\stackrel{?}{g}$ \\
\hline & 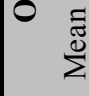 & 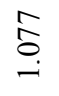 & $\begin{array}{l}\text { N̂ } \\
\text { ò }\end{array}$ & ले & $\begin{array}{l}0 \\
\& \\
\stackrel{0}{0} \\
i\end{array}$ & 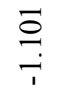 & $\underset{\hat{0}}{\stackrel{\hat{O}}{0}}$ & స్ర్రి & 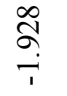 & $\underset{i}{\stackrel{q}{T}}$ & $\begin{array}{l}8 \\
8 \\
0 \\
1\end{array}$ & $\begin{array}{l}\stackrel{n}{\dddot{m}} \\
\stackrel{+}{*}\end{array}$ \\
\hline 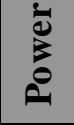 & 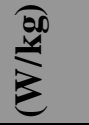 & $\bar{I}$ & $\tilde{Z}$ & $\underline{\mathbf{I}}$ & lૈ & $\bar{z}$ & $\tilde{Z}$ & $\hat{z}$ & $\underset{z}{ \pm}$ & $\underline{12}$ & $\bar{Z}$ & $\mathcal{Z}$ \\
\hline
\end{tabular}




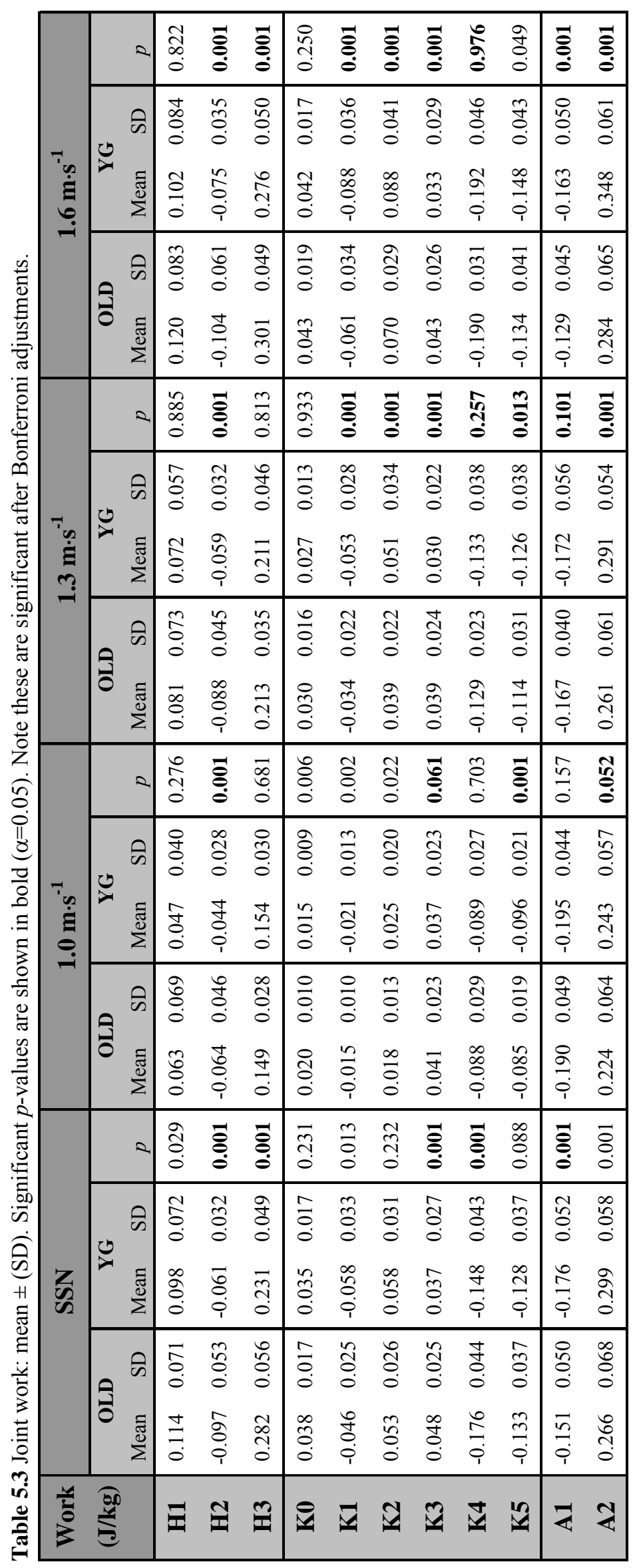


From the $1.0 \mathrm{~m} \cdot \mathrm{s}^{-1}$ to $1.6 \mathrm{~m} \cdot \mathrm{s}^{-1}$ speed, the older adults increased $\mathrm{H} 1$ peak power by $167 \%$ and $\mathrm{H} 1$ mechanical work by $90 \%$. In comparison the young adults increased H1 peak power by $186 \%$ and H1 mechanical work by $118 \%$. A similar trend was found for $\mathrm{H} 2$ peak power and mechanical work. For the older adults these measures increased by $140 \%$ and $63 \%$ respectively, and by $145 \%$ and $71 \%$ in the young adults. From the $1.0 \mathrm{~m} \cdot \mathrm{s}^{-1}$ to $1.6 \mathrm{~m} \cdot \mathrm{s}^{-1}$, the older adults increased $\mathrm{H} 3$ peak power and mechanical work more than young adults. In the older adult, these increased by $150 \%$ and $102 \%$ respectively, whereas in the young adults these increased by $132 \%$ and $80 \%$.

\subsubsection{Knee Kinetics}

The young adults exhibited significantly higher $\mathrm{K} 0$ peak power generation at the $1.6 \mathrm{~m} \cdot \mathrm{s}^{-1}$ speed $(p<0.05)$ than the older adults. On average, $\mathrm{K} 0$ peak power was $6 \%$ greater in the young adults at $1.3 \mathrm{~m} \cdot \mathrm{s}^{-1}$ and $1.6 \mathrm{~m} \cdot \mathrm{s}^{-1}$. In contrast, $\mathrm{K} 0$ peak power was $13 \%$ greater in the older adults at the $1.0 \mathrm{~m} \cdot \mathrm{s}^{-1}$ and SSN speeds. These differences were higher at $1.0 \mathrm{~m} \cdot \mathrm{s}^{-1}$ and SSN (16\% and 24\%, respectively). Compared to the young adults, the older adults exhibited lower K1 peak power absorption at all speeds. These differences, however, were only significant $(p<0.05)$ at $1.3 \mathrm{~m} \cdot \mathrm{s}^{-1}$ and $1.6 \mathrm{~m} \cdot \mathrm{s}^{-1}$. At these speeds, K1 peak power differences reached $40 \%$ and $34 \%$ respectively. Combining all speeds, older adults exhibited 24\% less K2 peak power than young adults. These differences were significant only at $1.3 \mathrm{~m} \cdot \mathrm{s}^{-1}$ and $1.6 \mathrm{~m} \cdot \mathrm{s}^{-1}(p<0.05)$. Older adults generated significantly greater K3 peak power $(p<0.05)$ at all speeds. Combining all speeds, the older adults, on average, exhibited 38\% more K3 peak power than young adults.

On average, combining all speeds, K4 peak power absorption was 14\% higher in the older adults. This difference was significant at all speeds $(p<0.05)$ except for $1.0 \mathrm{~m} \cdot \mathrm{s}^{-1}$. On average, combining only matched speeds, K5 peak power absorption was $21 \%$ higher in the young adults. However, these differences were only significant at $1.0 \mathrm{~m} \cdot \mathrm{s}^{-1}$ and $1.3 \mathrm{~m} \cdot \mathrm{s}^{-1}(p<0.05)$. The smallest difference of $3 \%$ occurred at the selfselected speed. 
On average, combing all speeds, K0 mechanical work was $14 \%$ lower in the older adults. K0 mechanical work was only significantly different at $1.0 \mathrm{~m} \cdot \mathrm{s}^{-1}$ $(p<0.05)$ where it was $33 \%$ lower in the older adults. At all speeds, K1 mechanical work was significantly lower in the older adults $(p<0.05)$. On average, these differences reached $41 \%$. The difference was greatest at $1.3 \mathrm{~m} \cdot \mathrm{s}^{-1}$ reaching $57 \%$. On average, combining all speeds, K2 mechanical work was 26\% lower and K3 mechanical work was $25 \%$ higher in the older adult group. These differences were significant at $1.3 \mathrm{~m} \cdot \mathrm{s}^{-1}$ and $1.6 \mathrm{~m} \cdot \mathrm{s}^{-1}(p<0.05)$. A significant difference for $\mathrm{K} 3$ mechanical work was also found at SSN $(p<0.05)$. K4 mechanical work was only significantly higher at self-selected speed $(p<0.05)$ for the older adults. At this speed, the older adults exhibited 18\% more K4 mechanical work than the young adults. On average, combining only matched speeds, $\mathrm{K} 5$ mechanical work was $12 \%$ lower in the older adults. It was only significantly lower at $1.0 \mathrm{~m} \cdot \mathrm{s}^{-1}$ speed $(p<0.05)$. For the SSN speed, K5 mechanical work was $4 \%$ lower in the young adults.

From the $1.0 \mathrm{~m} \cdot \mathrm{s}^{-1}$ to $1.6 \mathrm{~m} \cdot \mathrm{s}^{-1} \mathrm{speed}$, the older adults increased $\mathrm{K} 0$ peak power by $177 \%$ and K0 mechanical work by $112 \%$. In comparison the young adults increased K0 peak power by $263 \%$ and K0 mechanical work by $175 \%$. From the 1.0 $\mathrm{m} \cdot \mathrm{s}^{-1}$ to $1.6 \mathrm{~m} \cdot \mathrm{s}^{-1}$ speed, the older adults increased $\mathrm{K} 1$ peak power by $390 \%$ and $\mathrm{K} 1$ mechanical work by $308 \%$. In comparison the young adults increased K1 peak power by $459 \%$ and K1 mechanical work by $327 \%$. Similar trends were observed in both groups for K2 and K3 mechanical work. From the $1.0 \mathrm{~m} \cdot \mathrm{s}^{-1}$ to $1.6 \mathrm{~m} \cdot \mathrm{s}^{-1} \mathrm{speed}$, the older adults increased K4 peak power by $169 \%$ and mechanical work by $116 \%$. In comparison the young adults increased $\mathrm{K} 4$ peak power by $138 \%$ and mechanical work by $115 \%$. Similar increases were observed in K5 peak power and mechanical work for both groups.

\subsubsection{Ankle Kinetics}

On average, combining all speeds, older adults exhibited 20\% less A1 peak power than the young adults. A1 peak power was significantly lower $(p<0.05)$ at all speeds except $1.0 \mathrm{~m} \cdot \mathrm{s}^{-1}$. Significant group differences $(p<0.05)$ were found in A2 peak power for the matched speeds. On average, when combining all speeds, older adults 
exhibited $12 \%$ less A2 peak power than young adults. At the $1.6 \mathrm{~m} \cdot \mathrm{s}^{-1}$ walking speed this difference reached $22 \%$.

Small between group differences (lower in older adults) in A1 mechanical work were found for the $1.0 \mathrm{~m} \cdot \mathrm{s}^{-1}$ and $1.3 \mathrm{~m} \cdot \mathrm{s}^{-1}$ speeds. Significantly lower A1 mechanical work was found in the older adults for the SSN and $1.6 \mathrm{~m} \cdot \mathrm{s}^{-1}$ speeds $(p<0.05)$. Significantly lower A2 mechanical work $(p<0.05)$ was found in the older adults for the $1.3 \mathrm{~m} \cdot \mathrm{s}^{-1}, 1.6 \mathrm{~m} \cdot \mathrm{s}^{-1}$ and SSN speeds. At $1.6 \mathrm{~m} \cdot \mathrm{s}^{-1}$, this difference reached $23 \%$. When combining all speeds, A2 mechanical work was $14 \%$ lower in the older adults.

From the $1.0 \mathrm{~m} \cdot \mathrm{s}^{-1}$ to $1.6 \mathrm{~m} \cdot \mathrm{s}^{-1}$ speed, the older adults increased A1 mechanical work by $19 \%$. In comparison, young adults increased A1 mechanical work by $34 \%$. From the $1.0 \mathrm{~m} \cdot \mathrm{s}^{-1}$ to $1.6 \mathrm{~m} \cdot \mathrm{s}^{-1} \mathrm{speed}$, the older adults increased A2 peak power by $64 \%$ and A2 mechanical work by $44 \%$. In comparison the young adults increased A2 peak power by $83 \%$ and A 2 mechanical work by $27 \%$. 

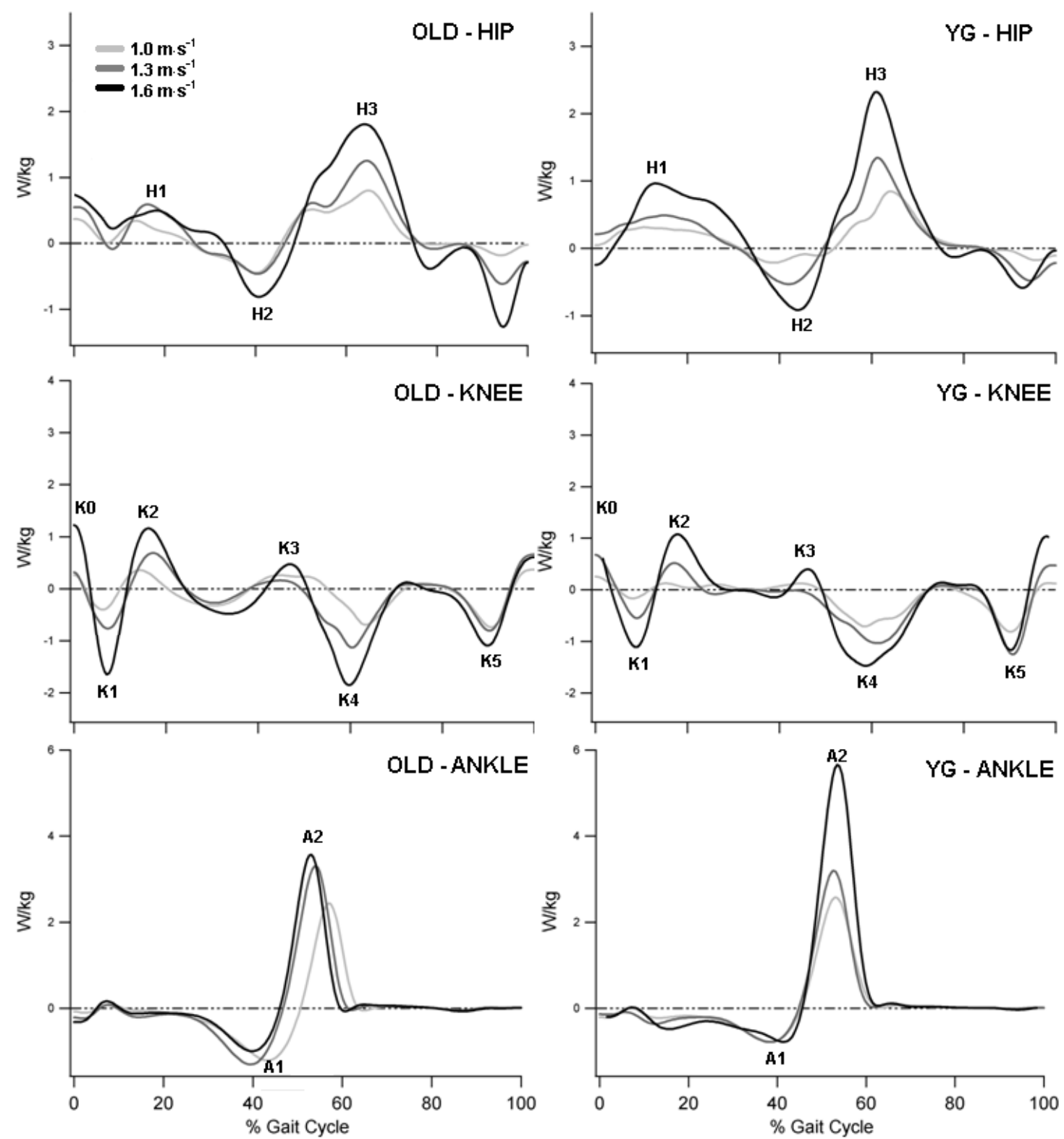

Figure 5.4 Typical plots of joint power and mechanical work for an older adult (EM68) and young adult (YF23). EM68: 68 year old male. YF23; 23 year old female. 


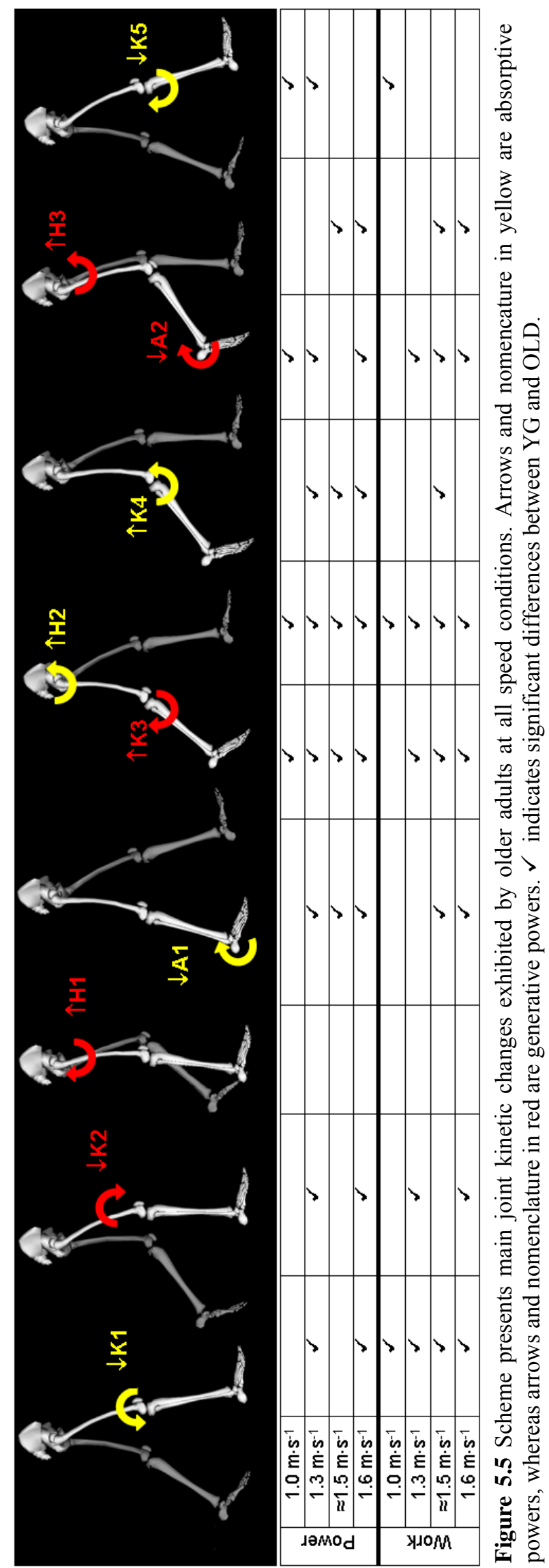




\subsection{Basic Spatiotemporal and Kinetic Correlations}

Significant relationships with speed were found for both the basic spatiotemporal and kinetic variables (please refer to Appendix 1). For the entire sample, significant high positive correlations were found between speed and cadence ( $r=0.86, p<0.01)$, speed and step length $(r=0.76, p<0.01)$, speed and stride length $(r$ $=0.76, p<0.01)$. The older adults, however, were found to rely more on an increase in cadence than an increase in step and stride length to walk at the same speed as the young adults. This is demonstrated by the higher correlation between speed and cadence in the older adults $(r=0.88, p<0.01)$ than in the young adults $(r=0.83$, $p<0.01)$. Also lower correlations between speed and step length, speed and stride length were found in the older adults $(r=0.71, p<0.01$ and $r=0.68, p<0.01$, respectively) than the young adults ( $r=0.82, \quad p<0.01$ and $r=0.84, p<0.01$, respectively).

Plots of correlations between A2 peak power and speed, H3 peak power and speed, $\mathrm{H} 1$ peak power and speed, are shown in figures 5.6, 5.7 and 5.8 respectively. For the entire sample, significant positive correlations were found between speed and H3 peak power $(r=0.81, p<0.01)$, speed and H3 mechanical work $(r=0.81, p<0.01)$. Furthermore, for the entire sample, significant positive correlations were found between speed and A2 peak power $(r=0.73, p<0.01)$, speed and A2 mechanical work $(r=0.46, p<0.01)$. When analyzing the groups separately, the older adults exhibited a higher positive correlation between speed and H3 peak power $(r=0.82, p<0.01)$, speed and $\mathrm{H} 3$ mechanical work $(r=0.85, p<0.01)$ than the young adults. In contrast, the young adults exhibited higher correlations between speed and A2 peak power ( $r=$ $0.80, p<0.01)$, speed and A2 mechanical work $(r=0.57, p<0.01)$ than the older adults (figure 5.5).

For the entire sample, high negative correlations were found between speed and $\mathrm{K} 4$ peak power absorption $(r=-0.82, p<0.01)$, speed and $\mathrm{K} 4$ mechanical work $(r$ $=-0.78, p<0.01)$. These correlations were higher for the older adults. For the entire sample, a moderate to high inverse relationship was found between speed and K1 peak power $(r=-0.71, p<0.01)$. Only a moderate positive correlation was found between speed and K1 mechanical work. 
For the entire sample, very high negative correlations were found between K4 and H3 peak powers $(r=-0.92, p<0.01)$. High negative correlations were found between $\mathrm{K} 1$ and $\mathrm{K} 2$ peak powers $(r=-0.86, p<0.01)$, between $\mathrm{K} 4$ and $\mathrm{H} 3$ mechanical work $(r=-0.83, p<0.01)$, and between $\mathrm{K} 1$ and $\mathrm{K} 2$ mechanical work $(r=-0.78$, $p<0.01)$. Correlations between these variables were similar in the young and older adult groups.

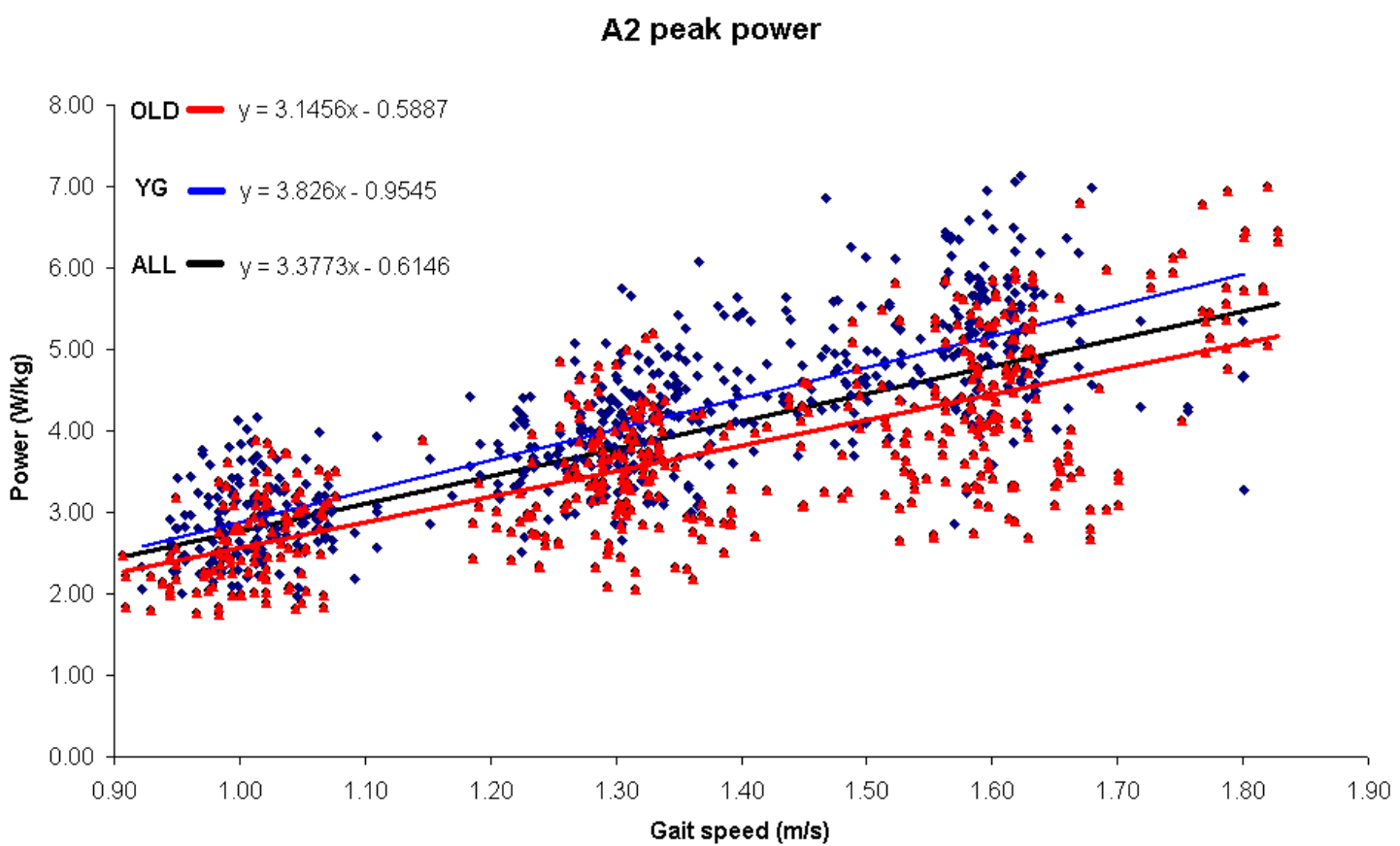

Figure 5.6 Plot shows correlations between A2 peak power and speed for older adults (red), young adults (blue) and both groups together (black line). 


\section{H3 peak power}

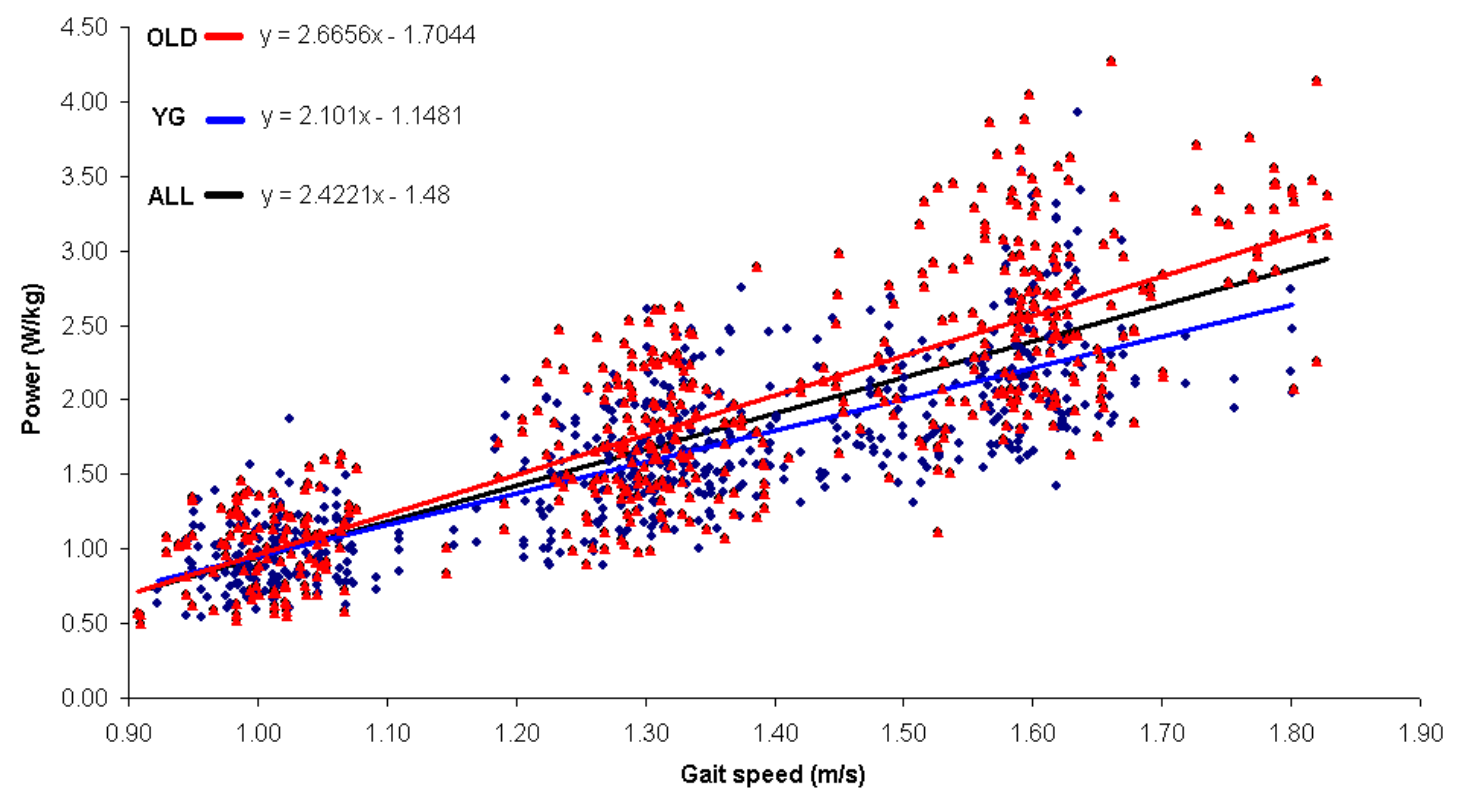

Figure 5.7 Plot shows correlations between H3 peak power and speed for older adults (red), young adults (blue) and both groups together (black line).

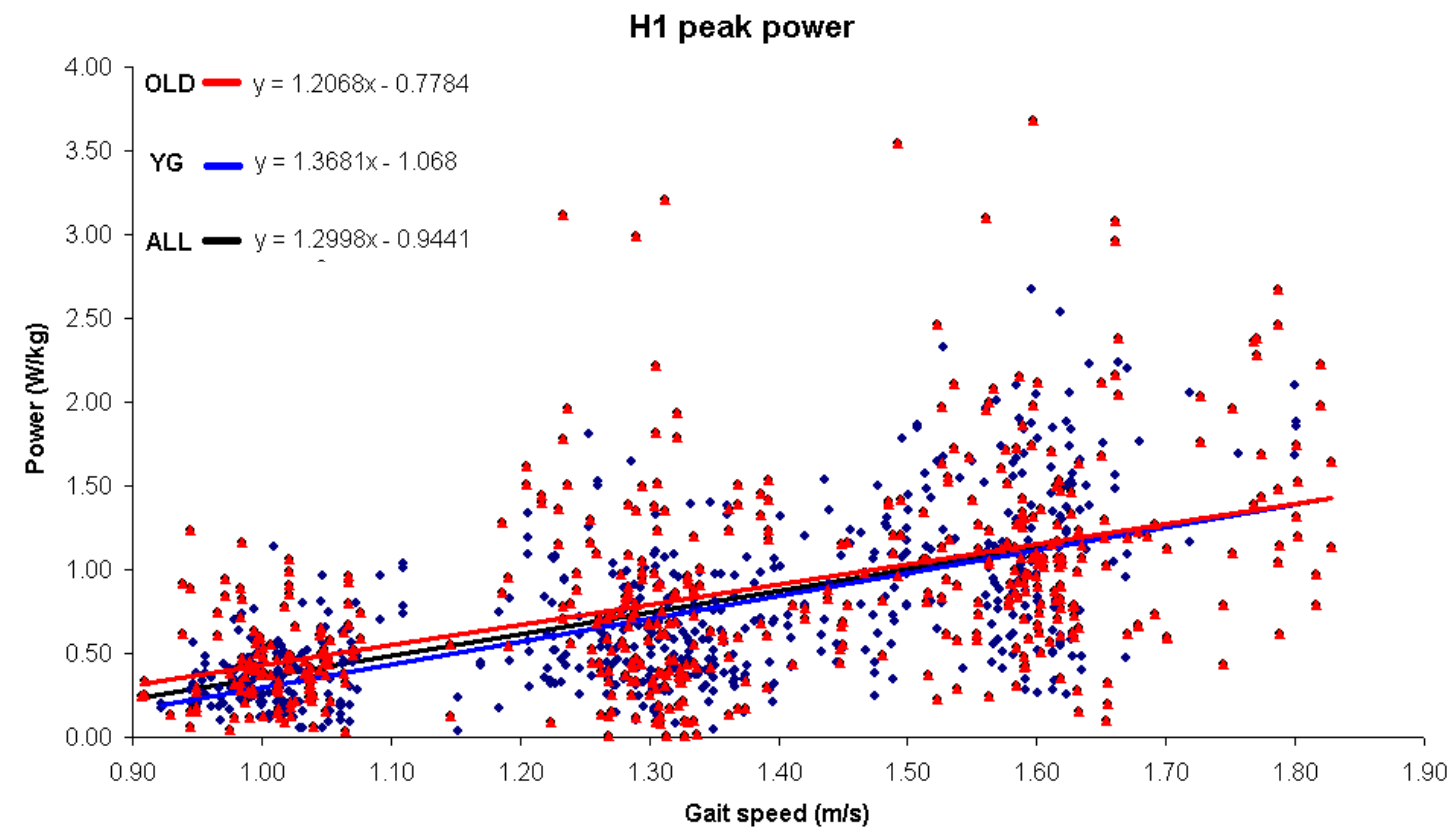

Figure 5.8 Plot shows correlations between $\mathrm{H} 1$ peak power and speed for older adults (red), young adults (blue) and both groups together (black line). 


\section{Chapter 6: Discussion and Conclusion}

There are four major sections in this discussion. These sections are: (1) importance of controlling gait speed when investigating aging gait; (2) neuromuscular adaptations in elderly gait; (3) limitations of the study; and (4) conclusions. The second section is further divided into three sub-sections: (1) importance of ankle function in elderly gait; (2) reliance by elderly on hip muscle activity during gait; and (3) the role of knee flexion in aging gait.

There is general agreement in the literature that ankle joint function is compromised by aging. However, there is little agreement about the compensatory actions made by older adults, compared to young adults, to maintain or increase walking speed. A reason for the lack of agreement probably lies in the fact that studies have not rigorously controlled gait speed. Walking speed is the main determinant of the motor output of gait in healthy humans (Chen et al., 1997, Lelas et al., 2003). It has a major effect upon muscular activity, joint kinetics, joint kinematics and basic spatiotemporal measures of gait (Chen et al., 1997, Kirtley et al., 1985, Lelas et al., 2003, Stansfield et al., 2001, Schwartz et al., 2008, Ivanenko et al., 2006). In this study, walking speed was rigorously controlled by a protocol that employed fixed matched walking speeds for a group of young and older adults. This protocol minimized the influence of speed and hence provided the experimental conditions to better identify age-related neuromuscular adaptations and compensatory actions in aging gait.

The aim of this investigation was to identify and better understand the core or fundamental compensatory actions made by older adults to walk at the same speed as young adults. This information is important in order to gain better insight into the neuromuscular mechanisms behind the emergence of gait changes with aging which may also lead to a dysfunctional gait 


\subsection{Importance of controlling gait speed when investigating aging gait}

It is known that speed has a profound effect on joint kinetics. Lelas et al. (2003) found that relatively small changes $\left( \pm 0.1 \mathrm{~m} \cdot \mathrm{s}^{-1}\right)$ in speed lead to large alterations in joint kinematic and kinetic patterns. For instance, hip peak power, specifically $\mathrm{H} 1$ and $\mathrm{H} 3$ peak power generation, were shown to increase by more than $14 \%$ as walking speed increased from $1.3 \mathrm{~m} \cdot \mathrm{s}^{-1}$ to $1.4 \mathrm{~m} \cdot \mathrm{s}^{-1}$, whereas as walking speed reduced from $1.3 \mathrm{~m} \cdot \mathrm{s}^{-1}$ to $1.2 \mathrm{~m} \cdot \mathrm{s}^{-1}$ these measures fell by $13 \%$. This shows that speed can significantly affect joint kinetics. This may partly explain the failure by Silder et al. (2008) to find significant aging differences in H3 and A2 peak power since speed variability ranged from $0.10 \mathrm{~m} \cdot \mathrm{s}^{-1}$ to $0.16 \mathrm{~m} \cdot \mathrm{s}^{-1}$. Importantly, in the current investigation, gait variability fell below $0.058 \mathrm{~m} \cdot \mathrm{s}^{-1}$ which minimized the confounding influence of speed. This provided the experimental conditions to better compare young and older adult gait patterns.

In this study, the older adults walked faster than the young adults at the selfselected speed (SSN) condition (OLD: $1.49 \mathrm{~m} \cdot \mathrm{s}^{-1}$; YG: $1.39 \mathrm{~m} \cdot \mathrm{s}^{-1}, p<0.05$ ). This finding was unexpected, since previous work found that older adults walk slower than younger adults when self-selected speed protocols are used (Judge et al., 1996a, Kerrigan et al., 1998, McGibbon and Krebs, 1999, McGibbon and Krebs, 2004, Watelain et al., 2000, Winter et al., 1990). This may partly explain why no reductions in step and stride length were found for the older adults in this investigation. It is interesting to note that the older adults' cadence and step length at the SSN speed $\left(1.49 \pm 0.19 \mathrm{~m} \cdot \mathrm{s}^{-1}\right)$ are comparable to the values reported by DeVita and Hortobágyi (2000) for a group of older adults walking at $1.48 \mathrm{~m} \cdot \mathrm{s}^{-1}\left(\mathrm{SD}=0.11 \mathrm{~m} \cdot \mathrm{s}^{-1}\right)$.

The older adults were apparently healthy since no gait, balance, strength deficits (Short Physical Performance Battery) or medical conditions known to affect gait were reported. This may partly explain why they achieved walking speeds higher than what is considered to be a functional speed (Shumway-Cook and Woollacott, 2001). A functional speed is considered to be around $1.4 \mathrm{~m} \cdot \mathrm{s}^{-1}$ which allows older adults to move freely and safely (e.g. pedestrian crossing) in the community (Fildes, 
1994). Other factors such as personality traits may have also influenced the older adults walking speed (Tolea et al., 2010).

The walking protocol in this study involved three fixed matched gait speeds that were not constrained by cadence or step length. Participants were able to freely adjust step/stride length, step width and cadence, so as to allow natural strategies to control gait speed. It has been shown that older adults prefer to modify cadence instead of adjusting step/stride length when walking at similar speeds to young adults (Crowinshield et al., 1978, DeVita and Hortobágyi, 2000). In this study, however, significant age differences in basic spatiotemporal measures of step/stride length and cadence were only found for the $1.6 \mathrm{~m} \cdot \mathrm{s}^{-1}$ walking speed. This observation has been reported by DeVita and Hortobágy (2000) for a group of older adults walking at the same speed $\left(1.48 \mathrm{~m} \cdot \mathrm{s}^{-1}\right)$ as a group of young adults. Therefore, it seems plausible that a speed threshold may exist where healthy older adults choose to increase cadence over increases in step or stride length. This suggests that once a speed threshold is reached, compensatory actions are not sufficient to maintain or increase walking speed by increasing step length. Since an increase in step length is no longer a viable option, the only remaining strategy to walk faster or at speeds above $1.5 \mathrm{~m} \cdot \mathrm{s}^{-1}$ is to increase cadence.

\subsection{Neuromuscular adaptations in elderly gait}

In a review article, McGibbon $(2003 ; 102)$ has defined the neuromuscular adaptations in aging gait as "a response to age-related impairment". Hence, neuromuscular adaptations are most probably the cause of the observed compensatory actions in elderly gait (DeVita and Hortobágyi, 2000, McGibbon, 2003). Based on the findings of the current investigation it is reasonable to classify these actions as either active or passive. An active compensatory action is that produced by increased eccentric or concentric muscular contraction, whereas a passive compensatory action is that generated by increased storage and return of elastic energy from the muscletendon unit. For example, increased activity of iliopsoas muscle during H3 peak power results in an active compensatory action that pulls the leg into swing. On the other hand, increased stretching of rectus femoris during $\mathrm{K} 4$ peak power (storage of 
elastic energy), results in a passive compensatory action that transfers energy from the knee to the hip to help propel the limb into swing.

It is thought that compensatory actions in elderly gait emanate from increased activity of the hip flexor and extensor muscles. However, it is still not clear as to which muscle group compensates for impairments leading to decreased ankle plantar flexor function with aging (McGibbon, 2003). In this investigation, H3 peak power and mechanical work were found to be greater in the older adults at the SSN and 1.6 $\mathrm{m} \cdot \mathrm{s}^{-1}$ speeds. This supports the idea that increased activation of hip flexors probably compensates for decreased ankle plantar flexor function in older adult gait (refer to figure 6.1). It is likely that the increased (although not significant) H1 peak power serves to stabilize the pelvis and trunk in older adult gait (McGibbon, 2003).

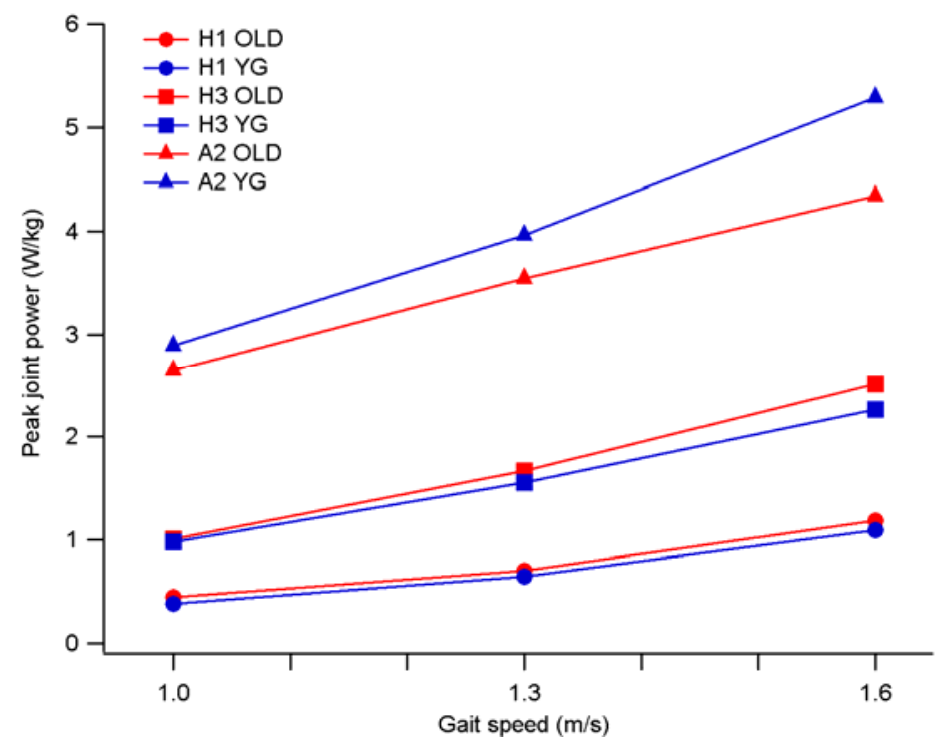

Figure 6.1 Plots of mean $\mathrm{H} 1, \mathrm{H} 3$ and A2 peak joint powers for the three matched speeds for the older (OLD) and young adult (YG) groups.

DeVita and Hortobágyi (2000) have proposed that compensatory actions are not required when older adults walk at slow speeds. In the current investigation when both groups walked at $1.0 \mathrm{~m} \cdot \mathrm{s}^{-1}$, a relatively slow speed, compensatory actions associated with forward propulsion of the body were not evident in the older adults. This is probably due to the fact that at slow walking speeds the propulsive requirements are much lower. 
The older adults in this study exhibited less A2 peak power (strong predictor of step length and gait speed). However, the basic spatiotemporal gait characteristics (step/stride length, cadence and gait speed) of the older adults were comparable to those exhibited by the young adults at the $1.0 \mathrm{~m} \cdot \mathrm{s}^{-1}$ and $1.3 \mathrm{~m} \cdot \mathrm{s}^{-1}$ speeds but not at SSN and $1.6 \mathrm{~m} \cdot \mathrm{s}^{-1}$ speeds. These outcomes may be due to decreased $\mathrm{K} 5$ power and increased $\mathrm{H} 2$ power in the older adults (Watelain et al., 2000). Again, this suggests the existence of a speed threshold at around $1.5 \mathrm{~m} \cdot \mathrm{s}^{-1}$, above which the older adults choose to increase cadence to increase gait speed. This strategy may be implemented by the older adults as a safer way to increase gait speed since increases in step length have been linked to greater falls risk (Espy et al., 2010).

The loss of ankle joint function observed in older adults may be due to a loss of type II fibers in the plantar flexor muscles (Coggan et al., 1992) and increased antagonist activity, commonly referred to as co-activation (Hortobágyi and DeVita, 2006). The neuromuscular adaptations observed in the older adults most likely emanate from increased iliopsoas and rectus femoris activity coupled with an increased return of elastic energy from passive structures.

\subsubsection{Importance of ankle function in elderly gait}

A reduction in ankle plantar flexion motion in elderly gait has been widely reported and confirmed in this investigation (DeVita and Hortobágyi, 2000, Judge et al., 1996a, Kerrigan et al., 1998, Monaco et al., 2009, Silder et al., 2008, Begg and Sparrow, 2006, Ostrosky et al., 1994, Prince et al., 1997, Ko et al., 2009). Importantly, this kinematic change has been associated with a reduction in ankle plantar flexor power generation (DeVita and Hortobágyi, 2000, Judge et al., 1996a, Kerrigan et al., 1998, Monaco et al., 2009, Watelain et al., 2000, Winter et al., 1990). Although the role of ankle plantar flexion remains controversial (Sadeghi, 2003), it is thought to be the major contributor to the forward propulsion of the body (Meinders et al., 1998, Winter, 1983a) and a strong predictor of step length (Judge et al., 1996a). Hence, the significant A2 reduction found in the older adults for the $1.6 \mathrm{~m} \cdot \mathrm{s}^{-1}$ speed in this investigation may explain the aging reductions in step/stride length and associated increase in cadence. These changes in step/stride length and cadence were not 
observed for the $1.0 \mathrm{~m} \cdot \mathrm{s}^{-1}, 1.3 \mathrm{~m} \cdot \mathrm{s}^{-1}$ and SSN speeds. At these speeds it is likely that the increased $\mathrm{H} 3$ peak power observed in the elderly compensated for the reduction in A2 peak power generation.

For the SSN speed, the older adults walked faster $(p<0.05)$ and generated less A2 peak power and mechanical work than the young adults. These findings are partly supported by Kerrigan et al. (1998) who also found A2 peak power to be lower in a group of older adults walking faster $(p<0.05)$ than a group of young adults (OLD: $1.55 \mathrm{~m} \cdot \mathrm{s}^{-1}$; YG: $1.37 \mathrm{~m} \cdot \mathrm{s}^{-1}$ ). This shows that older adults do not increase gait speed by increasing A2 peak power but employ compensatory actions from the more proximal joints.

Lower activity of the soleus during late stance (Schmitz et al., 2009) may be responsible for the observed reduction in A2 peak power and mechanical work found in the older adults for the $1.3 \mathrm{~m} \cdot \mathrm{s}^{-1}$ and $1.6 \mathrm{~m} \cdot \mathrm{s}^{-1}$ speeds. It is thought that soleus is the major contributor to the ankle plantar flexion at the end of stance (Stewart et al., 2007) and is crucial in propelling the body forward. It is also thought that ankle plantar flexor power is assisted by the elastic energy stored in the Achilles tendon as gastrocnemius is activated from midstance to heel-off (Neptune et al., 2004, Neptune et al., 2001, Stewart et al., 2007, Schmitz et al., 2009). It is known that gastrocnemius activity during gait is relatively maintained with aging (Schmitz et al., 2009), therefore reductions in A2 may be mainly caused by reductions in soleus activity. This shows that soleus muscle power may be an important determinant of aging gait (figure 6.2). 


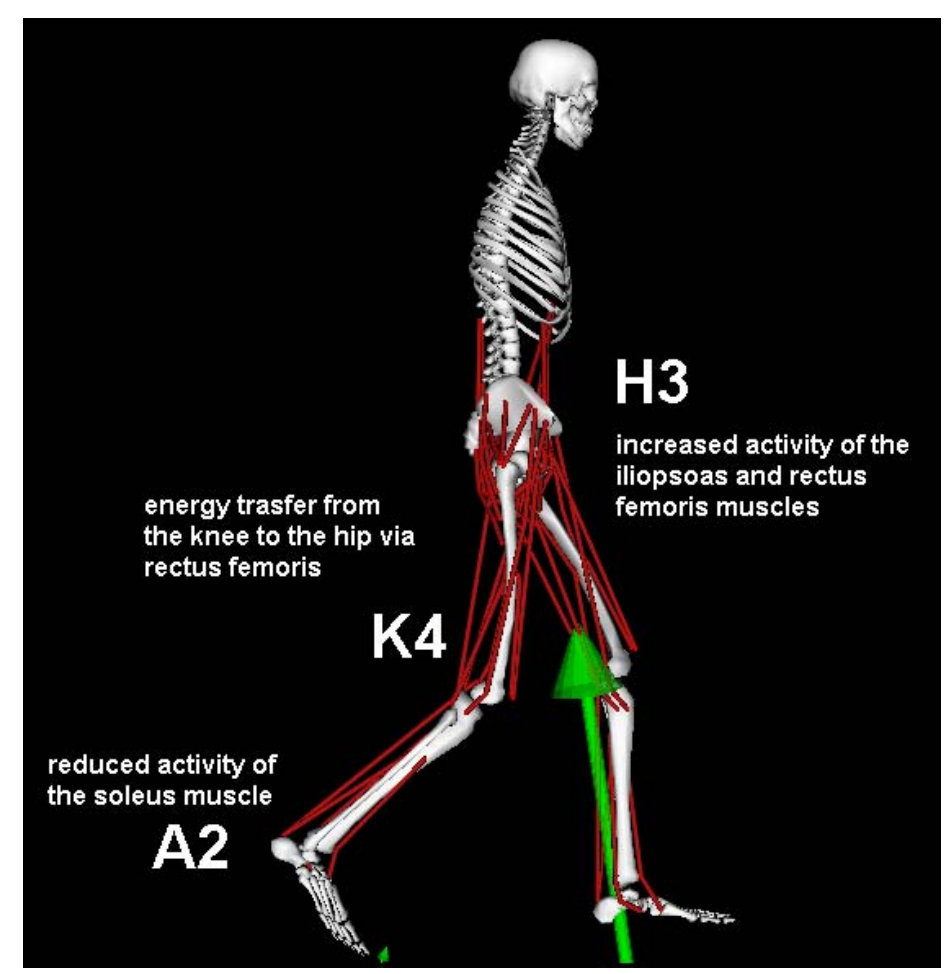

Figure 6.2 Schematic representation of the aging affect on A2, K4 and H3 peak power observed in older adult gait in this study.

Atrophy of the type II muscle fibers (Coggan et al., 1992) and a diminished capacity to generate muscle power by the ankle plantar flexors (Gajdosik et al., 1999) have been reported in older adults. Other age-related changes in the muscle-tendon unit include increased tendon stiffness and more intramuscular non-contractile elements (Kent-Braun et al., 2000, Narici and Maffulli, 2010, Tuite et al., 1997). It is highly likely that these factors reduce the capacity to store elastic energy during A1 peak power absorption which was found to be significantly lower in the older adults in this study (except at $1.0 \mathrm{~m} \cdot \mathrm{s}^{-1}$ speed). As a result of these changes, less elastic energy is returned (stored during A1) and less muscle power is generated during A2 power by the ankle plantar flexors. This would increase the need to generate more power by the more proximal muscles to pull the leg into swing. 
Schmitz et al. (2009) has shown that young and older adults exhibit similar patterns of soleus activity when walking at slow speed. This may partly explain why the young and older adults in this study exhibited similar A1 and A2 peak powers and associated mechanical work for the $1.0 \mathrm{~m} \cdot \mathrm{s}^{-1}$ speed. Moreover, decreased soleus and gastrocnemius activity (den Otter et al., 2004) and decreased recovery of elastic energy (Neptune et al., 2008) have been observed when walking speed decreases. It is thought that slow speeds diminish peak ground reaction forces and leads to reduced activity of the ankle plantar flexors (af Klint et al., 2010, Stansfield et al., 2001). Furthermore, lower A2 peak power and mechanical work generation for the $1.0 \mathrm{~m} \cdot \mathrm{s}^{-1}$ speed may be a strategy to maintain balance rather than propel the body forward (Liu et al., 2008).

A2 power reduction has been linked to reduced ankle plantar flexor strength (Judge et al., 1996a, Silder et al., 2008). However, interventions that have included strengthening of these muscles have only shown weak correlations with gait functionality improvements (i.e. gait speed) (Lopopolo et al., 2006). Considering that muscle power is more affected than muscle strength by aging (Skelton et al., 1994), it seems reasonable to propose that therapies and interventions should target muscle power and elasticity of the ankle plantar flexors.

\subsubsection{Reliance by the elderly on hip muscle activity during gait}

Previous studies (Kerrigan et al. 1998; 2003) have found that older adults walk with less hip extension than young adults. In contrast, this study found that average hip extension was around $1^{\circ}$ greater in the older adults. This finding is supported by Silder et al. (2008) who similarly found older adults walk with about $1^{\circ}$ more hip extension. It is important to note that in the current investigation, maximum hip extension in the young adults was around $15^{\circ}$ for the SSN speed $\left(1.39 \mathrm{~m} \cdot \mathrm{s}^{-1}\right)$. This is similar to magnitudes reported in earlier investigations (Judge et al., 1996a, McGibbon and Krebs, 2004, Silder et al., 2008, Winter et al., 1990) but falls well below the magnitudes $\left(21^{\circ}\right)$ reported by Kerrigan et al. (1998) for a walking speed of $1.37 \mathrm{~m} \cdot \mathrm{s}^{-1}$. It is possible that greater hip extension observed in the older adults in the 
current investigation serves to increase elastic energy stored during the period of $\mathrm{H} 2$ power absorption leading to greater energy return to help propel the limb into swing.

Studies have reported increased anterior pelvic tilt (Judge et al., 1996a, Kerrigan et al., 1998, Røislien et al., 2009) associated with less hip extension brought about by hip flexor contracture in gait with aging (Kerrigan et al., 2001, Kerrigan et al., 1998, Lee et al., 2005, DeVita and Hortobágyi, 2000). This study also found increased anterior pelvic tilt but it was not associated with decreased hip extension nor muscle contracture since the integrity of the hip flexors length was confirmed by the Thomas test (Peeler and Anderson, 2007). It is possible that the increased pelvic tilt in the older adults was brought about by abdominal muscle weakness that makes the control of pelvic tilt more difficult during gait (Røislien et al., 2009).

The increased anterior pelvic tilt in the older adults was associated with a small increase in hip extension. These actions would increase the stretch of the iliopsoas muscle leading to increased storage and return of elastic energy for propelling the leg into swing. It is important to note that the magnitudes of pelvic tilt found in this investigation agree with the magnitudes (OLD: $14^{\circ}$; YG: $10^{\circ}$ ) reported by Judge et al. (1996) but not with the magnitudes (OLD: $2.7^{\circ}$; YG: $0.03^{\circ}$ ) reported by Kerrigan et al. (1998). This lack of agreement with Kerrigan et al's study may be due to the fact that the current investigation used a similar motion capture system and modeling process as Judge et al (1996).

It is still not clear as to what is the main role of the hip extensor joint power (H1) during the first half of stance (McGibbon, 2003). It is thought that $\mathrm{H} 1$ power and mechanical work generation assist trunk stabilization, forward propulsion of the body and contra-lateral limb swing initiation (McGibbon, 2003, McGibbon and Krebs, 2004, Winter and Eng, 1995, DeVita and Hortobágyi, 2000). It has been proposed by DeVita and Hortobágyi (2000) that in order to walk at the same speed as young adults, older adults increase $\mathrm{H} 1$ peak power to overcome the loss of A2 peak power. The current investigation, however, did not find any significant aging effect on $\mathrm{H} 1$ peak power and mechanical work generation. It is difficult to compare the outcomes of these studies since the older adults in DeVita and Hortobágyi's study walked with 
significantly $(p<0.05)$ higher cadence, shorter steps and less hip extension than the young adults.

Lewis and Ferris (2008) found no major change in H1 peak power generation when adults voluntarily decreased A2 peak power generation when walking at set speeds and similar step lengths. Therefore, it is reasonable to propose that the primary function of the observed increase in $\mathrm{H} 1$ peak power (though non-significant) by the older adults in the current investigation served to stabilize the pelvis and trunk (figure 6.3) (Allard et al., 1996, Eng and Winter, 1995, McGibbon and Krebs, 2004). This idea is supported by gait simulation studies that showed the gluteus maximus contributes more to support than forward progression of the body as walking speed increases (Liu et al., 2008, Neptune et al., 2008).

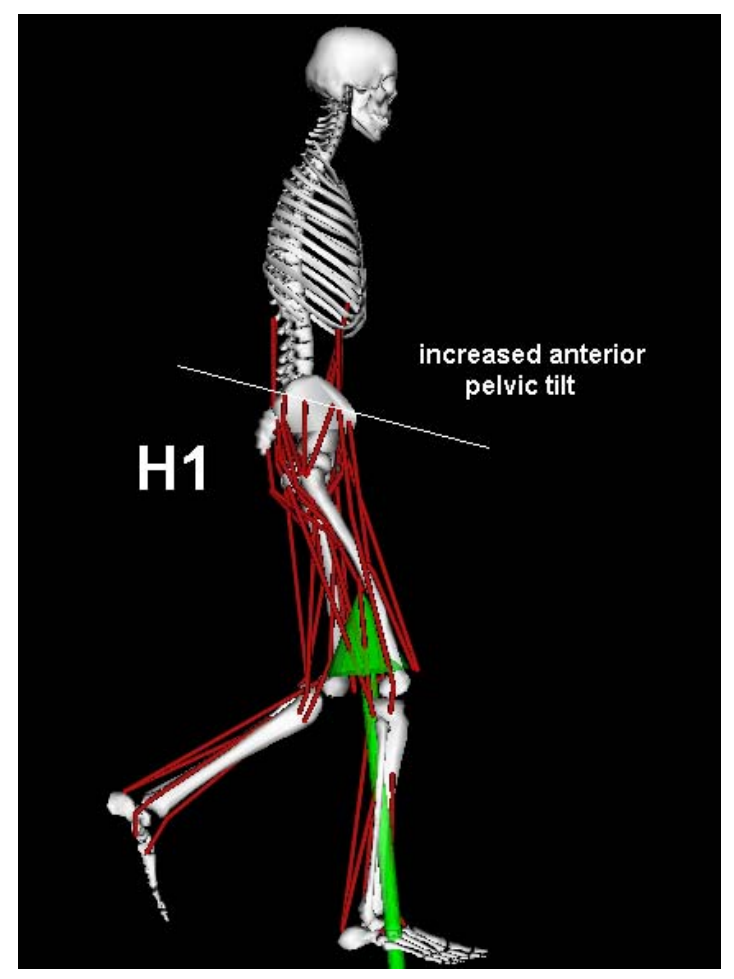

Figure 6.3 Schematic representation of the aging affect on $\mathrm{H} 1$ peak power observed in older adult gait in this study. 
It is thought that increased $\mathrm{H} 2$ peak power and mechanical work helps propel the leg into swing (McGibbon, 2003) whereas a decrease may account for a shorter stride (Watelain et al., 2000). Except at the $1.6 \mathrm{~m} \cdot \mathrm{s}^{-1}$ speed, the older adults in this investigation produced greater $\mathrm{H} 2$ peak power and mechanical work $(\mathrm{p}<0.05)$ but walked with similar step/stride lengths to the young adults. It seems reasonable that the role of increased $\mathrm{H} 2$ peak power and mechanical work observed at the $1.0 \mathrm{~m} \cdot \mathrm{s}^{-1}$ and $1.3 \mathrm{~m} \cdot \mathrm{s}^{-1}$ speeds in the older adults may have served to achieve similar step/stride length and speed as young adults (Watelain et al., 2000).

Tendon stiffness is known to increase with aging (Tuite et al., 1997) which may increase the elastic energy stored in the iliopsoas during the period of H2 peak power and ultimately contribute to the energy used to propel the limb into swing (McGibbon, 2003, Reich et al., 2000). However, Silder et al. (2008) found older adults were not more reliant on the periarticular passive structures of the hip joint to increase limb propulsion through hip flexor power than young adults (Silder et al., 2008). In a gait simulation study, Neptune et al. (2008) reported that the magnitude of stretch of the hip flexors during gait is probably not sufficient to store elastic energy. However, the stretching of other soft tissues (e.g. joint capsule) does store elastic energy which reduces the work by the iliopsoas to pull the leg into swing (Neptune et al., 2008). The discrepancies about the contribution of stored elastic energy in the hip flexors during $\mathrm{H} 2$ may lie in the different characteristics of tendon stiffness in people (Neptune et al., 2008). However, it is also possible that current techniques used to investigate the passive contribution (i.e. return of elastic energy) may not reflect the actual muscle-tendon behaviour when muscles are actively stretched during gait.

Greater maximum hip flexion $(p<0.05)$ in the older adults was found for the $1.0 \mathrm{~m} \cdot \mathrm{s}^{-1}$ and $1.3 \mathrm{~m} \cdot \mathrm{s}^{-1}$ speeds. Although not significant, previous studies have also reported greater hip flexion with aging (Ostrosky et al., 1994, Silder et al., 2008, Monaco et al., 2009, Mills and Barrett, 2001). At the $1.6 \mathrm{~m} \cdot \mathrm{s}^{-1}$ speed, however, hip flexion did not differ between the groups. This may be explained by the fact that the older adults took shorter steps with greater cadence $(p<0.05)$ than the young adults. Other possibilities may be that increased hip flexion during gait leads to increases in 
instability or that increased stiffness of the hip extensors restricts greater hip flexion of older adults in final swing.

The older adults exhibited greater $\mathrm{H} 3$ peak power and mechanical work than young adults for the $1.6 \mathrm{~m} \cdot \mathrm{s}^{-1}$ and self-selected speeds. However, for the SSN condition the older adults walked faster than the young adults. This most likely account for higher hip flexor power used by the elderly to propel the body forward. Silder et al. (2008) also found that H3 mechanical work was greater in older adults than young adults when walking at self-selected fast speed. Judge et al. (1996a) suggested that in order to compensate for a loss in A2 power, older adults increase H3 power even when walking slower than young adults. An important finding of this current investigation was that for the $1.6 \mathrm{~m} \cdot \mathrm{s}^{-1}$ speed, the $\mathrm{H} 3$ mechanical work by the older adults was greater than the A2 mechanical work (refer to figure 6.4). This finding was unexpected since previous significant work by Winter et al. (1991) reported that A2 power contains the greatest amount of mechanical work in the sagittal plane for different cadences.

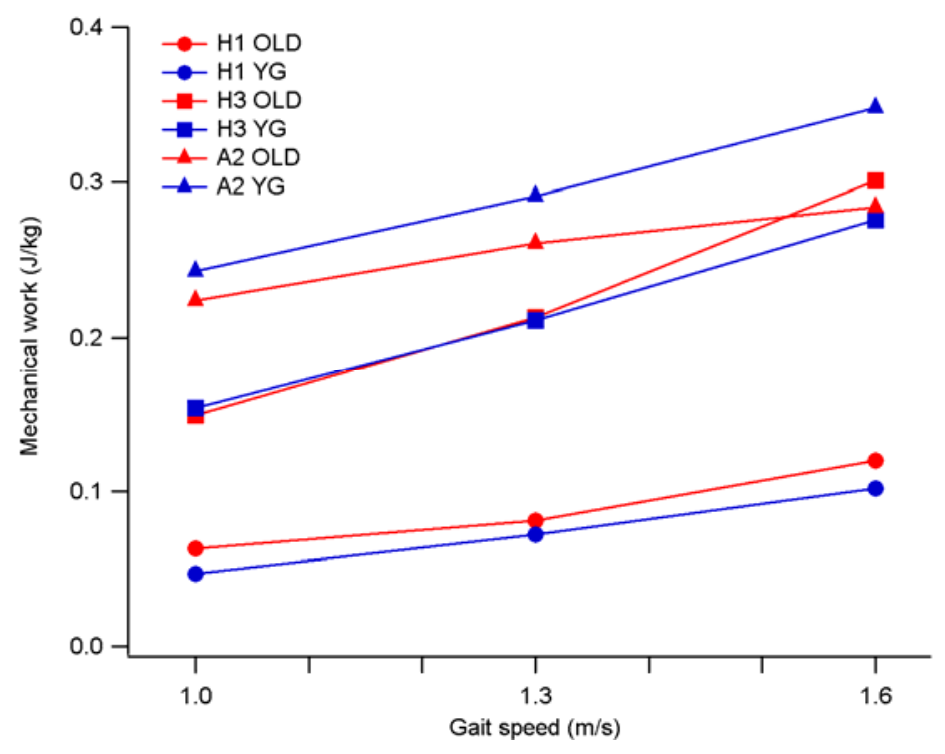

Figure 6.4 Plots of mean $\mathrm{H} 1, \mathrm{H} 3$ and A2 mechanical work for the three matched speeds for the older (OLD) and young adult (YG) groups. 
Increased iliopsoas and rectus femoris muscle activity most probably accounts for the increased H3 peak power and mechanical work in older adults (Schmitz et al., 2009). It is also possible that older adults use energy stored through passive stretch of these muscles as a mechanism to help pull the leg into swing (McGibbon, 2003, McGibbon and Krebs, 2004, Whittington et al., 2008). The recovery of elastic energy reduces the active work by the iliopsoas (Neptune et al., 2008) whereas the stretch of the rectus femoris transfers energy from the knee to the hip (Whittington et al., 2008). It has been shown that iliopsoas and rectus femoris activity (Ivanenko et al., 2006) as well as the contribution of passive structures to $\mathrm{H} 3$ peak power increase with speed (Whittington et al., 2008, Silder et al., 2008). These strategies most probably explain the significant $\mathrm{H} 3$ peak power and mechanical work differences found between the young and older adults for the $1.6 \mathrm{~m} \cdot \mathrm{s}^{-1}$ and SSN speeds.

$\mathrm{H} 3$ and $\mathrm{A} 2$ peak power and mechanical work did not differ between the young and the older adults for the $1.0 \mathrm{~m} \cdot \mathrm{s}^{-1}$. This indicates that at slower speeds, compensatory actions are not necessary to maintain step/stride length and ultimately gait speed. For the $1.3 \mathrm{~m} \cdot \mathrm{s}^{-1}$ speed, the older adults compensated a loss in A2 peak power by increasing H3 peak power. It is important to note that these differences were not significant after a Bonferroni correction. However, it seems plausible that the loss of A2 peak power in older adults required another compensatory action from the knee joint. The observed K5 peak power reduction in older adults $(p<0.05)$, for example, may also help them to walk with similar step length to young adults.

\subsubsection{The role of knee flexion in aging gait}

For the $1.0 \mathrm{~m} \cdot \mathrm{s}^{-1}$ speed, the older adults generated greater $\mathrm{K} 0$ peak power and mechanical work than the young adults. This strategy was not implemented for the other speeds. The older adults probably used this strategy so as to increase stability at the slow walking speed (den Otter et al., 2004). In contrast, the young adults generated greater $\mathrm{K} 0$ peak power for the $1.6 \mathrm{~m} \cdot \mathrm{s}^{-1}$ walking speed. This action ensures the knee is flexed and stable at initial contact especially when gait speed is increased through longer steps. 
In early stance, the older adults produced significantly less K1 peak power and mechanical work at all speed conditions. At this point of the gait cycle, the vastus medialis and lateralis muscles contract eccentrically and control the rate of knee flexion to prevent the collapse of the body (Nene et al., 2004, Sadeghi et al., 2004, Winter et al., 1995). These aging differences increased with walking speed with the greatest effect at $1.6 \mathrm{~m} \cdot \mathrm{s}^{-1}$ walking speed. For this fast walking speed, the young adults took longer steps but had lower cadence than the older adults. As a result of taking longer steps to increase gait speed, the young adults needed to increase eccentric knee power to deal with a greater foot-ground impact. This is probably linked to a reduction in vastus lateralis activity since Schmitz et al. (2009) observed that older adults reduce this activity when walking at a relatively fast speed $\left(1.58 \mathrm{~m} \cdot \mathrm{s}^{-1}\right)$. A deficit in knee extensor eccentric power may explain the observed reductions in K1 for the older adults, since it is known that eccentric strength is relatively preserved in older adults (Roig et al., 2010).

In early stance the older adults generated significantly less K2 peak power and mechanical work for the $1.3 \mathrm{~m} \cdot \mathrm{s}^{-1}$ and $1.6 \mathrm{~m} \cdot \mathrm{s}^{-1}$ speeds. This power is produced by concentric contraction of the monoarticular knee extensors. The reduction in K2 peak power may result from a more rapid decline in muscle concentric power than strength in the knee extensor muscles with aging (Skelton et al., 1994). Schmitz et al. (2009), however, found that at this stage of the gait cycle (during K2 peak power), older adults displayed significantly higher vastus lateralis activity when walking at a selfselected fast speed. This finding was attributed to increased co-activation with the biceps femoris muscle so as to enhance gait stability. It is also possible that the high negative correlation found between $\mathrm{K} 1$ and $\mathrm{K} 2$ peak power and mechanical work in the current investigation suggests that reduced power absorption requires less power generation during the early stance of gait (figure 6.5). 


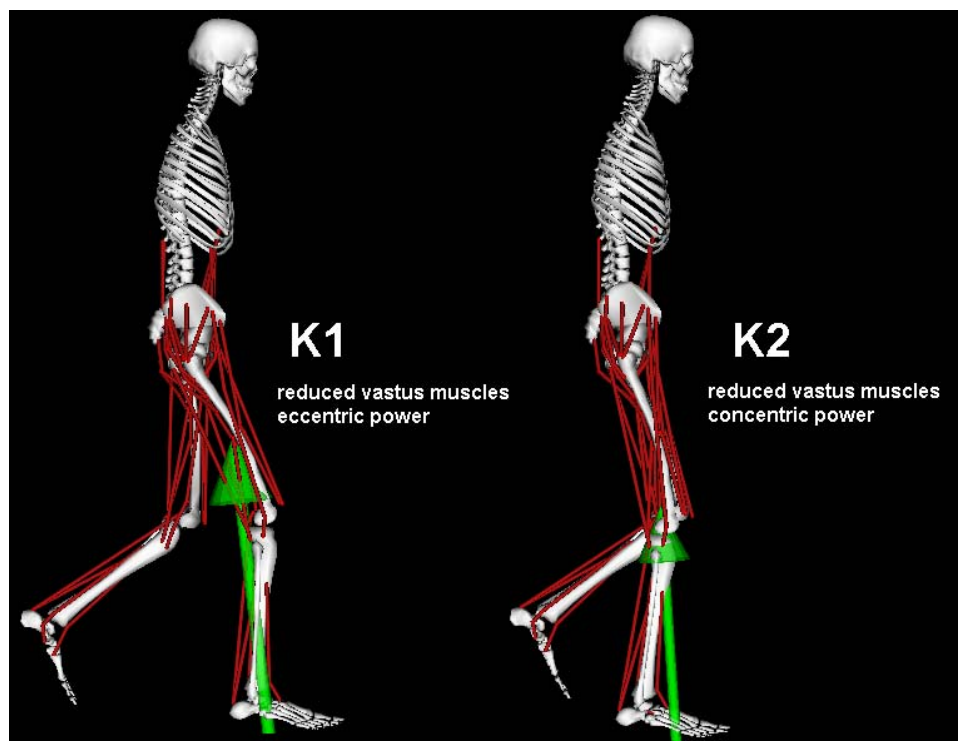

Figure 6.5 Schematic representation of the aging affect on $\mathrm{K} 1$ and $\mathrm{K} 2$ peak powers observed in the older adult gait in this study.

In late stance the older adults generated significantly greater $\mathrm{K} 3$ peak power and mechanical work for the $1.3 \mathrm{~m} \cdot \mathrm{s}^{-1}$ and $1.6 \mathrm{~m} \cdot \mathrm{s}^{-1}$ speeds. This power is produced by concentric activity of the gastrocnemius which has been reported to be greater in older adult gait (Schmitz et al., 2009). It seems likely that most of the gastrocnemius muscle work performed at this point of the gait cycle is used to flex the knee instead of generating more ankle plantar flexor power (Stewart et al., 2007). Moreover, it may cause rapid stretching of the rectus femoris leading to greater storage of elastic energy and triggering muscle activity through the stretch reflex. It is important to note that K3 peak power has only been reported in the gait literature by McGibbon et al. (1999 and 2004). K3 peak power deficiency has been identified in older adults with knee and hip OA (McGibbon and Krebs, 2002) and other major systemic and musculoskeletal problems (McGibbon and Krebs, 2004).

Many studies have reported that older adults produce greater K4 peak power and mechanical work than young adults when walking at comparable, faster or slower speeds (Kerrigan et al., 1998, McGibbon and Krebs, 2004, Monaco et al., 2009, Winter et al., 1990). The current investigation also found that older adults produce significantly greater $\mathrm{K} 4$ peak power for the $1.3 \mathrm{~m} \cdot \mathrm{s}^{-1}$ and $1.6 \mathrm{~m} \cdot \mathrm{s}^{-1}$ speeds, whereas mechanical work differences were small. A strategy involving an increase in K4 peak 
power is probably used to produce more stretch in the rectus femoris so as to induce greater muscular activity in aging gait (Chung and Wang, 2010). It has been observed that rectus femoris activity mainly occurs during late stance and initial swing for speeds over $1.3 \mathrm{~m} \cdot \mathrm{s}^{-1}$, whereas at slower speeds its activity is small (Hof et al., 2002, Nene et al., 2004). This explains why there was no aging effect in K4 peak power for the $1.0 \mathrm{~m} \cdot \mathrm{s}^{-1}$ in the current investigation.

An alternative role of the rectus femoris during late stance and initial swing may be to restrict knee flexion produced by the gastrocnemius after heel-off (Nene et al., 2004). However, it seems that its main role is to increase energy transfer from the knee to the hip in order to produce higher $\mathrm{H} 3$ peak power to pull the limb into swing (Whittington et al., 2008, Neptune et al., 2008). In the current investigation, increased $\mathrm{K} 4$ peak power and mechanical work were coupled with increased $\mathrm{H} 3$ peak power and mechanical work was more evident in the older adults. These parameters exhibited very high correlations which supports the premise that increased K4 absorption assists H3 power. This compensatory action helps propel the body forward in elderly gait. It is reasonable to propose the existence of an energy flow in older adult gait where K3 power produces a rapid stretch of the rectus femoris leading to increased K4 power which ultimately results in greater energy transfer to the hip for the generation of $\mathrm{H} 3$ power.

It has been reported that in older adults, quadriceps strength is a strong predictor of the ability to walk at fast speeds (Callisaya et al., 2010a, Gibbs et al., 1996). This association is explainable by the mechanisms previously described which may allow a faster speed in older adults by increasing the activity of the rectus femoris muscle (Whittington et al., 2008).

During late swing, the older adults produced significantly less K5 peak power and mechanical work at the $1.0 \mathrm{~m} \cdot \mathrm{s}^{-1}$ and $1.3 \mathrm{~m} \cdot \mathrm{s}^{-1}$ speeds. This power is produced by eccentric contraction of the hamstrings muscles to decelerate the forward rotation of the tibia (figure 6.6). The reductions in $\mathrm{K} 5$ power observed in the older adults probably help to maintain the same step/stride length as young adults when walking at the $1.0 \mathrm{~m} \cdot \mathrm{s}^{-1}$ and $1.3 \mathrm{~m} \cdot \mathrm{s}^{-1}$ speeds (Watelain et al., 2000). Although not acknowledged, 
the plots of hamstrings activity during gait for the older adult group in Schmitz et al.'s $(2009 ; 1088)$ paper show increased activity when walking at a speed of $1.58 \mathrm{~m} \cdot \mathrm{s}^{-1}$. This provides some explanation of why no significant aging effect in K5 power absorption was found for the $1.6 \mathrm{~m} \cdot \mathrm{s}^{-1}$ speed. Hamstring muscles also restrict hip flexion, hence it seems feasible that this mechanism may be responsible for the failure to find an aging effect in maximum hip flexion at the $1.6 \mathrm{~m} \cdot \mathrm{s}^{-1}$ speed. It is thought that reductions in K5 power can compromise gait stability. This may partly explain the increased cadence used by the older adults to achieve same speed as young adults (Watelain et al., 2000). It is important to recognize that the presence of hamstrings contracture may limit hip flexion and knee extension in older adult during late swing. This would impede older adults from achieving the same gait speed as young adults through increases in step/stride length. Future studies should consider assessing hamstrings contracture when studying elderly gait.

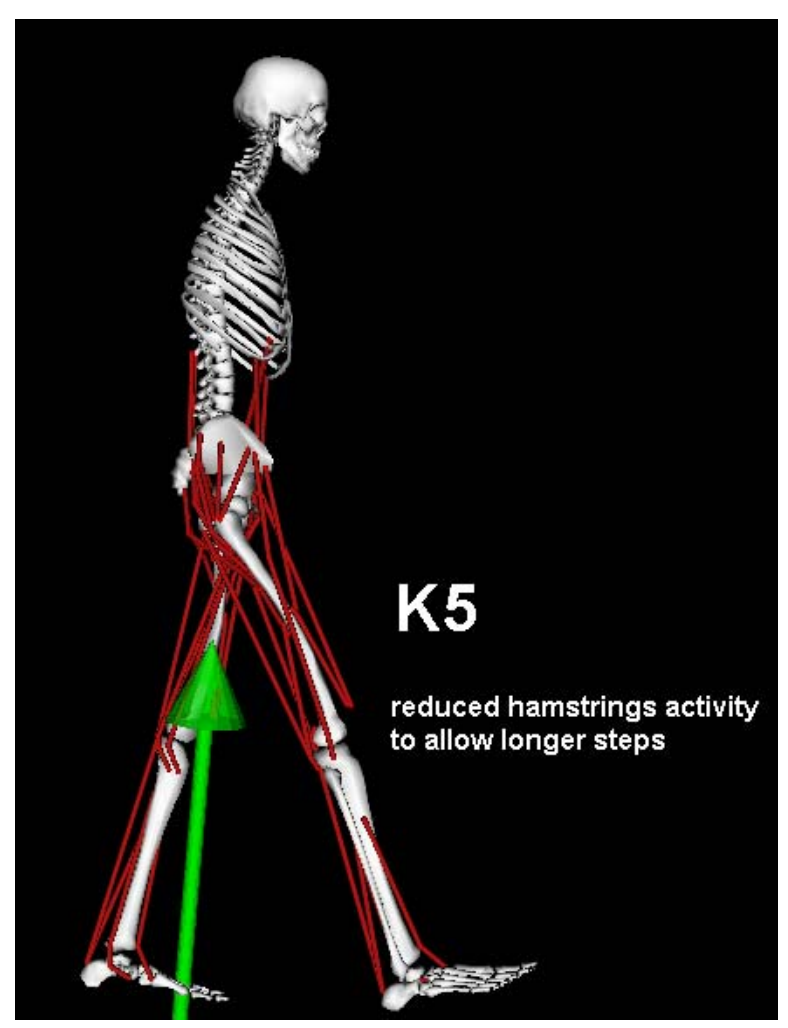

Figure 6.6 Schematic representation of the aging affect on K5 peak powers observed in the older adult gait in this study. 


\subsection{Limitations of the study}

There were two important limitations in this study. First, only the kinematics and kinetics in the sagittal plane were analyzed. Second, the Plug-in-Gait model contains recognized simplifications due to the use of manufacturer specific anthropometric regression equations (Schwartz et al., 2008).

This study did not assess hamstrings contracture, therefore it is not possible to determine whether the $\mathrm{K} 5$ peak power increase was due to a stiffer muscle restricting knee extension and hip flexion in late swing at faster speeds.

This study did not analyze possible compensatory actions produced by the lower back and trunk movements that may have affected pelvic and hip motion and kinetics. 


\subsection{Conclusions}

The neuromuscular adaptations and core compensatory actions made by a group of older adults when walking at self-selected speed and at a range of matched speeds compared to a group of young adults were identified in this investigation. This information is important in order to better understand the neuromuscular mechanisms behind the emergence of gait changes with healthy aging. Identifying how gait changes with aging is vital since it impacts on the capacity to perform daily life tasks and independence. These factors ultimately affect socialization, well-being and the quality of life.

It is known that during walking ankle function reduces with aging. There remains, however, no consensus as to what fundamental or core compensatory actions occur at the knee and hip in order to maintain gait functionality. This investigation shows that a reason for the lack of agreement can be attributed to a failure by studies to adequately control the confounding influence of speed. It is well known that speed affects joint kinematics, joint kinetics and basic spatiotemporal measures of gait. This investigation rigorously controlled speed and minimized speed variability without constraining the natural over-ground gait pattern.

This investigation showed that ankle plantar flexor function is influenced by aging. The older adults used less ankle plantar flexion motion and less A2 power generation when walking at the same speeds as young adults. These outcomes were more evident as gait speed increased. It seems reasonable to conclude that this loss of ankle power is probably due to a diminished ability to generate concentric power by the soleus muscle coupled with a diminished capacity to return elastic energy stored by the ankle plantar flexors during the period of A1 power absorption period (between midstance and heel-off). 
The older adults were found to rely more on hip extensor power (H1) to propel the body forward during early stance. It seems likely that older adults used hip extensor power to help stabilize the pelvis since there was greater anterior pelvic tilt in this group. This counters work by DeVita and Hortobágyi (2000) who found increased hip extensor power generation to be the main compensatory action used by older adults to ambulate when ankle function is diminished with aging.

The older adults hip flexor function was greater than young adults at all walking speeds. Hence, increased hip flexor activity during $\mathrm{H} 3$ power, therefore, is the core compensatory action used to propel the body forward when ankle plantar flexor function is compromised. This is supported by previous work by Lewis and Ferris (2008) who found the natural response made by adults to maintain speed and step length after voluntarily reducing ankle plantar flexor power was to increase hip flexor joint power.

The observed increases in hip power absorption (H2) during midstance indicate that older adults take advantage of elastic energy stored by the muscle-tendon units of the hip flexors to increase energy return to help propel the body forward. This is supported by the strong correlations, particularly for the older adults, found between hip flexor power (H3) and K4 absorption. This supports the idea that energy is transferred from the knee to the hip (via rectus femoris) in order to increase hip flexor function during late stance so as to help pull the leg into swing. It is possible that this mechanism explains why reduced knee extensor muscle strength has been directly linked to reduced gait functionality in older adults (Callisaya et al., 2010b).

Stewart et al. (2007) have shown that the primary role of the gastrocnemius is to flex the knee whereas the primary role of soleus is to plantar flex the ankle in the period between heel-off and toe-off. This investigation showed that decreases in A2 power were coupled with increases in K3 power in the older adults. With these facts in mind, it is reasonable to conclude that the older adults compensated for reduced soleus activity by increasing gastrocnemius activity. 
The older adults produced less knee power absorption (K5) during late swing for the slower walking speeds. This strategy probably allows older adults to take similar step and stride lengths as young adults. Watelain et al. (2000), however, have argued that this strategy may make the gait of an older adult more unstable. This may explain why this strategy was not used by the older adults at the $1.6 \mathrm{~m} \cdot \mathrm{s}^{-1}$ speed. It seems that when walking at fast speeds it is safer for an older adult to reduce step/stride length and increase cadence.

The majority of the age differences were found for the fast walking speed (1.6 $\left.\mathrm{m} \cdot \mathrm{s}^{-1}\right)$. This signals the existence of a speed threshold above which older adults generate a gait pattern that is inherently different to that of a young adult. It also shows that compensatory actions at the hip and knee are not sufficient to increase or maintain speed. Above this threshold, the only viable option for an older adult to maintain speed and stability in elderly gait is to increase cadence.

The majority of the compensatory actions made by the older adults were used to pull the leg into swing to advance the body. These include increased K3 and H3 power generation, and increased $\mathrm{K} 4$ and $\mathrm{H} 2$ power absorption. The knee joint powers reflect an increased contribution by rectus femoris whereas the hip joint powers reflect an increased contribution by the iliopsoas muscle.

Heel-off was found to be a critical point in the gait cycle. This event delineates the period of stance where stored elastic energy is returned. It seems that more elastic energy was retuned from the knee and hip passive structures than the ankle passive structures in the older adults. This finding is supported by the observed increases in $\mathrm{K} 4$ and $\mathrm{H} 2$ powers, and the observed decreases in A1 power absorption with aging.

This investigation showed that joint eccentric and concentric powers produced by the monoarticular knee flexors during the first half of stance (K1 and K2 powers) were affected by aging. This reflects a reduced ability to produce muscle power to absorb energy (eccentric muscle contraction) during ground impact and to generate muscle power to rapidly extend the knee (concentric muscle contraction). 
The findings of this investigation show that in order to maintain gait functionality with aging, interventions should maintain or improve ankle plantar flexor muscle eccentric and concentric power. This would reduce hip flexor work, increase stability and thereby maintain gait speed and step length in the older adult population. Future work in this field should focus on frontal and transverse joint kinetics, joint energy transfer and muscle co-activation. This investigation highlighted the need to control speed in any comparisons of older and young adult gait. Finally, future work should also seek to clarify the role of each joint peak power in gait. 


\section{References}

AF KLINT, R., CRONIN, N. J., ISHIKAWA, M., SINKJAER, T. \& GREY, M. J. 2010. Afferent Contribution to Locomotor Muscle Activity During Unconstrained Overground Human Walking: An Analysis of Triceps Surae Muscle Fascicles. Journal of Neurophysiology, 103, 1262-1274.

Allard, P., LACHANCE, R., AISSAOUI, R. \& DUHAIME, M. 1996. Simultaneous bilateral 3-D able-bodied gait. Human Movement Science, 15, 327-346.

BEAN, J. F., LEVEILLE, S. G., KIELY, D. K., BANDINELLI, S., GURALNIK, J. M. \& FERRUCCI, L. 2003. A comparison of leg power and leg strength within the InCHIANTI study: Which influences mobility more? Journals of Gerontology Series a-Biological Sciences and Medical Sciences, 58, 728-733.

BEGG, R. K. \& SPARROW, W. A. 2006. Ageing effects on knee and ankle joint angles at key events and phases of the gait cycle. Journal of Medical Engineering \& Technology, 30, 382-389.

BENDALL, M. J., BASSEY, E. J. \& PEARSON, M. B. 1989. Factors affecting walking speed of elderly people. Age Ageing, 18, 327-32.

BERTRAM, J. \& RUINA, A. 2001. Multiple walking speed-frequency relations are predicted by constrained optimization. Journal of Theoretical Biology, 209, 445-453.

BLANKE, D. \& HAGEMAN, P. 1989. Comparison of gait of young men and elderly men. Physical Therapy, 69, 144-148.

CALliSAYA, M. L., BLIZZARD, L., MCGINLEY, J. L., SCHMIDT, M. D. \& SRIKANTH, V. K. 2010a. Sensorimotor Factors Affecting Gait Variability in Older People-A Population-Based Study. Journals of Gerontology Series aBiological Sciences and Medical Sciences, 65, 386-392.

CALliSAYA, M. L., BLIZZARD, L., SCHMIDT, M. D., MCGINLEY, J. L. \& SRIKANTH, V. K. 2010b. Ageing and gait variability-a population-based study of older people. Age and Ageing, 39, 191-197.

CAMPBELL, A., BORRIE, M. \& SPEARS, G. 1989. Risk-factors for falls in a community-based prospective-study of people 70 years and older. Journal of Gerontology, 44, M112-M117. 
CAMPBEll, A., REINKEN, J., ALLAN, B. \& MARTINEZ, G. 1981. Falls in old age: a study of frequency and related clinical factors. Age \& Ageing, 10, 264270.

CANAVAN, P., CAHAlin, L., LOWE, S., FITZPATRICK, D., HARRIS, M. \& PLUMMER-D'AMATO, P. 2009. Managing Gait Disorders in Older Persons Residing in Nursing Homes: A Review of Literature. Journal of the American Medical Directors Association, 10, 230-237.

CARAVAGGI, P., LEARDINI, A. \& CROMPTON, R. 2010. Kinematic correlates of walking cadence in the foot. Journal of Biomechanics, 43, 2425-2433.

CHAN, K. M., DOHERTY, T. J. \& BROWN, W. F. 2001. Contractile properties of human motor units in health, aging, and disease. Muscle \& Nerve, 24, 11131133.

CHEN, I., KUO, K. \& ANDRIACCHI, T. 1997. The influence of walking speed on mechanical joint power during walking. Gait \& Posture, 6, 171-176.

CHESTER, V. 2008. The identification of age-related differences in kinetic gait parameters using principal component analysis. Clinical Biomechanics, 212220.

CHUNG, M.-J. \& WANG, M.-J. J. 2010. The change of gait parameters during walking at different percentage of preferred walking speed for healthy adults aged 20-60 years. Gait \& Posture, 31, 131-135.

COGGAN, A. R., SPINA, R. J., KING, D. S., ROGERS, M. A., BROWN, M., NEMETH, P. M. \& HOLLOSZY, J. O. 1992. Histochemical and enzymatic comparison of the gastrocnemius-muscle of young and elderly men and women. Journals of Gerontology, 47, B71-B76.

CROSBIE, J. \& VACHALATHITI, R. 1997. Synchrony of pelvic and hip joint motion during walking. Gait \& Posture, 6, 237-248.

CROSBIE, J., VACHALATHITI, R. \& SMITH, R. 1997. Patterns of spinal motion during walking. Gait \& Posture, 5, 6-12.

CROWINSHIELD, R. D., BRAND, R. A. \& JOHNSTON, R. C. 1978. The effects of walking velocity and age on hip kinematics and kinetics. Clinical Orthopaedics and Related Research, 140-4.

DEN OTTER, A. R., GEURTS, A. C. H., MULDER, T. \& DUYSENS, J. 2004. Speed related changes in muscle activity from normal to very slow walking speeds. Gait \& Posture, 19, 270-278. 
DESHPANDE, N. \& PATLA, A. 2006. Visual-vestibular interaction during goal directed locomotion: effects of aging and blurring vision. Experimental Brain Research, 176, 43-53.

DEVITA, P., HELSETH, J. \& HORTOBÁGYI, T. 2007. Muscles do more positive than negative work in human locomotion. The Journal of Experimental biology, 210, 3361-3373.

DEVITA, P. \& HORTOBÁGYI, T. 2000. Age causes a redistribution of joint torques and powers during gait. Journal of Applied Physiology, 88, 1804-1811.

DIETZ, V. \& DUYSENS, J. 2000. Significance of load receptor input during locomotion: a review. Gait \& Posture, 11, 102-110.

DIRKS, A. J. \& LEEUWENBURGH, C. 2005. The role of apoptosis in age-related skeletal muscle atrophy. Sports Medicine, 35, 473-483.

DOBBS, R. J., CHARLETT, A., BOWES, S. G., ONEILl, C. J. A., WELlER, C., HUGHES, J. \& DOBBS, S. M. 1993. IS THIS WALK NORMAL. Age and Ageing, 22, 27-30.

DOHERTY, T. 2003. Invited review: aging and sarcopenia. Journal of Applied Physiology, 95, 1717-27.

DONELAN, J. M., SHIPMAN, D. W., KRAM, R. \& KUO, A. D. 2004. Mechanical and metabolic requirements for active lateral stabilization in human walking. Journal of Biomechanics, 37, 827-835.

ENG, J. \& WINTER, D. 1995. Kinetic analysis of the lower limbs during walking: what infomation can be gained from a three-dimensional model? Journal of Biomechanics, 28, 753-758.

ENG JJ \& WINTER DA 1995. Kinetic analysis of the lower limbs during walking: what infomation can be gained from a three-dimensional model? Journal of Biomechanics, 28, 753-758.

ENOKA, R. 2002. Neuromechanics of human movement, Champaign, Human Kinetics.

ESPY, D. D., YANG, F., BHATT, T. \& PAI, Y. C. 2010. Independent influence of gait speed and step length on stability and fall risk. Gait \& Posture, 32, 378382 .

FILDES, B. 1994. Falls among the elderly: falls at home and pedestrian accidents, Melbourne, Collins Dove Publications. 
FOX, M. D. \& DELP, S. L. 2010. Contributions of muscles and passive dynamics to swing initiation over a range of walking speeds. Journal of Biomechanics, 43, 1450-1455.

GAJDOSIK, R., LINDEN, D. V. \& WILLIAMS, A. 1999. Concentric isokinetic torque characteristics of the calf muscles of active women aged 20 to 84 years. The Journal of Orthopaedic and Sports Physical Therapy, 29, 181-190.

GAJDOSIK, R. L., VANDER LINDEN, D. W., MCNAIR, P. J., RIGGIN, T. J., ALBERTSON, J. S., MATTICK, D. J. \& WEGLEY, J. C. 2005. Viscoelastic properties of short calf muscle-tendon units of older women: effects of slow and fast passive dorsiflexion stretches in vivo. European Journal of Applied Physiology, 95, 131-139.

GANLEY, K. J. \& POWERS, C. M. 2005. Gait kinematics of 7-year-old children: a comparison to adults using age-specific anthropometric data. Gait \& Posture, 21, 141-5.

GIBBS, J., HUGHES, S., DUNLOP, D., SINGER, R. \& CHANG, R. W. 1996. Predictors of change in walking velocity in older adults. Journal of the American Geriatrics Society, 44, 126-132.

GRAF, A., JAMES, M., JUDGE, O., OUNPUU, S. \& THELEN, D. 2005. The effect of walking speed on lower-extremity joint powers among elderly adults who exhibit low physical performance. Archives of Physical Medicine and Rehabilitation, 86.

GURALNIK JM, SIMONSICK EM, FERRUCCI L, GLYNN RJ, BERKMAN LF, BLAZER DG, SCHERR PA \& WALACE RB 1994. A short physical performance battery assessing lower extremity function: association with selfreported disability and prediction of mortality and nursing home admission. Journals of Gerontology Series a-Biological Sciences and Medical Sciences, 49 85-94.

HAGEMAN, P. A. \& BLANKE, D. J. 1986. Comparison of gait of young-women and elderly women. Physical Therapy, 66, 1382-1387.

HAUSDORFF, J. M., RIOS, D. A. \& EDELBERG, H. K. 2001. Gait variability and fall risk in community-living older adults: A 1-year prospective study. Archives of Physical Medicine and Rehabilitation, 82, 1050-1056.

HELBOSTAD, J. L., VEREIJKEN, B., HESSEBERG, K. \& SLETVOLD, O. 2009. Altered vision destabilizes gait in older persons. Gait \& Posture, 30, 233-238. 
HIMANN, J. E., CUNNINGHAM, D. A., RECHNITZER, P. A. \& PATERSON, D. H. 1988. Age-related-changes in speed of walking. Medicine and Science in Sports and Exercise, 20, 161-166.

HIROKAWA, S. 1989. Normal gait characteristics under temporal and distance constraints. Journal of Biomedical Engineering, 11, 449-456.

HOF, A. L., ElZINGA, H., GRIMMIUS, W. \& HALBERTSMA, J. P. K. 2002. Speed dependence of averaged EMG profiles in walking. Gait \& Posture, 16, 78-86.

HORTOBÁGYI, T. \& DEVITA, P. 2006. Mechanisms responsible for the ageassociated increase in coactivation of antagonist muscles. Exercise and Sport Sciences Reviews, 34, 29-35.

HORTOBÁGYI, T., SOLNIK, S., GRUBER, A., RIDER, P., STEINWEG, K., HELSETH, J. \& DEVITA, P. 2009. Interaction between age and gait velocity in the amplitude and timing of antagonist muscle coactivation. Gait \& Posture, $29,558-564$.

ISHIKAWA, M., KOMI, P. V., GREY, M. J., LEPOLA, V. \& BRUGGEMANN, G. P. 2005. Muscle-tendon interaction and elastic energy usage in human walking. Journal of Applied Physiology, 99, 603-608.

IVANENKO, Y. P., POPPELE, R. E. \& LACQUANITI, F. 2006. Spinal cord maps of spatiotemporal alpha-motoneuron activation in humans walking at different speeds. Journal of Neurophysiology, 95, 602-618.

JANSSEN, I., HEYMSFIELD, S. B. \& ROSS, R. 2002. Low relative skeletal muscle mass (sarcopenia) in older persons is associated with functional impairment and physical disability. Journal of the American Geriatrics Society, 50, 889896.

JANSSEN, I., HEYMSFIELD, S. B., WANG, Z. M. \& ROSS, R. 2000. Skeletal muscle mass and distribution in 468 men and women aged 18-88 yr. Journal of Applied Physiology, 89, 81-88.

JUDGE, J. O., DAVIS, R. B. \& OUNPUU, S. 1996a. Step length reductions in advanced age: the role of ankle and hip kinetics. Journal of Gerontology, 51A, 303-312.

JUDGE, J. O., SCHECHTMAN, K. \& CRESS, E. 1996b. The relationship between physical performance measures and independence in instrumental activities of daily living. Journal of the American Geriatrics Society, 44, 1332-1341. 
KADHIRESAN, V. A., HASSETT, C. A. \& FAULKNER, J. A. 1996. Properties of single motor units in medial gastrocnemius muscles of adult and old rats. Journal of Physiology-London, 493, 543-552.

KANG, H. G. \& DINGWELL, J. B. 2008. Separating the effects of age and walking speed on gait variability. Gait \& Posture, 27, 572-577.

KENT-BRAUN, J. A., NG, A. V. \& YOUNG, K. 2000. Skeletal muscle contractile and noncontractile components in young and older women and men. Journal of Applied Physiology, 88, 662-668.

KERRIGAN, D. C., LEE, L. W., COLLINS, J. J., RILEY, P. O. \& LIPSITZ, L. A. 2001. Reduced hip extension during walking: Healthy elderly and fallers versus young adults. Archives of Physical Medicine and Rehabilitation, 82, 26-30.

KERRIGAN, D. C., TODD, M. K., CROCE, U. D., LiPSTIZ, L. A. \& COLlinS, J. J. 1998. Biomechanical gait alterations independent of speed in healthy elderly: evidence for specific limiting impairments. Archives of Physical Medicine and Rehabilitation, 79, 317-322.

KERRIGAN, D. C., XENOPOULOS-ODDSSON, A., SULLIVAN, M. J., LELAS, J. J. \& RILEY, P. O. 2003. Effect of a hip flexor-stretching program on gait in the elderly. Archives of Physical Medicine and Rehabilitation, 84, 1-6.

KIRTLEY, C., WHITTLE, M. W. \& JEFFERSON, R. J. 1985. Influence of walking speed on gait parameters. Journal of Biomedical Engineering, 7, 282-288.

KJAER, M. 2004. Role of Extracellular Matrix in Adaptation of Tendon and Skeletal Muscle to Mechanical Loading. Physiological Reviews, 84, 649-698.

KO, S. U., LING, S. M., WINTERS, J. \& FERRUCCI, L. 2009. Age-related mechanical work expenditure during normal walking: The Baltimore Longitudinal Study of Aging. Journal of Biomechanics, 42, 1834-1839.

KWON, Y. H., CHANG, J. S., LEE, M. H., KIM, J. H., HYOUK, H. I., NAM, K. S., JANG, S. H. \& KIM, C. S. 2010. Evidence of Neuromuscular Adaptation According to Motor Sequential Learning in the Serial Reaction Time Task. Journal of Physical Therapy Science, 22, 117-121.

LEE, L. W. \& KERRIGAN, D. C. 1999. Identification of kinetic differences between fallers and nonfallers in the elderly. American Journal of Physical Medicine \& Rehabilitation, 78, 242-246. 
LEE, L. W., ZAVAREI, K., EVANS, J., LELAS, J. J., RILEY, P. O. \& KERRIGAN, D. C. 2005. Reduced hip extension in the elderly: Dynamic or postural? Archives of Physical Medicine and Rehabilitation, 86, 1851-1854.

LELAS, J. L., MERRIMAN, G. J., RILEY, P. O. \& KERRIGAN, D. C. 2003. Predicting peak kinematic and kinetic parameters from gait speed. Gait \& Posture, 17, 106-112.

LEWIS, C. L. \& FERRIS, D. P. 2008. Walking with increased ankle pushoff decreases hip muscle moments. Journal of Biomechanics, 41, 2082-2089.

LEXELL, J., HENRIKSSONLARSEN, K., WINBLAD, B. \& SJOSTROM, M. 1983. Distribution of different fiber types in human skeletal-muscles - effects of aging studied in whole muscle cross-sections. Muscle \& Nerve, 6, 588-595.

LINDEMANN, U., NAJAFI, B., ZIJLSTRA, W., HAUER, K., MUCHE, R., BECKER, C. \& AMINIAN, K. 2008. Distance to achieve steady state walking speed in frail elderly persons. Gait \& Posture, 27, 91-96.

LIU, M. Q., ANDERSON, F. C., SCHWARTZ, M. H. \& DELP, S. L. 2008. Muscle contributions to support and progression over a range of walking speeds. Journal of Biomechanics, 41, 3243-3252.

LOPOPOLO, R. B., GRECO, M., SULlIVAN, D., CRAIK, R. L. \& MANGIONE, K. K. 2006. Effect of therapeutic exercise on gait speed in communitydwelling elderly people: A meta-analysis. Physical Therapy, 86, 520-540.

LYTHGO, N., WILSON, C. \& GALEA, M. 2009. Basic gait and symmetry measures for primary school-aged children and young adults whilst walking barefoot and with shoes. Gait \& Posture, 30, 502-506.

MACFARLANE, P. \& LOONEY, M. 2008. Walkway length determination for steady state walking in young and older adults. Research Quarterly for Exercise and Sport, 79, 261-267.

MAGNUSSON, S. P., BEYER, N., ABRAHAMSEN, H., AAGAARD, P., NEERGAARD, K. \& KJAER, M. 2003. Increased cross-sectional area and reduced tensile stress of the Achilles tendon in elderly compared with young women. Journals of Gerontology Series a-Biological Sciences and Medical Sciences, 58, 123-127.

MAKI, B. 1997. Gait changes in older adults: predictors of falls or indicators of fear? Journal of the American Geriatrics Society, 45, 313-320. 
MALATESTA, D., SIMAR, D., DAUVILLIERS, Y., CANDAU, R., BORRANI, F., PREFAUT, C. \& CAILLAUD, C. 2003. Energy cost of walking and gait instability in healthy 65-and 80-yr-olds. Journal of Applied Physiology, 95, 2248-2256.

MCGIBBON, C. \& KREBS, D. 2001. Age-related changes in lower trunk coordination and energy transfer during gait. Journal of Neurophysiology, 85, 1923-1931.

MCGIBBON, C. \& KREBS, D. 2002. Compensatory gait mechanics in patients with unilateral knee arthritis. The Journal of Rheumatology, 29, 2410-2419.

MCGIBBON, C. A. 2003. Toward a better understanding of gait changes with age and disablement: neuromuscular adaptation. Exercise and Sport Sciences Reviews, 31, 102-108.

MCGIBBON, C. A. 2006. Toward a better understanding of gait changes with age and disablement: neuromuscular adaptation. Exercise and Sport Sciences Reviews, 31, 102-108.

MCGIBBON, C. A. \& KREBS, D. E. 1999. Effects of age and functional limitation on leg joint power and work during stance phase of gait. Journal of Rehabilitation Research and Development, 36, 173-182.

MCGIBBON, C. A. \& KREBS, D. E. 2004. Discriminating age and disability effects in locomotion: neuromuscular adaptations in musculoskeletal pathology. Journal of Applied Physiology, 96, 149-60.

MCGIBBON, C. A., KREBS, D. E. \& PUNIELLO, M. S. 2001a. Mechanical energy analysis identifies compensatory strategies in diasbled elder's gait. Journal of Biomechanics, 34, 481-490.

MCGIBBON, C. A., PUNIELLO, M. S. \& KREBS, D. E. 2001b. Mechanical energy transfer during gait in relation to strength impairment and pathology in elderly women. Clinical Biomechanics, 16, 324-333.

MEINDERS, M., GITTER, A. \& CZERNIECKI, J. M. 1998. The role of ankle plantar flexor muscle work during walking. Scandinavian Journal of Rehabilitation Medicine, 30, 39-46.

MIAN, O. S., THOM, J. M., ARDIGO, L. P., NARICI, M. V. \& MINETTI, A. E. 2006. Metabolic cost, mechanical work, and efficiency during walking in young and older men. Acta Physiologica, 186, 127-139. 
MILLS, P. M. \& BARRETT, R. S. 2001. Swing phase mechanics of healthy young and elderly men. Human Movement Science, 20, 427-446.

MOE-NILSSEN, R. \& HELBOSTAD, J. L. 2005. Interstride trunk acceleration variability but not step width variability can differentiate between fit and frail older adults. Gait \& Posture, 21, 164-170.

MONACO, V., GHIONZOLI, A., DARIO, P., MICERA, S. \& IEEE 2008. Muscle synergies during walking: comparison between young and elderly people. Preliminary results. 2008 30th Annual International Conference of the Ieee Engineering in Medicine and Biology Society, Vols 1-8. New York: Ieee.

MONACO, V., RINALDI, L. A., MACRI, G. \& MICERA, S. 2009. During walking elders increase efforts at proximal joints and keep low kinetics at the ankle. Clinical Biomechanics, 24, 493-498.

NARICI, M., MAGANARIS, C., REEVES, N. \& CAPODAGLIO, P. 2003. Effect of aging on human muscle architecture. Journal of Applied Physiology, 95, 22292234.

NARICI, M. V. \& MAFFULLI, N. 2010. Sarcopenia: characteristics, mechanisms and functional significance. British Medical Bulletin, ldq008.

NENE, A., BYRNE, C. \& HERMENS, H. 2004. Is rectus femoris really a part of quadriceps? Assessment of rectus femoris function during gait in able-bodied adults. Gait \& Posture, 20, 1-13.

NENE, A., MAYAGOITIA, R. \& VELTINK, P. 1999. Assessment of rectus femoris function during initial swing phase. Gait \& Posture, 9, 1-9.

NEPTUNE, R., KAUTZ, S. \& ZAJAC, F. 2001. Contributions of the individual ankle plantar flexors to support, forward progression and swing initiation during walking. Journal of Biomechanics, 34, 1387-1398.

NEPTUNE, R. R., SASAKI, K. \& KAUTZ, S. A. 2008. The effect of walking speed on muscle function and mechanical energetics. Gait \& Posture, 28, 135-143.

NEPTUNE, R. R., ZAJAC, F. E. \& KAUTZ, S. A. 2004. Muscle force redistributes segmental power for body progression during walking. Gait \& Posture, 19, 194-205.

OBERG, T., KARSZNIA, A. \& OBERG, K. 1994. Joint angle parameters on gait: reference data for normal subjects, 10-79 years of age. Journal of Rehabilitation Research and Development, 31, 199-213. 
OSTROSKY, K. M., VANSWEARINGEN, J. M., BURDETT, R. G. \& GEE, Z. 1994. A comparison of gait characteristics in young and old subjects. Physical Therapy, 74, 637-644.

PATERSON, K. L., LYTHGO, N. D. \& HILL, K. D. 2009. Gait variability in younger and older adult women is altered by overground walking protocol. Age and Ageing, 38, 745-748.

PATLA, A. 1991. Adaptability of human gait: Implications for the control of locomotion, New York, Elsevier Sciences.

PEELER, J. \& ANDERSON, J. 2007. Reliability of the Thomas test for assessing range of motion about the hip. Physical Therapy in Sports, 8, 14-21.

PERRY, J. 1992. Gait analysis normal and pathological function Thorofare, NJ, Slack Incorporated.

PETERSON, D. S. \& MARTIN, P. E. 2010. Effects of age and walking speed on coactivation and cost of walking in healthy adults. Gait \& Posture, 31, 355359.

PRINCE, F., CORRIVEAU, H., HEBERT, R. \& WINTER, D. A. 1997. Gait in the elderly. Gait \& Posture, 5, 128-135.

PRINCE, F., WINTER, D. A., STERGIOU, P. \& WALT, S. E. 1994. Anticipatory control of upper body balance during human locomotion. Gait \& Posture, 2, $19-25$.

REICH, T. E., LINDSTEDT, S. L., LASTAYO, P. C. \& PIEROTTI, D. J. 2000. Is the spring quality of muscle plastic? American Journal of Physiology-Regulatory Integrative and Comparative Physiology, 278, R1661-R1666.

RILEY, P. O., CROCE, U. D. \& CASEY KERRIGAN, D. 2001a. Propulsive adaptation to changing gait speed. Journal of Biomechanics, 34, 197-202.

RILEY, P. O., CROCE, U. D. \& KERRIGAN, D. C. 2001b. Effect of age on lower extremity joint moment contributions to gait speed. Gait \& Posture, 14, 264 270.

RODGERS, M. M. \& CAVANAGH, P. R. 1984. Glossary of biomechanical terms, concepts, and units. Physical Therapy, 64, 1886-1902.

ROIG, M., MACINTYRE, D. L., ENG, J. J., NARICI, M. V., MAGANARIS, C. N. \& REID, W. D. 2010. Preservation of eccentric strength in older adults: Evidence, mechanisms and implications for training and rehabilitation. Experimental Gerontology, 45, 400-409. 
RØISLIEN, J., SKARE, Ø., GUSTAVSEN, M., BROCH, N. L., RENNIE, L. \& OPHEIM, A. 2009. Simultaneous estimation of effects of gender, age and walking speed on kinematic gait data. Gait \& Posture, 30, 441-445.

ROSE, J. G., J. 1994. Human walking, Baltimore, MA, Williams \& Wilkins.

ROSENBERG, I. H. 1989. Summary comments. American Journal of Clinical Nutrition, 50, 1231-1233.

RYAN, A. S., DOBROVOLNY, C. L., SMITH, G. V., SILVER, K. H. \& MACKO, R. F. 2002. Hemiparetic muscle atrophy and increased intramuscular fat in stroke patients. Archives of Physical Medicine and Rehabilitation, 83, 17031707.

SADEGHI, H. 2000. Contributions of lower-limb muscle power in gait of people without impairments. Physical Therapy, 80, 1188-96.

SADEGHI, H. 2003. Local or global asymmetry in gait of people without impairments. Gait \& Posture, 17, 197-204.

SADEGHI, H., ALLARD, P. \& DUHAIME, M. 1997. Functional gait asymmetry in able-bodied subjects. Human Movement Science, 16, 243-258.

SADEGHI, H., PRINCE, F., ZABJEK, K. F. \& LABELLE, H. 2004. Simultaneous, bilateral, and three-dimensional gait analysis of elderly people without impairments. American Journal of Physical Medicine \& Rehabilitation, 83, $112-23$.

SADEGHI, H., SADEGHI, S., ALLARD, P., LABELLE, H. \& DUHAIME, M. 2001. Lower limb muscle power relationships in bilateral able-bodied gait. American Journal of Physical Medicine \& Rehabilitation, 80, 821-30.

SALZMAN, B. 2010. Gait and Balance Disorders in Older Adults. American Family Physician, 82, 61-68.

SCHMITZ, A., SILDER, A., HEIDERSCHEIT, B., MAHONEY, J. \& THELEN, D. G. 2009. Differences in lower-extremity muscular activation during walking between healthy older and young adults. Journal of Electromyography and Kinesiology, 19, 1085-1091.

SCHWARTZ, M. H., ROZUMALSKI, A. \& TROST, J. P. 2008. The effect of walking speed on the gait of typically developing children. Journal of Biomechanics, 41, 1639-1650. 
SELIKTAR, R. \& BO, L. 1995. The theory of kinetic analysis in human gait. In: CRAIK, R. \& OATIS, C. (eds.) Gait Analysis: Theory and Application. St Louis: Mosby.

SHUMWAY-COOK, A. \& WOOLLACOTT, M. 2001. Motor Control: Theory and Practical Applications, Baltimore, Maryland, Lippincott Williams \& Wilkins.

SILDER, A., HEIDERSCHEIT, B. \& THELEN, D. 2008. Active and passive contributions to joint kinetics during walking in older adults. Journal of Biomechanics, 41, 1520-1527.

SILDER, A., WHITTINGTON, B., HEIDERSCHEIT, B. \& THELEN, D. G. 2007. Identification of passive elastic joint moment-angle relationships in the lower extremity. Journal of Biomechanics, 40, 2628-2635.

SIU, P. M. 2009. Muscle Apoptotic Response to Denervation, Disuse, and Aging. Medicine and Science in Sports and Exercise, 41, 1876-1886.

SKELTON, D., GREIG, C., DAVIES, J. \& YOUNG, A. 1994. Strength, power and related functional ability of healthy people aged 65-89 years. Age and Ageing, $23,371-377$.

STANSFIELD, B. W., HILLMAN, S. J., HAZLEWOOD, M. E., LAWSON, A. A., MANN, A. M., LOUDON, I. R. \& ROBB, J. E. 2001. Normalized speed, not age, characterizes ground reaction force patterns in 5-to 12-year-old children walking at self-selected speeds. Journal of Pediatric Orthopaedics, 21, 395402.

STEWART, C., POSTANS, N., SCHWARTZ, M. H., ROZUMALSKI, A. \& ROBERTS, A. 2007. An exploration of the function of the triceps surae during normal gait using functional electrical stimulation. Gait \& Posture, 26, 482488.

SUTHERLAND, D. H., OLSHEN, R., BIDEN, E. N. \& WYATT, M. P. 1988. The Development of Mature Walking., London, Mac Keith Press.

THOM, J. M., MORSE, C. I., BIRCH, K. M. \& NARICI, M. V. 2007. Influence of muscle architecture on the torque and power-velocity characteristics of young and elderly men. European Journal of Applied Physiology, 100, 613-619.

TOLEA, M. I., COSTA, P. T., TERRACCIANO, A., GRISWOLD, M., SIMONSICK, E. M., NAJJAR, S. S., SCUTERI, A., DEIANA, B., ORRU, M., MASALA, M., UDA, M., SCHLESSINGER, D. \& FERRUCCI, L. 2010. Sex-Specific Correlates of Walking Speed in a Wide Age-Ranged Population. 
Journals of Gerontology Series B-Psychological Sciences and Social Sciences, $65,174-184$

TOMLINSON, B. E. \& IRVING, D. 1977. Numbers of limb motor neurons in human lumbosacral cord throughout life. Journal of the Neurological Sciences, 34, 213-219.

TUITE, D. J., RENSTROM, P. \& OBRIEN, M. 1997. The aging tendon. Scandinavian Journal of Medicine \& Science in Sports, 7, 72-77.

VANDERVOORT, A. A. 2002. Aging of the human neuromuscular system. Muscle \& Nerve, $25,17-25$.

VARDAXIS, V. G., ALlARD, P., LACHANCE, R. \& DUHAIME, M. 1998. Classification of able-bodied gait using 3-D muscle powers. Human Movement Science, 17, 121-136.

VERDU, E., CEBALlOS, D., VILCHES, J. \& NAVARRO, X. 2000. Influence of aging on peripheral nerve function and regeneration. Journal of the Peripheral Nervous System 5, 191-208.

VINCENT, W. 1995. Statistics in kinesiology, Champaign, IL, Human Kinetics.

WANG, F. C., DE PASQUA, V. \& DELWAIDE, P. J. 1999. Age-related changes in fastest and slowest conducting axons of thenar motor units. Muscle \& Nerve, 22, 1022-1029.

WATElain, E., BARBIER, F., ALlARD, P., THEVENON, A. \& ANGUÉ, J.-C. 2000. Gait pattern classification of healthy elderly men based on biomechanical data. Archives of Physical Medicine and Rehabilitation, 81, $579-586$.

WATELAIN, E., DUJARDIN, F., BABIER, F., DUBOIS, D. \& ALLARD, P. 2001. Pelvic and lower limb compensatory actions of subjects in an early stage of hip osteoarthritis. Archives of Physical Medicine and Rehabilitation, 82, 17051711.

WATT, J. R., FRANZ, J. R., JACKSON, K., DICHARRY, J., RILEY, P. O. \& KERRIGAN, D. C. 2010. A three-dimensional kinematic and kinetic comparison of overground and treadmill walking in healthy elderly subjects. Clinical Biomechanics, 25, 444-449.

WEARING, S. C., URRY, S. R. \& SMEATHERS, J. E. 2000. The effect of visual targeting on ground reaction force and temporospatial parameters of gait. Clinical Biomechanics, 15, 583-591. 
WHitTINGTON, B., SILDER, A., HEIDERSCHEIT, B. \& THELEN, D. G. 2008. The contribution of passive-elastic mechanisms to lower extremity joint kinetics during human walking. Gait \& Posture, 27, 628-634.

WHITTLE, M. 1993. Gait Analysis: an introduction, Oxford, Butterworth Heinemann.

WINEGARD, K. J., HICKS, A. L., SALE, D. G. \& VANDERVOORT, A. A. 1996. A 12-year follow-up study of ankle muscle function in older adults. Journals of Gerontology Series a-Biological Sciences and Medical Sciences, 51, B202B207.

WINTER, D. 1983a. Energy Generation and Absorption at the Ankle and Knee during Fast, Natural, and Slow Cadences. Clinical Orthopaedics and Related Research, 175, 147-154.

WINTER, D. 2005. Biomechanics and motor control of human movement, Hoboken, NJ, John Wiley and Sons, Inc.

WINTER, D., ENG, J. \& ISHAC, M. 1995. A review of kinetic parameters in human walking. In: CRAIK, R. \& OATIS, C. (eds.) Gait Analysis: Theory and Application. St Louis: Mosby.

WINTER, D., PATLA, A., FRANK, J. S. \& WALT, S. E. 1990. Biomechanical walking pattern changes in the fit and healthy elderly. Physical Therapy, 70, $340-347$.

WINTER, D. A. 1983b. Knee Flexion During Stance as a Determinant of Inefficient Walking. Physical Therapy, 63, 331-333.

WINTER, D. A. 1991. The Biomechanics and Motor Control of Human Gait: Normal, Elderly and Pathological (2nd ed.), Ontario, University of Waterloo Press.

WINTER, D. A. \& ENG, P. 1995. Kinetics: our window into the goals and strategies of the central nervous system. Behavioural Brain Research, 67, 111-120.

WOLFSON, L. 2001. Gait and balance dysfunction: A model of the interaction of age and disease. The Neuroscientist, 7, 178-183.

XI, M. C., LIU, R. H., ENGELHARDT, J. K., MORALES, F. R. \& CHASE, M. H. 1999. Changes in the axonal conduction velocity of pyramidal tract neurons in the aged cat. Neuroscience, 92, 219-225.

ZATSIORSKY, V. 2000. Biomechanics in sport : performance enhancement and injury prevention, Oxford, UK, Blackwell Science. 
ZIJLSTRA, W. 2004. Assessment of spatio-temporal parameters during unconstrained walking. European Journal of Applied Physiology, 92, 39-44. 


\section{Appendix 1: Correlation Tables}

\begin{tabular}{|c|c|c|c|c|c|c|c|c|c|c|c|c|c|c|c|c|c|c|c|c|c|c|c|c|c|c|}
\hline & 而 & 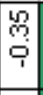 & & 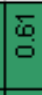 & |ִ & \begin{tabular}{|l|}
$\mathscr{0}$ \\
0 \\
0
\end{tabular} & & & 管 & 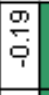 & \begin{tabular}{|l|l|}
\multirow{W}{*}{} \\
0 \\
\end{tabular} & 照 & & & 哥 & 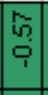 & 要 & \begin{tabular}{|l|l|}
$g$ \\
\end{tabular} & & $\begin{array}{l}\text { 等 } \\
\text { ch }\end{array}$ & & 筞 & & | & & 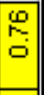 \\
\hline$\frac{9}{0}$ & 誉 & 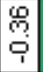 & 号 & 䍐 & |ִ. & 勿 & S্ & & 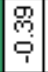 & 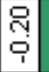 & $\begin{array}{l}3 \\
0 \\
0 \\
0\end{array}$ & 恕 & ্ָণ & & 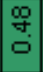 & 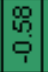 & 覀 & 总 & 吉 & 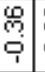 & $\stackrel{3}{s}$ & 罟 & & & & \begin{tabular}{l}
$\mathscr{Q}$ \\
\hdashline \\
\hdashline
\end{tabular} \\
\hline$\overline{0}$ & 筞 & 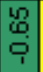 & $\begin{array}{l}\text { 品 } \\
\end{array}$ & 筞 & $\begin{array}{l}0 \\
\text { Wo } \\
\end{array}$ & 吕 & $\begin{array}{l}\text { D্ } \\
\mathrm{g}\end{array}$ & 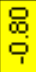 & 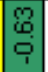 & \begin{tabular}{|l|}
$\frac{9}{6}$ \\
\end{tabular} & $\begin{array}{l} \\
\stackrel{8}{\circ} \\
\end{array}$ & $\frac{m}{\square}$ & ma & & ? & 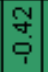 & 哭 & \begin{tabular}{|l|} 
\\
\\
\end{tabular} & $\begin{array}{l}\mathrm{N} \\
\square \\
\bar{G}\end{array}$ & $\begin{array}{l}\text { go } \\
\text { gr }\end{array}$ & ले & गे & & & & \begin{tabular}{l||}
$\mathscr{O}$ \\
$\square$ \\
$\square$
\end{tabular} \\
\hline$\frac{1}{3}$ & 总 & $\begin{array}{l} \\
\text { s. } \\
\text { : }\end{array}$ & 哭 & 今. & 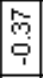 & \begin{tabular}{|l} 
\\
\\
$\circ$ \\
\end{tabular} & S & ș & $\frac{\text { o }}{\grave{Q}}$ & & & $\begin{array}{l}\text { 志 } \\
\\
\end{array}$ & 空 & $\mathbb{d}$ & ָ̦ & \begin{tabular}{|c|} 
\\
ğ \\
\end{tabular} & 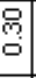 & $\overline{0}$ & $\begin{array}{l}\text { 芯 } \\
\text { i }\end{array}$ & 圀 & 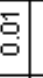 & & & & & \begin{tabular}{|l||} 
\\
\\
\end{tabular} \\
\hline$\frac{5}{3}$ & 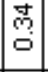 & 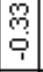 & 志 & 営 & 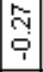 & 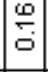 & ș & ک్ & $\mid \begin{array}{c}n \\
\\
\end{array}$ & & 骂 & ్ㅗㅇ & 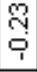 & 8 & 壳 & 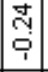 & 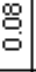 & 总 & 只 & $\begin{array}{l}\bar{y} \\
\bar{c}\end{array}$ & & S & 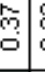 & త્ઞ & & m. \\
\hline$\frac{1}{3}$ & \begin{tabular}{|l} 
\\
\\
\end{tabular} & ले & 罗 & 导 & \begin{tabular}{|c} 
\\
s. \\
\end{tabular} & 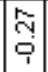 & ָ̧ & 8 & & 志 & 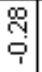 & 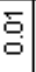 & $\stackrel{\mathscr{s}}{\mathrm{s}}$ & Y & $\begin{array}{l} \\
\text { s. } \\
口\end{array}$ & 芯 & $\overline{\mathrm{s}}$ & 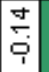 & 寸 & & $\bar{c} \bar{c}$ & $\underset{c}{m}$ & & ב⿱ & & 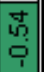 \\
\hline$\frac{8}{\xi}$ & \begin{tabular}{|c|} 
\\
mạ
\end{tabular} & \begin{tabular}{|c|}
\multicolumn{0}{c}{} \\
\end{tabular} & $\begin{array}{c}\bar{\phi} \\
口 \\
\end{array}$ & 臬 & $\begin{array}{l} \\
\text { No } \\
0\end{array}$ & 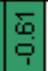 & & & & \begin{tabular}{|l|}
$\mathrm{g}$ \\
$\mathrm{g}$
\end{tabular} & 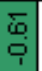 & 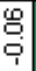 & 䖝 & 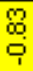 & \begin{tabular}{|l} 
\\
\\
9 \\
\end{tabular} & 筞 & 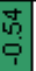 & \begin{tabular}{|c|} 
\\
\\
\end{tabular} & & 等 & 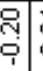 & 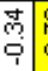 & $\begin{array}{c}N \\
\\
\end{array}$ & 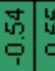 & & 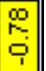 \\
\hline$\stackrel{\stackrel{3}{3}}{3}$ & 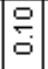 & 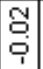 & 总 & 営 & $\bar{s}$ & 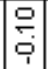 & & $\stackrel{g}{g}$ & \begin{tabular}{c}
9 \\
\multirow{3}{9}{}
\end{tabular} & 总 & 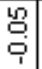 & $\stackrel{m}{-}$ & 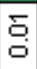 & $\stackrel{\mathscr{G}}{\mathrm{G}}$ & 告 & 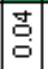 & 商 & & 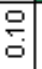 & 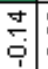 & go & $\bar{\delta}$ & $\begin{array}{c}S_{0} \\
\end{array}$ & go & & 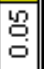 \\
\hline$\stackrel{9}{3}$ & 触 & $\begin{array}{l}\stackrel{p}{0} \\
\text { ì }\end{array}$ & 导 & 号 & & & 吉 & 曼 & 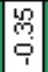 & & $\begin{array}{l} \\
\text { 足 } \\
\end{array}$ & $\frac{\infty}{5}$ & 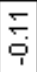 & 符 & 更 & 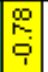 & & \begin{tabular}{|l|}
$\infty$ \\
\multicolumn{1}{c}{} \\
\end{tabular} & $\begin{array}{l}\text { 志 } \\
\text { 它 }\end{array}$ & $\begin{array}{l}\bar{y} \\
\bar{y}\end{array}$ & $\begin{array}{l}9 \\
\end{array}$ & 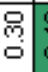 & 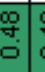 & g & & \begin{tabular}{l|l||}
$\mathscr{0}$ \\
\end{tabular} \\
\hline 产 & 寽 & 옴 & 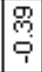 & 导 & & $\begin{array}{l}\bar{\infty} \\
\bar{\varphi} \\
\end{array}$ & $\frac{n}{6}$ & 刕 & \begin{tabular}{|l|} 
\\
$\mathrm{m}$ \\
$\mathrm{\sigma}$
\end{tabular} & 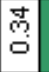 & $\begin{array}{l}\text { g } \\
\text { gi }\end{array}$ & $\begin{array}{l}\bar{m} \\
\vdots \\
\vdots\end{array}$ & $\stackrel{\mathscr{G}}{G}$ & 肙 & 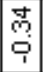 & & 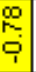 & \begin{tabular}{l|l} 
\\
\\
\end{tabular} & 筞 & 志 & 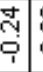 & \begin{tabular}{l}
0 \\
0 \\
\hdashline
\end{tabular} & & C & & \begin{tabular}{l||} 
\\
\\
\end{tabular} \\
\hline$\frac{P}{3}$ & m. & $\begin{array}{c}\bar{y} \\
\text { ì }\end{array}$ & 守 & & : & 骂 & $\stackrel{\mathscr{c}}{\mathrm{S}}$ & $\begin{array}{l}\text { 导 } \\
\text { i }\end{array}$ & 年 & 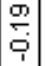 & $\begin{array}{l}\text { 肙 } \\
\mathrm{g}\end{array}$ & 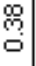 & 兽 & च & & 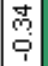 & 守 & 哭 & \begin{tabular}{l}
9 \\
\hdashline \\
\hdashline \\
1
\end{tabular} & 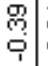 & $\begin{array}{l}\text { 导 } \\
\end{array}$ & $\stackrel{\text { ড̦ }}{\mathrm{s}}$ & & $\begin{array}{c}\text { go } \\
\mathrm{g}\end{array}$ & & 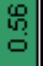 \\
\hline$\stackrel{M}{Y}$ & 肙 & 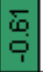 & & 号 & 守 & \begin{tabular}{|l}
2 \\
$\omega$ \\
0 \\
0
\end{tabular} & $\begin{array}{c}m \\
3 \\
6\end{array}$ & $\begin{array}{l}\mathscr{8} \\
\\
\end{array}$ & 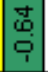 & $\frac{m}{c}$ & $\begin{array}{l}0 \\
0 \\
0\end{array}$ & $\frac{5}{6}$ & 多 & & 导 & $\begin{array}{l}\text { g. } \\
\text { g. } \\
\end{array}$ & 筞 & 営 & $\begin{array}{l}9 \\
0 \\
9 \\
1\end{array}$ & $\begin{array}{l}\mathscr{6} \\
0 \\
\\
\end{array}$ & $\begin{array}{l}3 \\
0 \\
0\end{array}$ & ָั & $\begin{array}{c}R \\
6\end{array}$ & $\bar{n}$ & & $\begin{array}{l}\bar{s} \\
\square\end{array}$ \\
\hline$\stackrel{N}{\frac{N}{3}}$ & $\frac{m}{5}$ & & 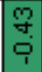 & ⿳亠丷冖̆丶 & 絗 & 告 & 总 & 寺 & $\begin{array}{l}\mathrm{g} \\
\mathrm{g} \\
\mathrm{g}\end{array}$ & \begin{tabular}{|l|} 
\\
\\
\\
\end{tabular} & $\begin{array}{l}\text { ç } \\
\text { ì }\end{array}$ & 塄 & & 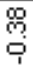 & 8 & 里 & 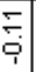 & (5) & 照 & $\stackrel{\mathscr{s}}{\mathrm{g}}$ & $\begin{array}{c}3 \\
\vdots \\
9\end{array}$ & 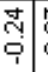 & ले & 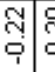 & & $\begin{array}{l}\mathscr{9} \\
\overline{0} \\
\end{array}$ \\
\hline$\stackrel{\bar{Y}}{\xi}$ & & $\frac{\mathrm{v}}{6}$ & $\frac{9}{5}$ & 총 & 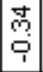 & \begin{tabular}{|c|}
\multirow{2}{}{} \\
ș
\end{tabular} & $\begin{array}{l}\stackrel{g}{\mathrm{~g}} \\
\mathrm{\sigma}\end{array}$ & $\frac{\mathrm{N}}{\mathrm{c}}$ & 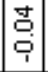 & 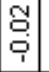 & $\frac{\mathrm{v}}{6}$ & & $\stackrel{g}{g}$ & 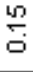 & 孚 & 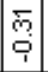 & $\stackrel{\infty}{\circ}$ & $\frac{m}{c}$ & 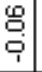 & S. & స్ & $\begin{array}{l}\text { 志 } \\
\text { ' }\end{array}$ & $\underset{\sigma}{\sigma}$ & & & $\bar{m}$ \\
\hline$\approx$ & ले & 导 & 5 & 筞 & \begin{tabular}{l}
0 \\
$\mathscr{w}$ \\
\multicolumn{1}{c}{}
\end{tabular} & 总 & $\frac{\mathrm{N}}{5}$ & $\begin{array}{l}\text { is } \\
\text { in }\end{array}$ & 寺 & \begin{tabular}{|l|} 
g. \\
\multirow{2}{*}{} \\
\end{tabular} & & $\frac{9}{5}$ & & 3 & 肙 & 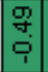 & 志 & \begin{tabular}{|l|}
\multicolumn{2}{|c|}{} \\
\\
\end{tabular} & 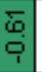 & $\begin{array}{l}\stackrel{9}{⿰} \\
\text { : }\end{array}$ & 孚 & & 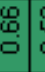 & 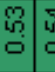 & 怘 & $\begin{array}{l}2 \\
\square \\
\square\end{array}$ \\
\hline $\bar{x}$ & 営 & 号 & $\frac{\infty}{\sigma}$ & 恣 & ले & 等 & 查 & $\stackrel{\mathrm{s}}{\mathrm{g}}$ & \begin{tabular}{|l|}
\multicolumn{2}{c}{} \\
\end{tabular} & & $\begin{array}{l}\text { ga } \\
\text { g. }\end{array}$ & 谷 & 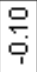 & $\frac{\mathrm{m}}{\mathrm{c}}$ & $\frac{\sigma}{\square}$ & 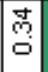 & 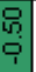 & \begin{tabular}{|c|}
8 \\
\end{tabular} & $\begin{array}{l}\stackrel{g}{\mathrm{~s}} \\
\mathrm{~g}\end{array}$ & 吉 & & 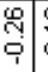 & $\frac{\sigma}{\square}$ & & & 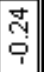 \\
\hline$\frac{5}{\frac{y}{2}}$ & $\mid \begin{array}{c}1 \\
\\
\end{array}$ & 号 & $\begin{array}{l}1 \\
1 \\
0\end{array}$ & $\begin{array}{l}\text { 䍐 } \\
\text { ○े }\end{array}$ & ज. & 守 & $\begin{array}{l}\stackrel{D}{2} \\
\text { ì }\end{array}$ & 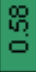 & & $\frac{\sigma}{5}$ & $\begin{array}{l}\text { J } \\
\text { gi }\end{array}$ & $\begin{array}{l}\text { 志 } \\
\\
\end{array}$ & $\stackrel{\mathrm{g}}{\mathrm{s}}$ & 志 & 罢 & \begin{tabular}{|l|} 
\\
$\mathrm{s}$ \\
$\mathrm{\sigma}$
\end{tabular} & '. & 畄 & 品 & & $\frac{5}{5}$ & $\frac{\sigma}{\square}$ & $\begin{array}{l}3 \\
0 \\
0 \\
0\end{array}$ & 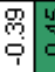 & 品 & 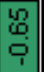 \\
\hline 产 & ma & $\mid \begin{array}{l}\mathscr{8} \\
\stackrel{8}{\circ}\end{array}$ & ๙ુ & 审 & $\mid \begin{array}{l}0 \\
\text { g } \\
0\end{array}$ & 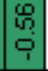 & ले & & 然 & $\stackrel{\mathrm{s}}{\mathrm{g}}$ & $\begin{array}{l}0 \\
0 \\
0 \\
0\end{array}$ & 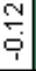 & 导 & $\begin{array}{l}\stackrel{9}{\circ} \\
口 \\
\end{array}$ & 导 & 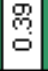 & 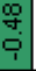 & 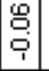 & & 号 & \begin{tabular}{l}
$\bar{c}$ \\
\hdashline \\
\end{tabular} & $\begin{array}{l}\text { ș } \\
\text { co }\end{array}$ & $\begin{array}{l}9 \\
0 \\
0 \\
\end{array}$ & 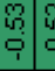 & & \begin{tabular}{l||} 
\\
0 \\
\\
1
\end{tabular} \\
\hline$\frac{9}{a}$ & ले & 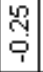 & ֻู & 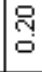 & 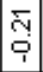 & 导 & & ָֻ & 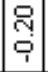 & 亘 & $\frac{9}{6}$ & 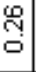 & 兽 & ב⿳⺈ & 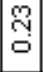 & $\frac{10}{\square}$ & 思 & & $\frac{\mathscr{\omega}}{\stackrel{c}{c}}$ & $\begin{array}{l}\text { ș } \\
\mathrm{g}\end{array}$ & ড̀ & Sั & 思 & 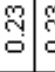 & & $\begin{array}{l}m \\
b\end{array}$ \\
\hline 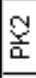 & 等 & \begin{tabular}{|l} 
\\
\\
\\
\end{tabular} & ?3. & 志 & \begin{tabular}{|l} 
\\
0 \\
\\
\end{tabular} & & 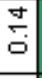 & $\begin{array}{l}9 \\
5 \\
0 \\
\\
\end{array}$ & $\begin{array}{c}\bar{q} \\
\\
\end{array}$ & $\begin{array}{l} \\
\text { 等 } \\
\end{array}$ & \begin{tabular}{|c|c|}
0 \\
0 \\
\end{tabular} & ֻू & (ָ) & 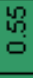 & \begin{tabular}{|l|} 
脟 \\
\end{tabular} & \begin{tabular}{|l}
$\bar{o}$ \\
$\bar{i}$ \\
\end{tabular} & & \begin{tabular}{|l|} 
\\
\\
\\
\end{tabular} & $\begin{array}{l}\overline{0} \\
\\
\end{array}$ & $\begin{array}{l}\text { ș } \\
\text { s. }\end{array}$ & $\stackrel{0}{\circ}$ & $\begin{array}{l}9 \\
\text { s. } \\
\end{array}$ & $\begin{array}{l}8 \\
8 \\
8 \\
\end{array}$ & 5 & 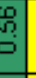 & $\stackrel{N}{\circ}$ \\
\hline 㝘 & $\begin{array}{c}\text { go } \\
\\
\end{array}$ & $\begin{array}{l}\text { g } \\
\text { g }\end{array}$ & 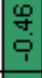 & $\begin{array}{l}3 \\
\text { Sִ } \\
\end{array}$ & & \begin{tabular}{|l} 
\\
0 \\
\\
\end{tabular} & $\begin{array}{l}\overline{\mathrm{c}} \\
\overline{\mathrm{i}}\end{array}$ & 哭 & $\begin{array}{c}\text { v } \\
\text { g. }\end{array}$ & \begin{tabular}{|c|} 
\\
0 \\
0
\end{tabular} & \begin{tabular}{l}
0 \\
0 \\
0 \\
\hdashline
\end{tabular} & 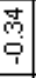 & $\stackrel{9}{\circ}$ & g & $\begin{array}{l}5 \\
0 \\
0 \\
\\
\end{array}$ & & 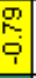 & $\bar{\delta}$ & $\sqrt{S}$ & $\stackrel{8}{\circ}$ & ș & 商 & & \begin{tabular}{c}
3 \\
\hdashline \\
\hdashline
\end{tabular} & & $\begin{array}{l}\stackrel{P}{8} \\
\stackrel{8}{1}\end{array}$ \\
\hline$\frac{8}{8}$ & $\bar{s}$ & $\begin{array}{c}\bar{s} \\
\overline{1} \\
\end{array}$ & ถึ & & 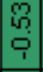 & 志 & 옹 & 艿 & 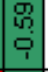 & $\begin{array}{l}\text { w } \\
\text { c. } \\
\end{array}$ & 等 & s̆ & $\stackrel{m}{\circ}$ & 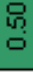 & & \begin{tabular}{|l} 
\\
J \\
ì
\end{tabular} & 号 & 魚 & 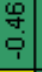 & $\begin{array}{l}\text { 导 } \\
\text { c. }\end{array}$ & 呂 & త్ & 筞 & 思 & & 哭 \\
\hline$\frac{7}{\frac{7}{2}}$ & 守 & $\mid$\begin{tabular}{l}
8 \\
0 \\
\hdashline
\end{tabular} & & 员 & \begin{tabular}{|l} 
\\
\\
\\
\end{tabular} & 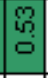 & 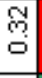 & ț. & $\begin{array}{l}5 \\
15 \\
0 \\
1\end{array}$ & \begin{tabular}{|l|} 
\\
\\
\end{tabular} & 紫 & $\stackrel{5}{5}$ & $\begin{array}{c}\text { ב. } \\
\end{array}$ & & $\begin{array}{c}\bar{g} \\
\end{array}$ & \begin{tabular}{|l|} 
\\
s. \\
i
\end{tabular} & 尃 & \begin{tabular}{|l|}
$g$ \\
\end{tabular} & $\begin{array}{l}\overline{5} \\
\overline{9} \\
\end{array}$ & $\begin{array}{l}\text { 总 } \\
\text { qu }\end{array}$ & 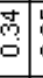 & 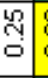 & $\circ$ & 号 & 点 & ${ }_{\delta}^{\bar{g}}$ \\
\hline$\frac{y}{2}$ & $\begin{array}{l}\overline{\widehat{y}} \\
\overline{\mathrm{c}}\end{array}$ & & דִ & $\begin{array}{l}\bar{c} \\
\mathrm{c}\end{array}$ & ș & $\begin{array}{l}\text { 肙 } \\
\text { 号 }\end{array}$ & $\begin{array}{l}5 \\
\text { ch } \\
\text { in }\end{array}$ & $\begin{array}{l}\mathscr{8} \\
\end{array}$ & 肙 & $\begin{array}{l}5 \\
\\
\end{array}$ & $\begin{array}{l}\text { J } \\
\text { ci } \\
\end{array}$ & $\frac{\mathrm{N}}{5}$ & & 5 & $\overline{\bar{y}}$ & 突 & 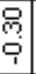 & \begin{tabular}{|c|} 
\\
\\
\\
\end{tabular} & 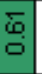 & ले & $\begin{array}{l}0 \\
\vdots \\
\vdots \\
1\end{array}$ & 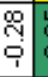 & 7 & "as & & \\
\hline 돔 & & $\begin{array}{c}\bar{y} \\
\text { c. }\end{array}$ & $=$ & ळ్ & $\begin{array}{l}\text { 罢 } \\
\text { 它 }\end{array}$ & 筞 & 勺े & ले & $\mid \begin{array}{c}n \\
\\
\end{array}$ & 急 & ले & & $\stackrel{m}{\circ}$ & & m. & 守 & 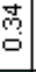 & 号 & ô & 骂 & 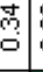 & 罟 & 筞 & 学 & 棸 & 思|| \\
\hline 푬 & & \begin{tabular}{|l|l}
8 \\
0 \\
0
\end{tabular} & 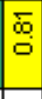 & 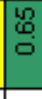 & 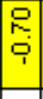 & $\begin{array}{c}\mathrm{O} \\
\mathrm{O}\end{array}$ & 勺্ & 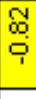 & & \begin{tabular}{|l|l}
\multirow{c}{*}{} \\
'
\end{tabular} & 9 & $\overline{\bar{s}}$ & 塄 & & $\begin{array}{l}0 \\
\text { w } \\
0\end{array}$ & 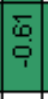 & 总 & \begin{tabular}{|l|l|}
5 \\
\\
\end{tabular} & 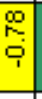 & 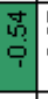 & s. & 寽 & 罗 & $\begin{array}{l}\mathscr{Q} \\
\stackrel{2}{\circ}\end{array}$ & & \\
\hline & İ & & & & 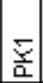 & 於 & & ti & $\frac{5}{a}$ & 8 & $a$ & $z$ & & & & $\bar{\Sigma}$ & & $\stackrel{2}{\xi}$ & & $y$ & $\xi$ & $\underset{8}{\Xi}$ & & $\frac{9}{00}$ & & 0 \\
\hline
\end{tabular}




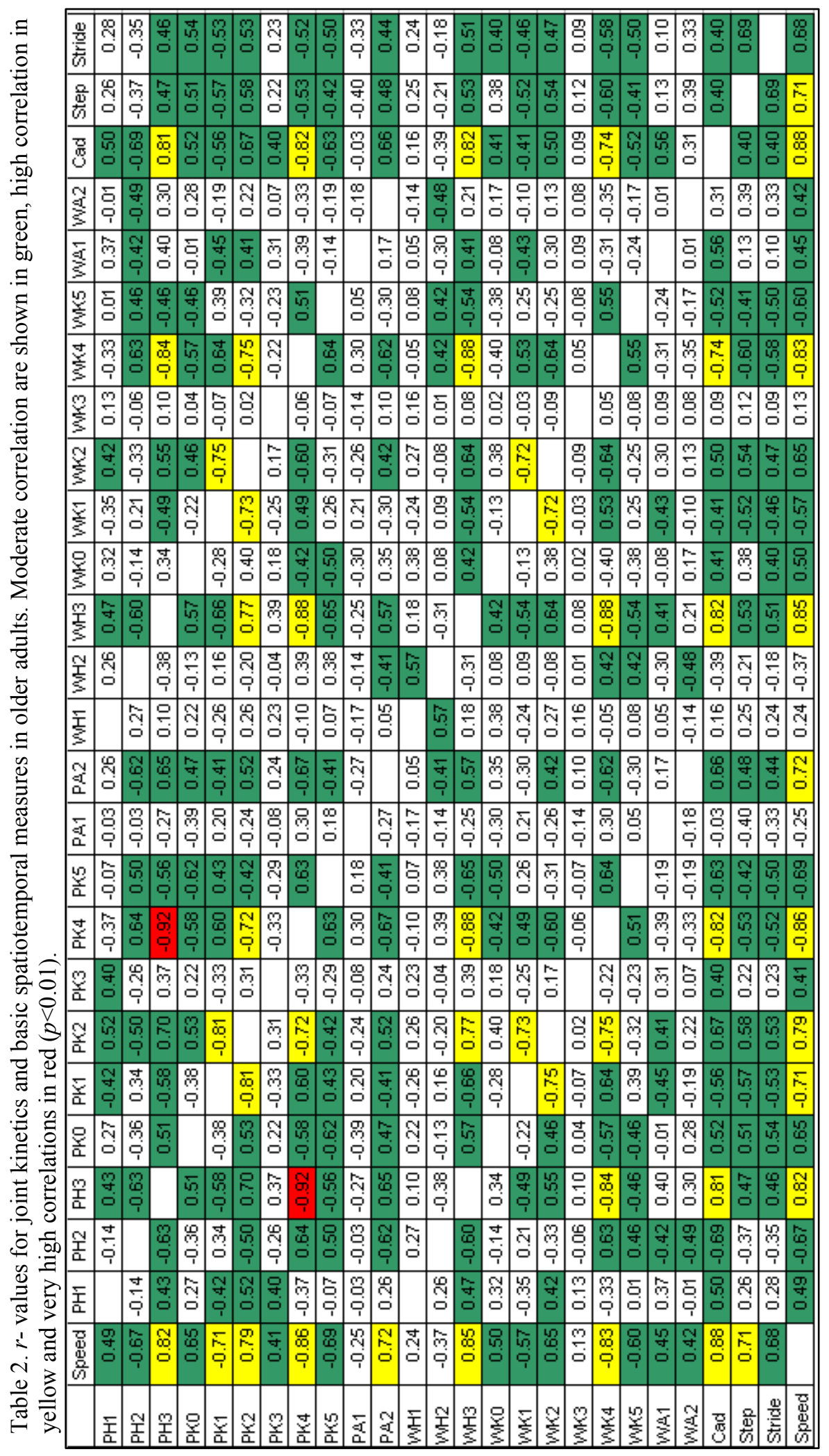




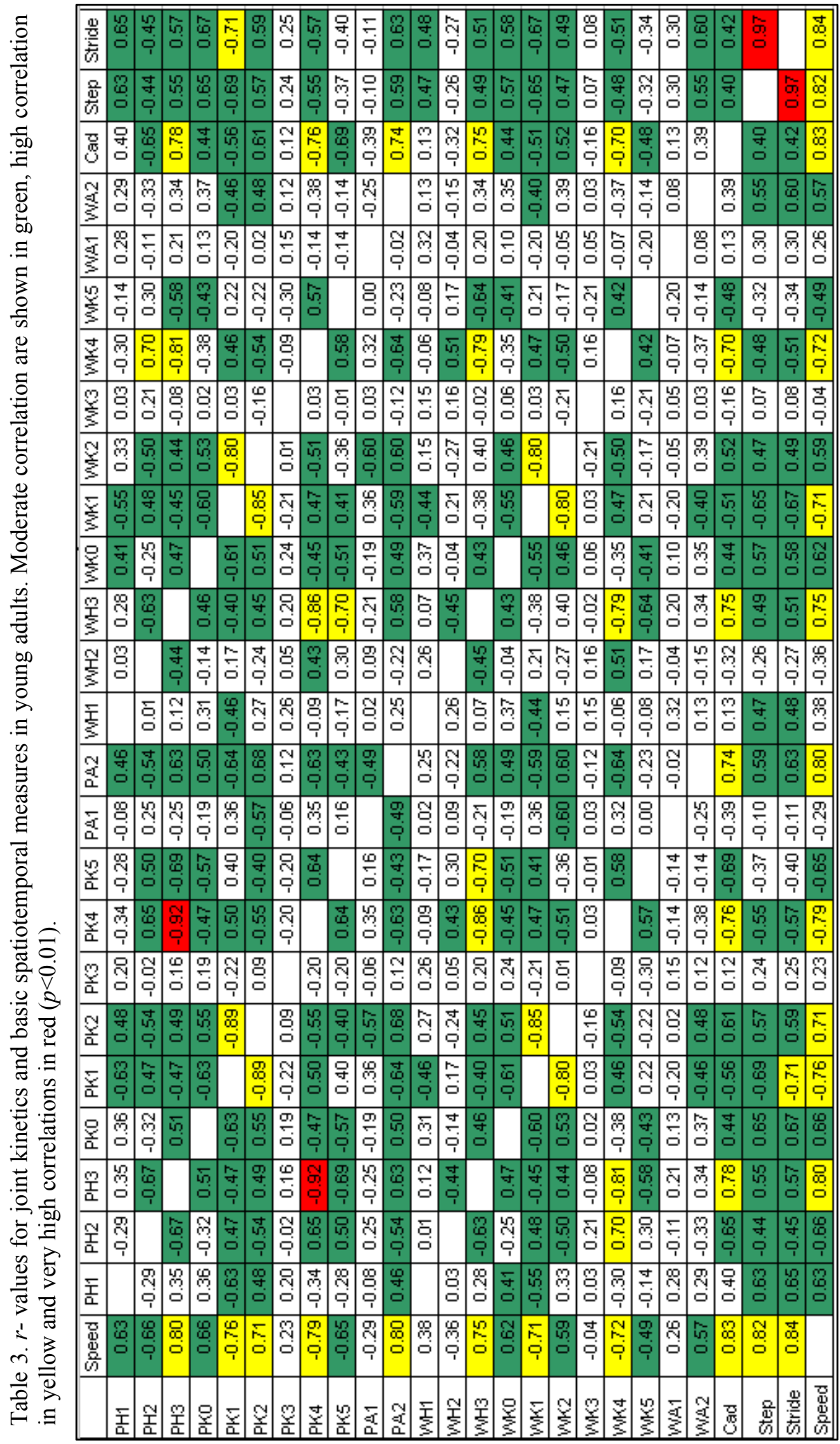




\section{Appendix 2: Ethics Approval Letter}

18 November 2009

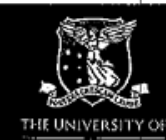

Professor M.G. Pandy

Mechanical Engineering

The University of Melbourne

Dear Professor Pandy

I am pleased to advise that the Health Sciences Human Ethics Sub-Committee approved the following Project:

Project title: Leg muscle function and coordination during over-ground walking, obstacle

Researchers: negotiation and step accommodation in young and older adults

Professor M. G. Pandy, Mr L. Cofre, Dr N. D. Lythgo, Mr Y. Lim

The Project has been approved for the period: 18-Nov-2009 to 31-Dec-2010.

It is your responsibility to ensure that all people associated with the Project are made aware of what has actually been approved.

Research projects are normally approved to 31 December of the year of approval. Projects may be renewed yearly for up to a total of five years upon receipt of a satisfactory annual report. If a project is to continue beyond five years a new application will normally need to be submitted.

Please note that the following conditions apply to your approval. Failure to abide by these conditions may result in suspension or discontinuation of approval and/or disciplinary action.

(a) Limit of Approval: Approval is limited strictly to the research as submitted in your Project application.

(b) Variation to Project: Any subsequent variations or modifications you might wish to make to the Project must be notified formally to the Human Ethics Sub-Commiltee for further consideration and approval. If the Sub-Committee considers that the proposed changes are significant, you may be required to submit a new application for approval of the revised Project.

(c) Incidents or adverse affects: Researchers must report immediately to the Sub-Committee anything which might affect the ethical acceptance of the protocol including adverse effects on participants or unforeseen events that might affect continued ethical acceptability of the Project. Failure to do so may result in suspension or cancellation of approval.

(d) Monitoring: All projects are subject to monitoring at any time by the Human Research Ethics Committee.

(e) Annual Report: Please be aware that the Human Research Ethics Committee requires that researchers submit an annual report on each of their projects at the end of the year, or at the conclusion of a project if it continues for less than this time. Failure to submit an annual report will mean that ethics approval will lapse.

(f) Auditing: All projects may be subject to audit by members of the Sub-Committee.

If you have any queries on these matters, or require additional information, please contact me using the details below.

Please quote the ethlcs registration number and the title of the Project in any future correspondence.

On behalf of the Sub-Commiltee I wish you well in your research.

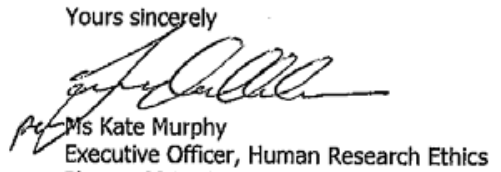

Executive Officer, Human Research Ethics

Phone: 83442073, Email: k.murphy@unimelb.edu.au

cC: HEAG Chair - Physiotherapy Dr N. Lythgo

Melbourne Research Office

The University of Melbourne Victoria 3010 Australia

T: $+61383442000 \quad$ F: +61393476739 W: http://www.research.unimelb.edu.au/ 


\section{Appendix 3: Interview Questionnaire}

1. Have you ever had a stroke?

2. Have you had low back pain during the last 6 months?

3. Have you had any joint replacement surgery?

4. Have you had a sprain in any of your lower limb joints during the last 6 months?

5. Have you had a contusion in any part of your lower limb during the last 6 months?

6. Have you had or currently have low back pain?

7. Have you had any accidental fall during the last 12 months? 


\section{Appendix 4: Short Physical Performance Battery}

Study ID Date Tester Initials

\section{SHORT PHYSICAL PERFORMANCE BATTERY PROTOCOL AND SCORE SHEET}

All of the tests should be performed in the same order as they are presented in this protocol. Instructions to the participants are shown in bold italic and should be given exactly as they are written in this script.

\section{BALANCE TESTS}

The participant must be able to stand unassisted without the use of a cane or walker. You may help the participant to get up.

Now let's begin the evaluation. I would now like you to try to move your body in different movements. I will first describe and show each movement to you. Then I'd like you to try to do it. If you cannot do a particular movement, or if you feel it would be unsafe to try to do it, tell me and we'll move on to the next one. Let me emphasize that I do not want you to try to do any exercise that you feel might be unsafe.

Do you have any questions before we begin?

\section{A. Side-by-Side Stand}

1. Now I will show you the first movement.

2. (Demonstrate) I want you to try to stand with your feet together, side-by-side, for about 10 seconds.

3. You may use your arms, bend your knees, or move your body to maintain your balance, but try not to move your feet. Try to hold this position until I tell you to stop.

4. Stand next to the participant to help him/her into the side-by-side position.

5. Supply just enough support to the participant's arm to prevent loss of balance.

6. When the participant has his/her feet together, ask "Are you ready?"

7. Then let go and begin timing as you say, "Ready, begin."

8. Stop the stopwatch and say "Stop" after 10 seconds or when the participant steps out of position or grabs your arm.

9. If participant is unable to hold the position for 10 seconds, record result and go to the gait speed test. 


\section{B. Semi-Tandem Stand}

1. Now I will show you the second movement.

2. (Demonstrate) Now I want you to try to stand with the side of the heel of one foot touching the big toe of the other foot for about 10 seconds. You may put either foot in front, whichever is more comfortable for you.

3. You may use your arms, bend your knees, or move your body to maintain your balance, but try not to move your feet. Try to hold this position until I tell you to stop.

4. Stand next to the participant to help him/her into the semi-tandem position

5. Supply just enough support to the participant's arm to prevent loss of balance.

6. When the participant has his/her feet together, ask "Are you ready?"

7. Then let go and begin timing as you say "Ready, begin."

8. Stop the stopwatch and say "Stop" after 10 seconds or when the participant steps out of position or grabs your arm.

9. If participant is unable to hold the position for 10 seconds, record result and go to the gait speed test.

C. Tandem Stand

1. Now I will show you the third movement.

2. (Demonstrate) Now I want you to try to stand with the heel of one foot in front of and touching the toes of the other foot for about 10 seconds. You may put either foot in front, whichever is more comfortable for you.

3. You may use your arms, bend your knees, or move your body to maintain your balance, but try not to move your feet. Try to hold this position until I tell you to stop.

4. Stand next to the participant to help him/her into the tandem position.

5. Supply just enough support to the participant's arm to prevent loss of balance.

6. When the participant has his/her feet together, ask "Are you ready?"

7. Then let go and begin timing as you say, "Ready, begin."

8. Stop the stopwatch and say "Stop" after 10 seconds or when the participant steps out of position or grabs your arm. 
SCORING:

A. Side-by-side-stand Held for $10 \mathrm{sec} \quad \square 1$ point Not held for $10 \mathrm{sec} \quad \square 0$ points Not attempted $\quad \square 0$ points If 0 points, end Balance Tests

Number of seconds held if less than $10 \mathrm{sec}$ : sec

B. Semi-Tandem Stand Not held for $10 \mathrm{sec}$ Not attempted $\square 1$ point $\square 0$ points $\square 0$ points (circle reason above) If 0 points, end Balance Tests

Number of seconds held if less than $10 \mathrm{sec}$ :

If participant did not attempt test or failed, circle why: Tried but unable 1

Participant could not hold position unassisted 2 Not attempted, you felt unsafe 3 Not attempted, participant felt unsafe $\quad 4$ Participant unable to understand instructions

Other (specify)

Participant refused

1
2
3
4
5
6
7


Study ID

Date

Tester Initials

2. GAIT SPEED TEST

Now I am going to observe how you normally walk. If you use a cane or other walking aid and you feel you need it to walk a short distance, then you may use it.

A. First Gait Speed Test

1. This is our walking course. I want you to walk to the other end of the course at your usual speed, just as if you were walking down the street to go to the store.

2. Demonstrate the walk for the participant.

3. Walk all the way past the other end of the tape before you stop. I will walk with you. Do you feel this would be safe?

4. Have the participant stand with both feet touching the starting line.

5. When I want you to start, I will say: "Ready, begin." When the participant acknowledges this instruction say: "Ready, begin."

6. Press the start/stop button to start the stopwatch as the participant begins walking.

7. Walk behind and to the side of the participant.

8. Stop timing when one of the participant's feet is completely across the end line.

\section{B. Second Gait Speed Test}

1. Now I want you to repeat the walk. Remember to walk at your usual pace, and go all the way past the other end of the course.

2. Have the participant stand with both feet touching the starting line.

3. When I want you to start, I will say: "Ready, begin." When the participant acknowledges this instruction say: "Ready, begin."

4. Press the start/stop button to start the stopwatch as the participant begins walking.

5. Walk behind and to the side of the participant.

6. Stop timing when one of the participant's feet is completely across the end line. 


\section{GAIT SPEED TEST SCORING:}

Length of walk test course: Four meters $\square \quad$ Three meters $\square$

A. Time for First Gait Speed Test (sec)

1. Time for 3 or 4 meters

2. If participant did not attempt test or failed, circle why:

Tried but unable 1

Participant could not walk unassisted 2

Not attempted, you felt unsafe 3

Not attempted, participant felt unsafe 4

Participant unable to understand instructions 5

Other (Specify)

Participant refused

6

Complete score sheet and go to chair stand test

3. Aids for first walk...............None $\square \quad$ Cane $\square$ 0ther $\square$

Comments:

B. Time for Second Gait Speed Test (sec)

1. Time for 3 or 4 meters _ _ _ _ _ sec

2. If participant did not attempt test or failed, circle why:

Tried but unable 1

Participant could not walk unassisted 2

Not attempted, you felt unsafe 3

Not attempted, participant felt unsafe 4

Participant unable to understand instructions 5

Other (Specify)

Participant refused

3. Aids for second walk........... None $\square \quad$ Cane $\square \quad$ Other $\square$

What is the time for the faster of the two walks?

Record the shorter of the two times

$\sec$

[If only 1 walk done, record that time]

If the participant was unable to do the walk: $\square 0$ points

For 4-Meter Walk:

If time is more than $8.70 \mathrm{sec}: \quad \square 1$ point

If time is 6.21 to 8.70 sec: $\quad \square 2$ points

If time is 4.82 to $6.20 \mathrm{sec}$ : $\quad \square 3$ points

If time is less than $4.82 \mathrm{sec}: \quad \square 4$ points
For 3-Meter Walk:

If time is more than $6.52 \mathrm{sec}$ : $\square 1$ point

If time is 4.66 to $6.52 \mathrm{sec}$ : $\quad \square 2$ points

If time is 3.62 to $4.65 \mathrm{sec}$ : $\quad \square 3$ points

If time is less than $3.62 \mathrm{sec}$ : $\quad \square 4$ points 
Study ID

Date Tester Initials

3. CHAIR STAND TEST

Single Chair Stand

1. Let's do the last movement test. Do you think it would be safe for you to try to stand up from a chair without using your arms?

2. The next test measures the strength in your legs.

3. (Demonstrate and explain the procedure.) First, fold your arms across your chest and sit so that your feet are on the floor; then stand up keeping your arms folded across your chest.

4. Please stand up keeping your arms folded across your chest. (Record result).

5. If participant cannot rise without using arms, say "Okay, try to stand up using your arms." This is the end of their test. Record result and go to the scoring page.

Repeated Chair Stands

1. Do you think it would be safe for you to try to stand up from a chair five times without using your arms?

2. (Demonstrate and explain the procedure): Please stand up straight as QUICKLY as you can five times, without stopping in between. After standing up each time, sit down and then stand up again. Keep your arms folded across your chest. I'll be timing you with a stopwatch.

3. When the participant is properly seated, say: "Ready? Stand" and begin timing.

4. Count out loud as the participant arises each time, up to five times.

5. Stop if participant becomes tired or short of breath during repeated chair stands.

6. Stop the stopwatch when he/she has straightened up completely for the fifth time.

7. Also stop:

- If participant uses his/her arms

- After 1 minute, if participant has not completed rises

- At your discretion, if concerned for participant's safety

8. If the participant stops and appears to be fatigued before completing the five stands, confirm this by asking "Can you continue?"

9. If participant says "Yes," continue timing. If participant says "No," stop and reset the stopwatch. 


\section{SCORING}

Single Chair Stand Test

A. Safe to stand without help

B. Results:

Participant stood without using arms

Participant used arms to stand

Test not completed

C. If participant did not attempt test or failed, circle why: Tried but unable

Participant could not stand unassisted

Not attempted, you felt unsafe

Not attempted, participant felt unsafe

Participant unable to understand instructions

Other (Specify)

Participant refused
ㄱ $\rightarrow$ Go to Repeated Chair Stand Test

$\square \quad \rightarrow$ End test; score as 0 points

$\square \quad \rightarrow$ End test; score as 0 points

\section{Repeated Chair Stand Test}

A. Safe to stand five times

B. If five stands done successfully, record time in seconds.

Time to complete five stands sec

C. If participant did not attempt test or failed, circle why: Tried but unable

Participant could not stand unassisted Not attempted, you felt unsafe

Not attempted, participant felt unsafe

Participant unable to understand instructions

Other (Specify)

Participant refused

coring the Repeated Chair Test

Participant unable to complete 5 chair stands or completes stands in $>60 \mathrm{sec}$ :

If chair stand time is $16.70 \mathrm{sec}$ or more:

$\square 1$ points

If chair stand time is 13.70 to $16.69 \mathrm{sec}$ :

$\square 2$ points

If chair stand time is 11.20 to $13.69 \mathrm{sec}$ :

$\square 3$ points

If chair stand time is $11.19 \mathrm{sec}$ or less:

$\square 4$ points 
Study ID Date Tester Initials

Scoring for Complete Short Physical Performance Battery

Test Scores

Total Balance Test score

Gait Speed Test score

points

Chair Stand Test score

points

Total Score

points (sum of points above)

\section{Short Physical Performance Battery}

1.

\section{Balance Tests}

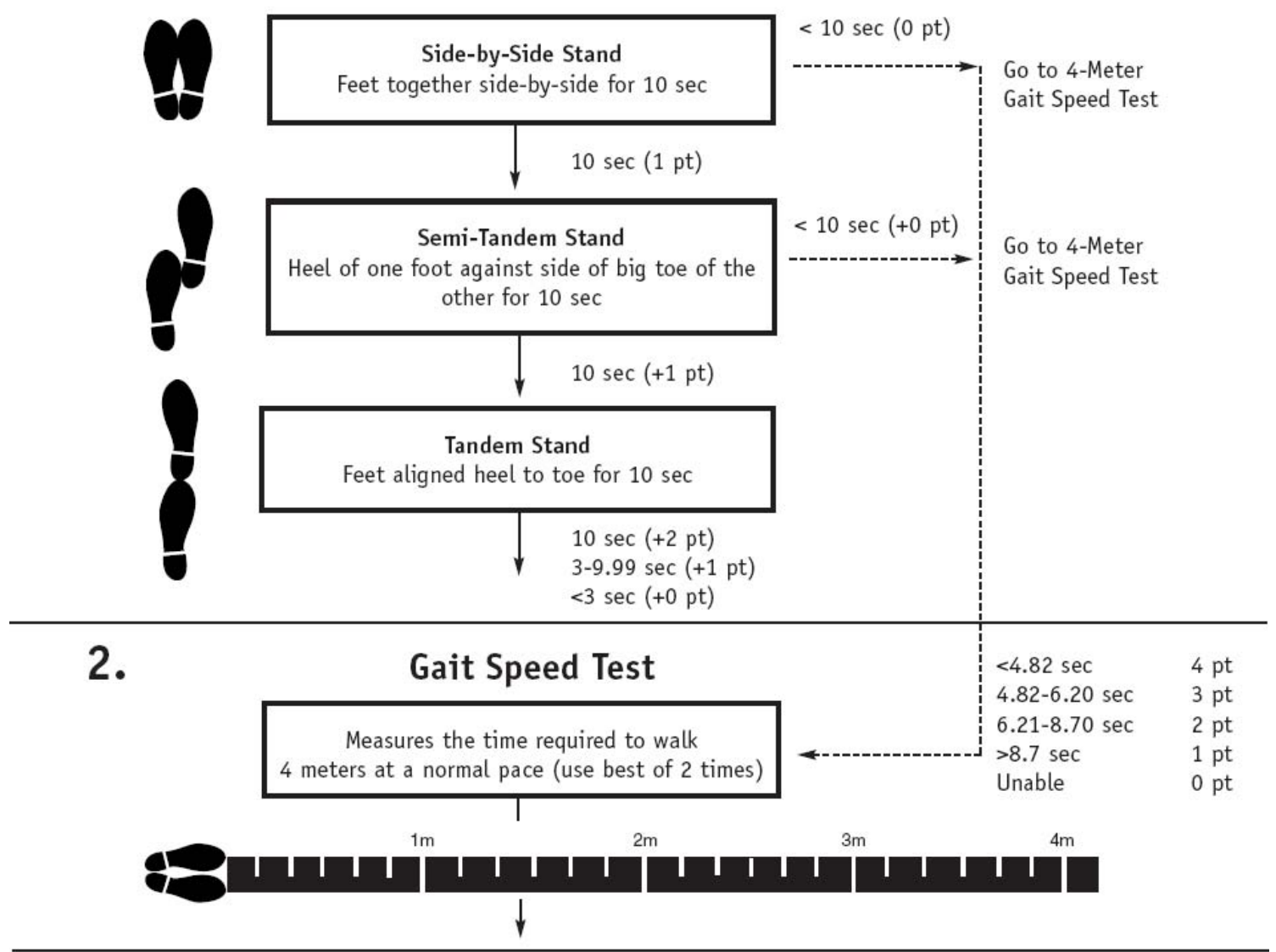

3.

Chair Stand Test

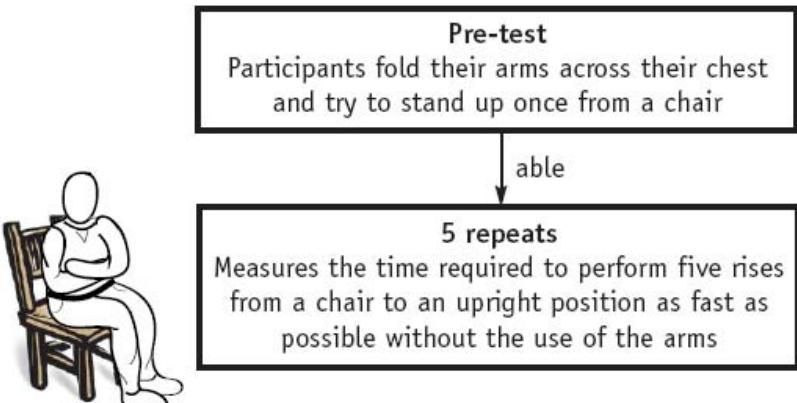

unable Stop (0 pt)
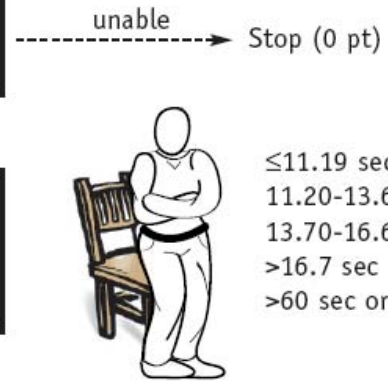

$\leq 11.19 \mathrm{sec} \quad 4 \mathrm{pt}$

11.20-13.69 sec $3 \mathrm{pt}$

$13.70-16.69 \mathrm{sec} \quad 2 \mathrm{pt}$

$>16.7 \mathrm{sec} \quad 1 \mathrm{pt}$

$>60 \mathrm{sec}$ or unable $0 \mathrm{pt}$ 


\section{University Library}

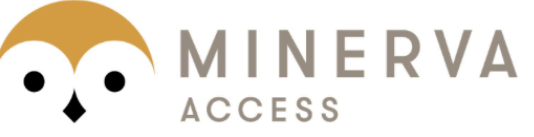

A gateway to Melbourne's research publications

Minerva Access is the Institutional Repository of The University of Melbourne

Author/s:

Cofré Lizama, Luis Eduardo

Title:

Aging modifies joint power and work when gait speeds are matched

Date:

2010

Citation:

Cofré Lizama, L. E. (2010). Aging modifies joint power and work when gait speeds are matched. Masters Research thesis, Medicine, Dentistry \& Health Sciences - Physiotherapy, The University of Melbourne.

Persistent Link:

http://hdl.handle.net/11343/35923

\section{Terms and Conditions:}

Terms and Conditions: Copyright in works deposited in Minerva Access is retained by the copyright owner. The work may not be altered without permission from the copyright owner. Readers may only download, print and save electronic copies of whole works for their own personal non-commercial use. Any use that exceeds these limits requires permission from the copyright owner. Attribution is essential when quoting or paraphrasing from these works. 